\title{
1 Global and context-specific transcriptional consequences of oncogenic Fbw7 mutations
}

3 H. Nayanga Thirimanne ${ }^{1,2,3}$, Feinan $\mathrm{Wu}^{4}$, Derek H Janssens ${ }^{5}$, Jherek Swanger ${ }^{1,2}$, Ahmed Diab ${ }^{1,2}$,

4 Heather M Feldman ${ }^{2}$, Robert A Amezquita ${ }^{6}$, Raphael Gottardo ${ }^{6}$, Patrick J Paddison ${ }^{2}$, Steven

5 Henikoff ${ }^{5,7,9 *}$, Bruce E Clurman ${ }^{1,2,3,8 *}$.

6

71 Clinical Research Division, Fred Hutchinson Cancer Research Center, Seattle, WA 98109

82 Human Biology Division, Fred Hutchinson Cancer Research Center, Seattle, WA 98109

93 Department of Pathology, University of Washington, Seattle WA 98109

104 Genomics and Bioinformatics Resource, Fred Hutchinson Cancer Research Center, Seattle,

11 WA 98109

125 Basic Science Division, Fred Hutchinson Cancer Research Center, Seattle, WA 98109

136 Vaccine and Infectious Disease Division, Fred Hutchinson Cancer Research Center, Seattle,

14 WA 98109

157 Genome Sciences, University of Washington, Seattle WA 98109

168 Department of Medicine, University of Washington, Seattle WA 98109

179 Howard Hughes Medical Institute, Chevy Chase, MD, USA

$18 *$ Corresponding Authors

19 Correspondence should be addressed to:

20 Bruce E Clurman, Email: bclurman@ @redhutch.org, phone: 206-667-4524 


\section{Abstract}

22 The Fbw7 ubiquitin ligase targets many proteins for proteasomal degradation, which include

23 oncogenic transcription factors (TFs) (e.g., c-Myc, c-Jun, Notch). Fbw7 is a tumor suppressor

24 and tumors often contain mutations in $F B X W 7$, the gene that encodes Fbw7. The complexity of

25 its substrate network has obscured the mechanisms of Fbw7-associated tumorigenesis, yet this

26 understanding is needed for developing therapies. We used an integrated approach employing

27 RNA-Seq and high-resolution mapping (CUT\&RUN) of histone modifications and TF

28 occupancy (c-Jun and c-Myc) to examine the combinatorial effects of mis-regulated Fbw7

29 substrates in colorectal cancer cells with engineered tumor-associated $F B X W 7$ null or missense

30 mutations. Both Fbw7 mutations caused widespread transcriptional changes associated with

31 active chromatin and altered TF occupancy: some were common to both Fbw7 mutant cell lines,

32 whereas others were mutation specific. We identified loci where both Jun and Myc were co-

33 regulated by Fbw7, suggesting that substrates may have synergistic effects. One co-regulated

34 gene was CIITA, the master regulator of MHC Class II gene expression. Fbw7 loss increased

35 MHC Class II expression and Fbw7 mutations were correlated with increased CIITA expression

36 in TCGA colorectal tumors and cell lines, which may have immunotherapeutic implications for

37 Fbw7-associated cancers. Analogous studies in neural stem cells in which $F B X W 7$ had been

38 acutely deleted closely mirrored the results in colorectal cancer cells. Gene set enrichment

39 analyses revealed Fbw7-asssociated pathways that were conserved across both cell types that

40 may reflect fundamental Fbw7 functions. These analyses provide a framework for understanding

41 normal and neoplastic context specific Fbw7 functions. 


\section{Introduction}

SCFs (Skp1-Cul1-F-box proteins) are multi-subunit ubiquitin ligases that target proteins

45 for degradation through the conjugation of polyubiquitin chains that signal their destruction by

46 the proteasome (Deshaies \& Joazeiro, 2009; Lee \& Diehl, 2014). F-box proteins are SCF

47 substrate receptors and often target proteins for ubiquitylation in response to substrate

48 modifications (Skaar et al., 2013; Yumimoto \& Nakayama, 2020). The Fbw7 F-box protein

49 binds to substrates after they become phosphorylated within conserved phosphodegron motifs

50 that mediate high-affinity interactions with the Fbw7 $\beta$-propeller (R. J. Davis et al., 2014; Hao et

51 al., 2007; Nash et al., 2001; Orlicky et al., 2003; Yumimoto \& Nakayama, 2020). Like its yeast

52 orthologues, Fbw7 functions as a dimer, which influences substrate ubiquitylation and substrate

53 binding (Hao et al., 2007; Kominami et al., 1998; Tang et al., 2007; Welcker et al., 2013;

54 Welcker \& Clurman, 2007; W. Zhang \& Koepp, 2006). The Fbw7 F-box binds to Skp1, which

55 allows Fbw7 to bring phosphorylated substrates into proximity with the remainder of the SCF

56 complex. Phosphodegrons vary in their affinity for Fbw7, and this influences substrate binding.

57 High affinity degrons are sufficient to enable productive binding to monomeric Fbw7, whereas

58 lower affinity substrates bind through the concerted interaction of two degrons, each with one

59 protomer of an Fbw7 dimer (Welcker et al., 2013, 2022)

60

Approximately 30 Fbw7 substrates are known. Most are broadly acting transcription

61 factors (TFs) that control processes such as proliferation, differentiation, and metabolism, and

62 these include c-Myc, Notch, c-Jun, PGC-1 $\alpha$, SREBP1/2, and others (Cremona et al., 2016; R. J.

63 Davis et al., 2014; Welcker \& Clurman, 2008; Yumimoto \& Nakayama, 2020). Fbw7 also

64 targets other proteins, most notably cyclin E and MCL-1. Fbw7's exerts its cellular functions

65 through the combined regulation of its many substrates, and different cell types express subsets 
66 of substrates that are targeted for degradation by Fbw7 only after they acquire specific

67 phosphorylation. Some substrates (cyclin E, SREBP) are highly Fbw7 dependent, whereas others

68 (e.g. Myc, Jun, Notch) have multiple turnover pathways and are only regulated by Fbw7 in

69 specific contexts (Carrieri \& Dale, 2017; Lopez-Bergami et al., 2010). In most cases, glycogen

70 synthase kinase $3 \beta$ (GSK-3 $\beta$ ) is one of the degron kinases, which may allow Fbw7 to

71 coordinately couple its substrate network to mitogenic signals. Some TFs are phosphorylated

72 when they are bound to their target genes (Fryer et al., 2004; Punga et al., 2006), providing

73 another control over their susceptibility to Fbw7-mediated degradation. This complexity has

74 made it difficult to fully ascertain Fbw7's functions, which is compounded by the fact that most

75 substrates are TFs that regulate gene networks themselves.

77 Fbw7 loss deregulates these oncoproteins and $F B X W 7$ is a commonly mutated tumor suppressor

78 gene (R. J. Davis et al., 2014; Shimizu et al., 2018; Tan et al., 2008; Yeh et al., 2018; Yumimoto

$79 \&$ Nakayama, 2020). The most frequent mutations are heterozygous missense mutations,

80 hereafter termed $\mathrm{Fbw} 7^{\mathrm{R} /+}$, that target one of three arginine residues that form Fbw7's substrate-

81 binding pocket. $\mathrm{Fbw} 7^{\mathrm{R} /+}$ weaken substrate binding and are thought to act as dominant negatives

82 by forming impaired $\mathrm{Fbw} 7^{\mathrm{R}} / \mathrm{Fbw} 7^{\mathrm{WT}}$ heterodimers (Hao et al., 2007; Welcker et al., 2013;

83 Welcker \& Clurman, 2007). While Fbw $7^{\mathrm{R} /+}$ mutations are common, Fbw $7^{+/-}$mutations are not,

84 suggesting that $\mathrm{Fbw} 7^{\mathrm{R} /+}$ mutations are not simple loss-of-function mutations, and this is

85 supported by Fbw $7^{\mathrm{R} /+}$ mouse models, which develop tumors to a greater extent than Fbw $7^{+/-}$mice

86 (R. J. Davis et al., 2014). Fbw $7^{\mathrm{R} /+}$ may preferentially disrupt the aspects of Fbw7 function that

87 depend upon fully functional Fbw7 dimers. The "just enough" model posits that Fbw $7^{\mathrm{R} /+}$ reduces

88 activity sufficiently to impair tumor suppressor functions while preserving beneficial Fbw7 
89 activities (H. Davis \& Tomlinson, 2012). In addition to $\mathrm{Fbw} 7^{\mathrm{R} /+}$, canonical bi-allelic loss of

90 function $\mathrm{Fbw}^{-/-}$mutations (e.g., nonsense, truncations, frame shifts, deletions) also occur in

91 tumors. Different cancers have different mutational spectra; T-cell acute lymphocytic leukemias

92 (T-ALLs) have almost exclusively $\mathrm{Fbw} 7^{\mathrm{R} / \mathrm{t}}$ whereas colorectal cancers have both $\mathrm{Fbw} 7^{\mathrm{R} / \mathrm{+}}$ and

$93 \mathrm{Fbw}^{-/-}$mutations. In all cases, tumorigenesis associated with Fbw7 mutations likely involves the

94 concerted activities of multiple oncogenic substrates.

95 We assessed the global transcriptional consequences of oncogenic Fbw7 mutations by

96 using RNA-Seq and high-resolution mapping of histone modifications and oncogenic TF (c-Jun

97 and c-Myc, here onwards Jun and Myc) occupancy in isogenic Hct116 colorectal cancer cells

98 with engineered $\mathrm{Fbw} 7^{-/ 2}$ and $\mathrm{Fbw} 7^{\mathrm{R} /+}$ mutations. Both mutations caused widespread, yet highly

99 context-specific transcriptional changes associated with active chromatin and altered TF

100 occupancy. Many deregulated genes and loci were shared between the two mutant cell lines, and

101 the consequences of $\mathrm{Fbw} 7^{-/-}$were generally greater than $\mathrm{Fbw} 7^{\mathrm{R} /+}$. While both mutations impacted

102 small subsets of mapped Jun and Myc loci, there was substantial overlap, and Jun and Myc were

103 co-regulated by Fbw7 at these shared binding sites. One co-regulated gene was CIITA (Class II

104 Major Histocompatibility Complex Transactivator), the master regulator of MHC class II gene

105 expression (Masternak et al., 2000; Reith et al., 2005). Jun and Myc occupancy upstream of

106 CIITA were increased in $\mathrm{Fbw} 7^{-1-}$ cells, leading to inappropriate MHC class II RNA and protein

107 expression. Analyses of TCGA colorectal cancer and cell lines further correlated Fbw7

108 mutations with MHC Class II gene expression, which may have important prognostic and

109 therapeutic implications for Fbw7-associated colorectal cancers. Because Fbw7 regulates neural

110 stem cells (NSCs) (Hoeck et al., 2010) and Fbw7 expression is repressed in glioblastomas

111 (Hagedorn et al., 2007), we studied neural stem cells (NSCs) in which Fbw7 was acutely deleted 
112 as an orthogonal system. The consequences of Fbw7 loss in NSCs closely mirrored the Hct116

113 results in the extent and patterns of transcriptional deregulation. Gene set enrichment analyses of

114 Fbw7-dependent genes revealed extensive conservation between NSCs and Hct116 with respect

115 to biologic processes, which included epithelial-mesenchymal transition and MHC Class II

116 complex. Overall, these data establish a framework for understanding the mechanisms of Fbw7

117 function and tumor suppression.

119 Results

120 Fbw7 null and missense mutations lead to distinct gene expression profiles.

121 We previously engineered a panel of isogenic Hct116 cells by mutating the endogenous

122 wild-type (WT) $F B X W 7$ locus to either a heterozygous $\mathrm{Fbw}^{\mathrm{R} 505 \mathrm{C} /+}\left(\mathrm{Fbw} 7^{\mathrm{R} /+}\right)$ or a homozygous

123 null (Fbw7 $7^{-/}$) mutation (Figure 1A) (R. J. Davis et al., 2018; Grim et al., 2008). We performed

124 RNA sequencing to identify the global transcriptome changes arising in both cell lines. Principal

125 component analysis (PCA) revealed that the $\mathrm{Fbw} 7^{\mathrm{R} /+}$ and $\mathrm{Fbw} 7^{-/-}$cells clustered apart from one

126 another, indicating that the two mutations have distinct effects on the transcriptome relative to

127 WT cells (Figure 1 - figure supplement 1). Compared with WT cells, $11.3 \%$ and 5.4\% of the

128 captured protein-coding genes were differentially expressed in Fbw $7^{-/-}$and $\mathrm{Fbw} 7^{\mathrm{R} /+}$ cells,

129 respectively. Some genes were differentially expressed in both $\mathrm{Fbw} 7^{-/-}$and $\mathrm{Fbw} 7^{\mathrm{R} /+}$ cells,

130 whereas others were unique to one cell line (Figure 1B, Figure 1 - source data 1). Hierarchical

131 clustering of the differentially expressed protein-coding genes identified transcripts that were: 1)

132 upregulated (cluster 1) or downregulated (cluster 2) in just Fbw $7^{-/-}$cells, 2) genes upregulated

133 (cluster 6) and downregulated (cluster 5) in just Fbw $7^{\mathrm{R} /+}$ cells, and 3) genes that show similar

134 expression changes in response to both Fbw7 mutations (clusters 3 and 4) (Figure 1C). 

enrichment of gene sets representing cellular pathways and processes using the Enrichr

137 enrichment analysis web-based tool (Figure 1D) (E. Y. Chen et al., 2013; Kuleshov et al., 2016).

138 Figure 1D highlights some significantly enriched gene sets representing transcription factor 139 targets (TRANSFAC \& JASPAR), gene ontologies (GO) and pathways (MSigDB). Figure 1 140 source data 3 contains the full listing of enriched terms and their constituent genes, for both $141 \mathrm{Fbw}^{-/-}$and $\mathrm{Fbw} 7^{\mathrm{R} /+}$ cells. Most enriched gene sets were common to both $\mathrm{Fbw} 7^{-/-}$and $\mathrm{Fbw} 7^{\mathrm{R} /+}$ 142 cells and some likely reflect known Fbw7 properties, such as the p53-p21 pathway. Fbw7 loss 143 causes p53 induction in cell lines and tumors, and also impacts the cell cycle through substrates 144 like cyclin E (Li et al., 2015; A. C. Minella et al., 2007; Alex C. Minella et al., 2002).

145 Accordingly, p21 mRNA expression was increased in Fbw $7^{-/-}$and Fbw $7^{\mathrm{R} /+}$ Hct116 cells (2.0-fold 146 and 2.3-fold, respectively, Figure 1 - source data 1) and both cell lines exhibited a modest 147 increase in doubling time and S-phase fraction (Figure 1- figure supplement 2). Gene sets related 148 to epithelial mesenchymal transition (EMT) were enriched in the upregulated transcripts in $149 \mathrm{Fbw}^{-/-}$and $\mathrm{Fbw} 7^{\mathrm{R} /+}$ cells, consistent with findings that $\mathrm{Fbw} 7$ targets proteins that control EMT 150 regulators such as Zeb2, Snail, and LSD-1 (Díaz \& de Herreros, 2016; Lan et al., 2019; Li et al., 151 2019; Y. Zhang et al., 2018). Other shared enriched genes sets may also be related to EMT, such 152 as extracellular matrix (ECM) and cell migration. Some of these same enriched gene sets were 153 found in downregulated transcripts in $\mathrm{Fbw} 7^{-/-}$and $\mathrm{Fbw} 7^{\mathrm{R} /+}$ cells, which also included pathways 154 related to NF-kB signaling and inflammation. MHC class II genes were enriched in only Fbw $7^{-/-}$ 155 cells and are studied in more detail below.

156 We also examined the differentially expressed genes for putative regulatory TFs that are 157 Fbw7 substrates. Intriguingly, gene sets associated with binding sites for KLF proteins, a TF 
158 family that is broadly targeted by Fbw7, were highly enriched in the upregulated differential 159 genes in both cell types, but not in the downregulated genes (Liu et al., 2010; S. Yu et al., 2018;

160 Yumimoto \& Nakayama, 2020; D. Zhao et al., 2010; Y. Zhao \& Sun, 2013). Although there

161 were gene clusters that were uniquely deregulated in $\mathrm{Fbw} 7^{\mathrm{R} /+}$ cells (Cluster 5 and 6, Figure 1C),

162 we did not find any $\mathrm{Fbw} 7^{\mathrm{R} /+}$ - specific enriched gene sets. 
Thirimanne 2021

A

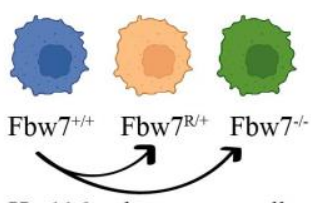

Hct116 colon cancer cells

C

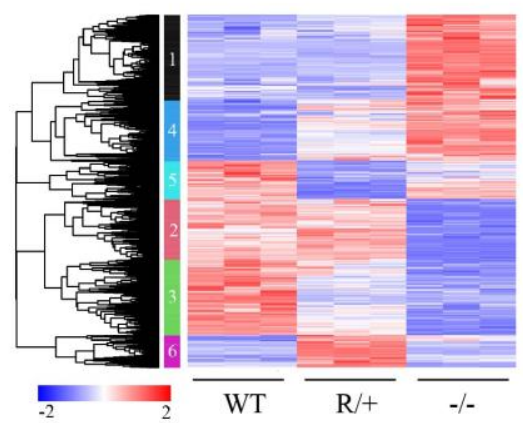

B

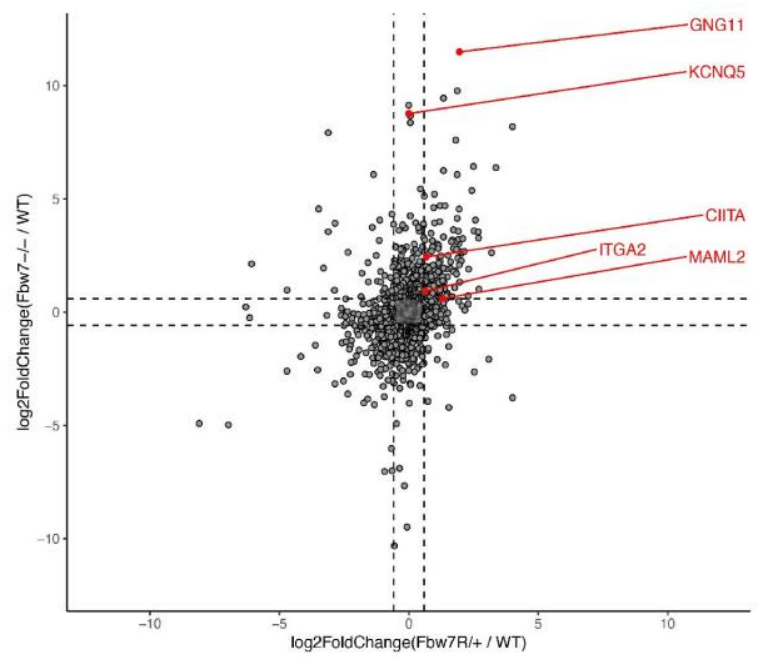

D

\begin{tabular}{|c|c|c|}
\hline Gene Set & Enriched TF/Pathway/GO Term & Adj.p-value \\
\hline Upregulated in Het116 & _KLF11 (TRANSFAC \& JASPPAR) _. . & $1.09 \mathrm{E}-13$ \\
\hline \multirow[t]{12}{*}{ Fbw $7 \%$} & p53 Pathway (MSigDB) & $1.47 \mathrm{E}-08$ \\
\hline & Epithelial Mesenchymal Transition (MSigDB) & $3.55 \mathrm{E}-05$ \\
\hline & Myogenesis (MSigDB) & $8.60 \mathrm{E}-03$ \\
\hline & Hypoxia (MSigDB) & $1.39 \mathrm{E}-02$ \\
\hline & Inflammatory Response (MSigDB) & $3.02 \mathrm{E}-02$ \\
\hline & Cell migration (GO BP) & $3.05 \mathrm{E}-04$ \\
\hline & DNA cytosine deamination (GO BP) & $3.05 \mathrm{E}-04$ \\
\hline & Cell population proliferation (GO BP) & $9.33 \mathrm{E}-04$ \\
\hline & Embryonic skeletal system development (GO BP) & $1.17 \mathrm{E}-03$ \\
\hline & Protein citrullination (GOBP) & 4.61E-02. \\
\hline & Collagen-containing extracellular matrix ( $\overline{\mathrm{G} O} \mathrm{C})$ & $6.25 \mathrm{E}-06$ \\
\hline & MHC class II protein complex (GO CC) & 3.73E-04 \\
\hline Upregulated in Het116 & KLF11 (TRANSFAC \& JASPAR). & $9.24 \mathrm{E}-07$. \\
\hline \multirow[t]{10}{*}{ Fbw $7 \mathrm{R} /+$} & Epithelial Mesenchymal Transition (MSigDB) & $1.62 \mathrm{E}-06$ \\
\hline & p53 Pathway (MSigDB) & $2.55 \mathrm{E}-05$ \\
\hline & Hypoxia (MSigDB) & 3.03E-04 \\
\hline & Cell population proliferation ( $\mathrm{GO} \mathrm{BP}$ ) & $1.93 \mathrm{E}-04$ \\
\hline & DNA cytosine deamination (GO BP) & $3.22 \mathrm{E}-03$ \\
\hline & Protein citrullination (GO BP) & $9.15 \mathrm{E}-03$ \\
\hline & Cell-matrix adhesion (GO BP) & $2.12 \mathrm{E}-02$ \\
\hline & Embryonic skeletal system development (GO BP) & $2.12 \mathrm{E}-02$ \\
\hline & Cell migration (GO BP) & 3.04E-02 \\
\hline & Collagen-containing extracellular matrix (GO CC) & $3.44 \mathrm{E}-06$ \\
\hline
\end{tabular}

Figure 1. RNA-Seq reveals differential gene expression in $\mathrm{Hct116} \mathrm{Fbw} 7^{-/-}$and $\mathrm{Fbw} 7^{\mathrm{R} /+}$ cells. (A) Genetically engineered isogenic cell lines used in the study: Hct116 wild-type (WT), $\mathrm{Fbw}^{-/}$and $\mathrm{Fbw} 7^{\mathrm{R} /+}$. (B) Differentially expressed protein-coding genes (represented by each dot) in $\mathrm{Fbw} 7^{-/-}$or Fbw $7^{\mathrm{R} /+}(\mathrm{FDR}<0.05)$. Dashed lines mark $\log _{2} \mathrm{FC}=0.6$. (C) Hierarchical clustering of differentially expressed protein-coding genes. The heatmap shows the intensity of expression of each gene (y axis) for three replicates per cell type (x axis). Three replicates per cell type were included. Replicates for each genotype were from a single clone, however from separately cultured samples. (D) Transcription factors, pathways (MSigDB), and GO terms that were enriched in genes upregulated in Fbw $7^{-1-}$ and $\mathrm{Fbw} 7^{\mathrm{R} /+} \mathrm{Hct} 116$ cells. Detailed output of differential expression analysis, hierarchical clustering, and Enrichr analysis are provided as Figure 1-source data file 1, 2, and 3 respectively. See Figure 1 - figure supplement 1 for the

173 PCA of Hct116 RNA-Seq and Figure 1 - figure supplement 2 for cell proliferation data. 


\section{Chromatin regulation in Fbw7 mutant cells}

175

176

177

178

179

180

181

182

183

184

185

186

187

We next studied how Fbw7 mutations globally influence chromatin marks and whether specific TF substrates were implicated in Fbw7-dependent active chromatin. Histone H3 lysine27 acetylation (H3K27ac) and Histone $\mathrm{H} 3$ lysine-27 trimethylation (H3K27me3) provide simple readouts of transcriptionally active versus repressive chromatin, respectively (Karlić et al., 2010). We used Cleavage Under Target and Release Using Nuclease (CUT\&RUN) (Janssens et al., 2018; Skene et al., 2018; Skene \& Henikoff, 2017) to obtain high resolution maps of H3K27ac and H3K27me3 in each of the Hct116 cell lines (Figure 2 - figure supplement 1). As expected, the $\mathrm{H} 3 \mathrm{~K} 27 \mathrm{ac}$ signal within the $2 \mathrm{~kb}$ region flanking the transcriptional start sites (TSSs) of genes was positively correlated with their expression $(r=0.44$, $\mathrm{p}$ value $<2.2 \mathrm{e}-16)$, whereas the amount of $\mathrm{H} 3 \mathrm{~K} 27 \mathrm{me} 3$ was negatively correlated $(\mathrm{r}=-0.22$, $\mathrm{p}$ value $<2.2 \mathrm{e}-16)$ (Figure 2A). For example, the GNG11 gene, whose expression is upregulated in $\mathrm{Fbw}^{7^{-/}}$cells, contains increased H3K27ac and decreased H3K27me3, compared with WT (Figure 1B, Figure 2B)

Genome-wide analysis identified sites with increased H3K27ac in Fbw7 mutant cells $\left(\mathrm{Fbw}^{-/-}: 9.4 \%, \mathrm{Fbw}^{\mathrm{R} /+}: 7.6 \%\right)$ compared with control cells, as well as sites where $\mathrm{H} 3 \mathrm{~K} 27 \mathrm{ac}$ was decreased $\left(\mathrm{Fbw}^{-/-}: 6.9 \%\right.$, Fbw $7^{\mathrm{R} /+}: 4.3 \%$ ) (Figure 2C, Figure 2 - source data 1$)$. Most nondifferential H3K27ac sites (those unaffected by Fbw7 status) were promoter-proximal, while loci with differential $\mathrm{H} 3 \mathrm{~K} 27 \mathrm{ac}$ in either $\mathrm{Fbw} 7^{\mathrm{R} /+}$ or $\mathrm{Fbw} 7^{-/-}$cells fell mostly within introns or intergenic regions ( $\mathrm{p}$ value $<0.0001$, Fisher test) (Figure 2D, Figure 2 - figure supplement 2). To determine whether these differential loci result from the altered binding of known Fbw7 substrates, we performed motif discovery analysis on the central 100 bp sequence of each peak. Strikingly, the AP-1 motif, which is bound by the Jun family, was found in $32 \%$ (p value $\leq 1.8 \mathrm{e}-$ 
197 5) of the H3K27ac sites upregulated in Fbw $7^{-/ 2}$ cells (Figure 2E, Figure 2 - figure supplement 198 3A). The AP-1 motif was also enriched in differential H3K27ac sites that were decreased in $199 \mathrm{Fbw}^{-/-}$cells, as well as in differential H3K27ac sites in Fbw $7^{\mathrm{R} /+}$ cells. In contrast, the AP-1 site 200 was not enriched in H3K27ac sites that were unaffected by either Fbw7 mutation (Figure 2 201 figure supplement 3B). The AP-1 motif enrichment in these differential sites suggests that Fbw7202 dependent Jun regulation may account, in part, for these changes in active chromatin. 
A

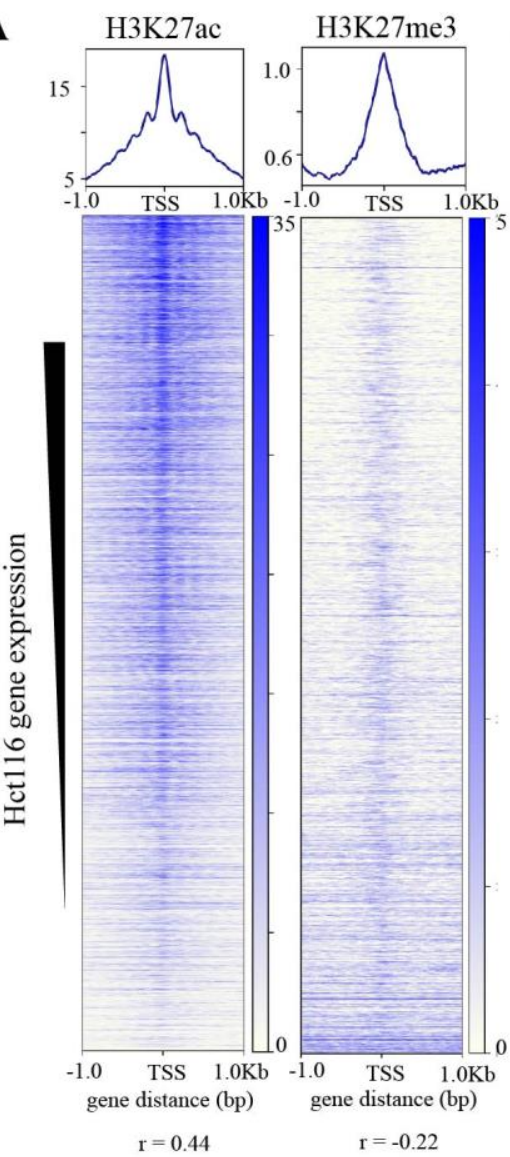

B

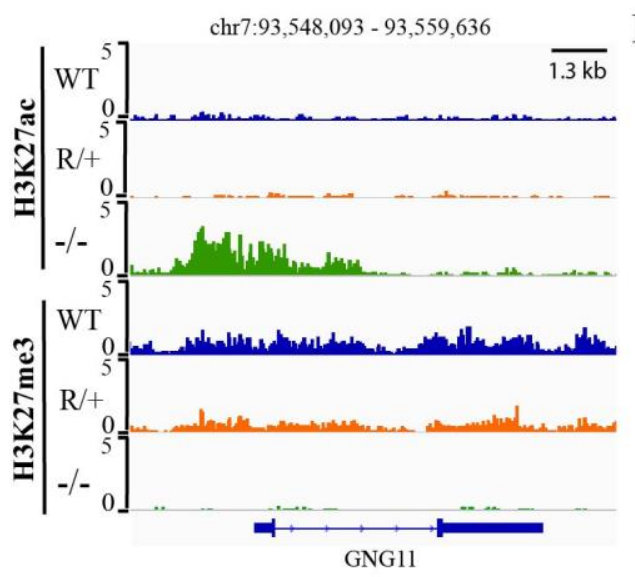

C

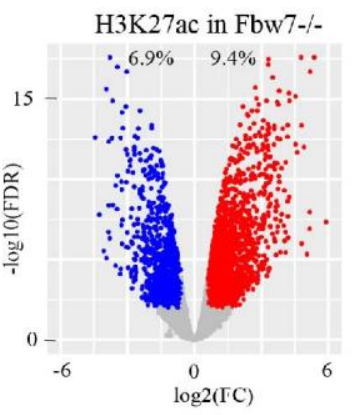

- Increased in mutant

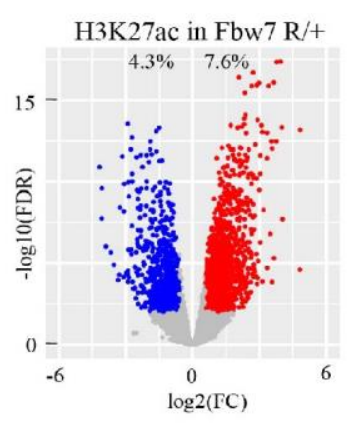

-Dccrcascd in mutant
$\mathbf{E}$

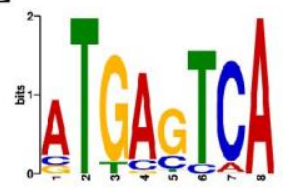

D Non-differential H3K27ac

$\mathrm{H} 3 \mathrm{~K} 27 \mathrm{ac}$ increased in $\mathrm{Fbw} 7^{*}$

$\mathrm{H} 3 \mathrm{~K} 27 \mathrm{ac}$ increased in $\mathrm{Fbw} 7^{\mathrm{R} /+}$
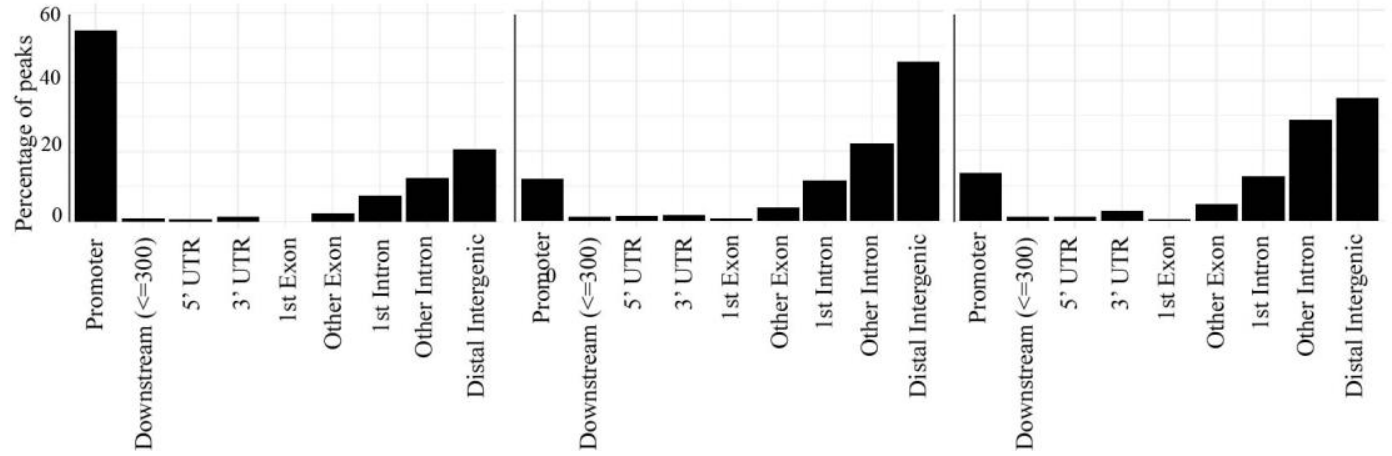

Figure 2. Differential H3K27ac signal in Hct116 Fbw7 mutant cells reveal genomic sites targeted by Fbw7.

(A) Heatmaps showing the correlation between CUT\&RUN profiles of H3K27ac and H3K27me3, and RNA-Seq in Hct116 WT cells. (B) Genome browser view of H3K27ac and H3K27me3 signal from Hct116 WT, Fbw $7^{\text {R/+ }}$ and

Fbw $7^{-/-}$cells at a representative gene. (C) Peaks with increased (red) or decreased (blue) H3K27ac signal in Hct116

$\mathrm{Fbw}^{-{ }^{--}}$and $\mathrm{Fbw} 7^{\mathrm{R} /+}$ cells compared to WT cells. Differential sites indicated as a percent of total H3K27ac peaks in Hct116 WT cells. (D) Percentage of H3K27ac peaks located within different gene regions. (E) Sequence logo for AP-1 motif enriched in $\mathrm{H} 3 \mathrm{~K} 27$ ac peaks increased in Fbw $7^{-/-}$cells $(\mathrm{E}$ value $=1.6 \mathrm{e}-3)$. See Figure $2-$ figure supplement 1, Figure 2 - figure supplement 2, Figure 2 - source data 1 and Figure 2 - source data 2. Figure 2 figure supplement 3 has the complete MEME output and details on the FIMO analysis. 


\section{Fbw7 preferentially regulates Jun and Myc occupancy at distal regulatory regions.}

Fbw7 targets some TF-substrates while they are bound to DNA (Fryer et al., 2004; Punga

215 et al., 2006). We thus speculated that substrates may recruit Fbw7 to chromatin and examined

216 Fbw7-chromatin association in Hct116 cells with endogenous heterozygous $\left(\mathrm{Fbw} 7^{\mathrm{R} /+}\right)$ or

217 homozygous $\left(\mathrm{Fbw} 7^{\mathrm{R} / \mathrm{R}}\right)$ mutations. Fbw7 was found in both the chromatin and soluble fractions

218 of WT cell lysates, but exclusively in the soluble fraction in Fbw $7^{\mathrm{R} / \mathrm{R}}$ cells (Figure $3 \mathrm{~A}$ ). The only

219 known consequence of $\mathrm{Fbw} 7^{\mathrm{R}}$ mutations is to prevent substrate binding, hence the loss of

220 chromatin bound Fbw7 in $\mathrm{Fbw} 7^{\mathrm{R} / \mathrm{R}}$ cells suggests that substrates recruit Fbw7 to chromatin.

221 Proteasome inhibition prevents substrate degradation and stabilizes Fbw7-substrate complexes.

222 Accordingly, proteasome inhibition with bortezomib further shifted Fbw7 to the chromatin

223 fraction (Figure 3 - figure supplement 1), further supporting the hypothesis that substrate binding 224 underlies Fbw7 chromatin association.

225 We next focused on two TF substrates: 1) Jun, because of the highly enriched AP-1

226 motifs in the Fbw7-dependent active chromatin, and 2) Myc, due to its prominent roles in Fbw7-

227 associated cancer (R. J. Davis et al., 2014). Myc deregulation in Fbw7-associated cancers

228 typically occurs through either Fbw7 or Myc-phosphodegron mutations (R. J. Davis et al., 2014;

229 Welcker et al., 2004; Yada et al., 2004; Yumimoto \& Nakayama, 2020). CPD phosphorylation

230 and Myc ubiquitylation also modulate Myc transcriptional activity (Endres et al., 2021; Gupta et

231 al., 1993; Hemann et al., 2005; Jaenicke et al., 2016; Thomas \& Tansey, 2011). Myc is stabilized

232 in Fbw $7^{-/-}$Hct116 cells, but its steady state abundance is less impacted due to negative

233 autoregulation of Myc transcription (Grim et al., 2008). Myc is partially stabilized in Hct116

$234 \mathrm{Fbw} 7^{\mathrm{R} /+}$ cells and Fbw7 $\Delta \mathrm{D}$ cells (in which endogenous Fbw7 dimerization is prevented) (R. J.

235 Davis et al., 2018; Welcker et al., 2013, 2022). These data implicate Fbw7 dimers in Myc 
236 turnover, which is mediated through two Myc degrons that concertedly bind Fbw7 dimers

237 (Welcker et al., 2022). Fbw7 targets Jun for degradation after multisite phosphorylation in two

238 identified degrons (Csizmok et al., 2018; Nateri et al., 2004; Wei et al., 2005). While we find

239 minimal impact of Fbw7 mutations on steady-state Jun abundance (R. J. Davis et al., 2018),

240 several factors have been described that regulate Jun degradation by Fbw7 in Hct116 cells,

241 including Rack1 (J. Zhang et al., 2012), BLM (Priyadarshini et al., 2018), and Usp28

242 (Diefenbacher et al., 2014).

243 We profiled genome-wide Jun and Myc occupancy (Figure 3 - figure supplement 2A) to

244 determine the extent that they are deregulated by Fbw7 mutations. As expected, Jun-binding and

245 Myc-binding site motifs were highly enriched in the respective datasets (Figure 3 - figure

246 supplement 2B). Differential binding analyses of the Jun and Myc peaks demonstrated that 5.3\%

247 and $3.8 \%$ of the Jun sites and 2.2\% and 3.3\% of the Myc sites exhibited differential occupancy in

$248 \mathrm{Fbw}^{-/-}$and $\mathrm{Fbw} 7^{\mathrm{R} /+}$ cells, respectively (Figure 3B, Figure 2 - source data 2). Fbw7 mutations

249 thus altered Myc and Jun occupancy at specific loci, rather than causing a global increase.

250 Like H3K27ac, most non-differential Myc binding sites were promoter-proximal,

251 whereas sites with increased Myc occupancy in Fbw7 mutant cells fell within introns and

252 intergenic regions (p value < 0.001, Fisher test) (Figure 3C, Figure 3 - figure supplement 3 ).

253 Compared with Myc, a smaller proportion of the total Jun sites in WT-Hct116 cells were

254 promoter-proximal, but again the sites with differential occupancy in Fbw7 mutant cells were

255 heavily biased to intronic and intragenic regions ( $\mathrm{p}$ value $<0.0001$, Fisher test) (Figure 3C). The

256 differential sites in introns and intergenic loci were enriched for H3K27ac and H3K4me1,

257 indicating that they may function within distal regulatory elements, such as enhancers (Figure

258 3D). 
To study the functional significance of Fbw7-dependent changes in Jun and Myc binding, 260 we examined the expression of genes that could be linked to the differential Jun or Myc sites that 261 fell within gene bodies or $10 \mathrm{~kb}$ upstream of TSS (Figure 3E). Approximately 39\% of genes with 262 increased promoter-proximal Jun occupancy and $46 \%$ of genes with decreased promoter263 proximal Jun occupancy in $\mathrm{Fbw}^{-/-}$cells exhibited corresponding increases or decreases in RNA 264 expression (Figure 3F). Of note, many of the genes with promoter-proximal Jun or Myc sites 265 were either not captured by RNA-Seq or had expression changes that were not statistically 266 significant. Similar associations were seen with Myc differential sites, although fewer could be 267 linked with transcripts (Figure 3 - figure supplement 4). Overall, the differential sites that could 268 be linked with associated genes showed good concordance between the changes in TF occupancy 269 and RNA expression. 
A

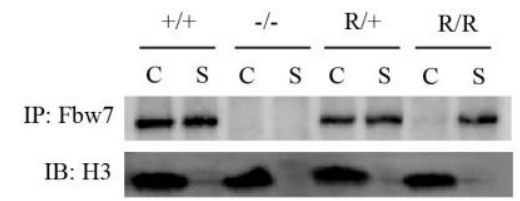

C

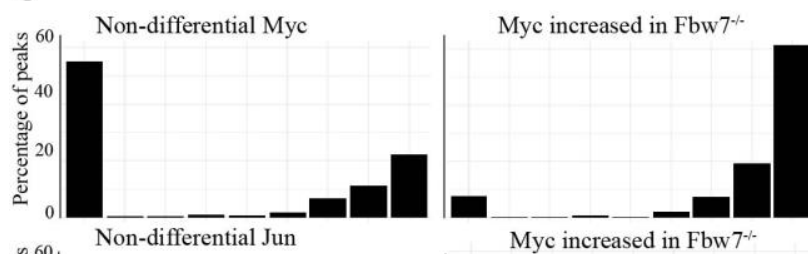

荧 40

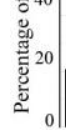

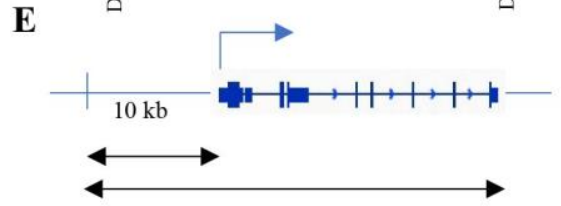

F

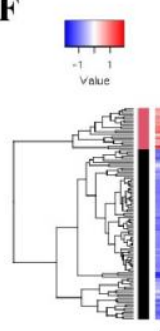
Figure 3 - figure supplement 1- 4 and Figure 3 - source data 1-2.
B
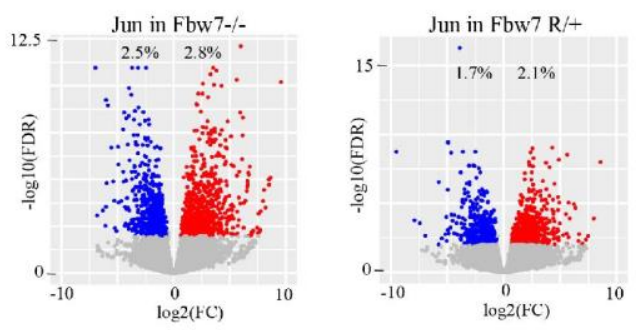

Myc in Fbw 7-/-

$0.8 \% \quad 1.4 \%$

Myc increased in $\mathrm{Fbw} 7 \%$

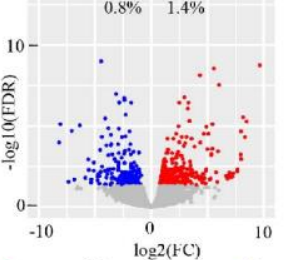

- Increased in mutant

-Decreased in mutant
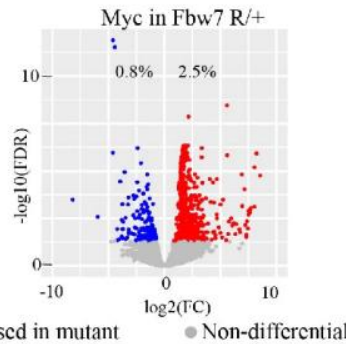

D
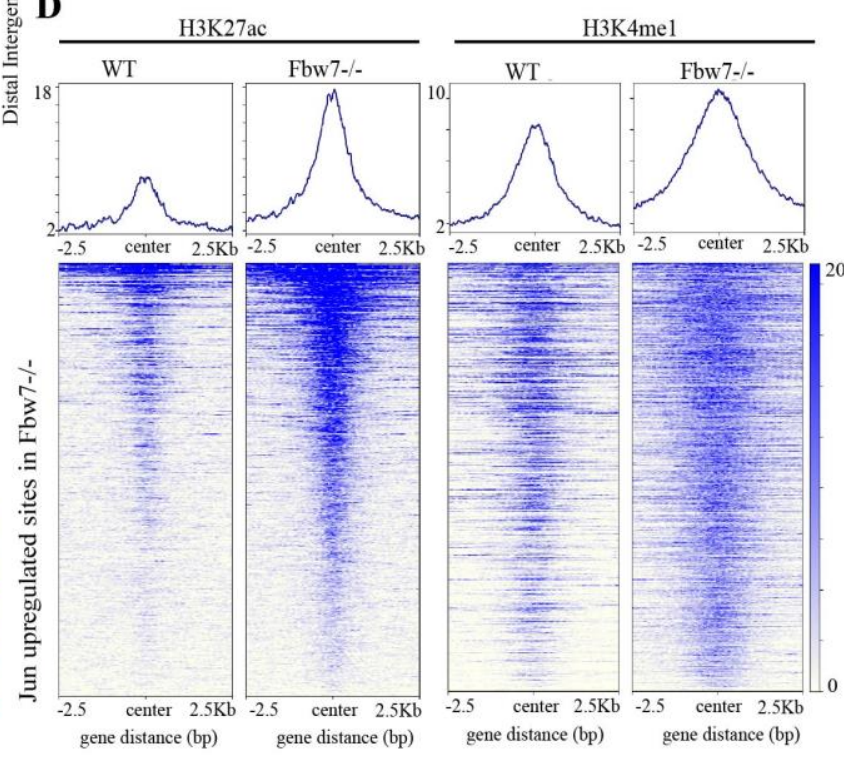

Figure 3. Fbw7 preferentially regulates Jun and Myc DNA occupancy at distal regulatory regions. (A) Fbw7 abundance in chromatin (C) and soluble (S) fractions from Hct116 WT, Fbw $7^{\mathrm{R} /+}$ and Fbw $7^{\mathrm{R} / \mathrm{R}}$ cells. Histone $\mathrm{H} 3$ was detected in chromatin fractions. (B) Increased (red) and decreased (blue) Jun and Myc sites in Hct116 Fbw $7^{-/-}$and Fbw $7^{\mathrm{R} / \mathrm{t}}$ cells compared to WT. (C) Non-differential and differential Jun and Myc peaks located within gene features. (D) H3K27ac and H3K4me1 CUT\&RUN signal from Hct116 WT and Fbw $7^{-1-}$ cells mapped on genomic sites that have increased Jun occupancy in Fbw $7^{-/-}$cells. (E) Schema depicting the filtering criteria applied to the annotated differential sites to select gene proximal sites. (F) Transcription of genes with increased or decreased Jun bound at a gene proximal site. (Each row is a gene and three replicates each from Hct116 WT and Fbw $7^{-/}$cells are shown. Replicates for each genotype were from a single clone, however from separately cultured samples.) See 


\section{$281 \mathrm{Fbw}^{-/-}$and $\mathrm{Fbw}^{\mathrm{R} /+}$ mutation-specific consequences.}

We next examined how Jun occupancy is differentially affected by $\mathrm{Fbw} 7^{\mathrm{R} /+}$ and $\mathrm{Fbw} 7^{-/-}$ mutations. Importantly, many differential Jun sites were common to both mutant cell lines: $48 \%$ of differential Jun sites in Fbw $7^{\mathrm{R} /+}(252 / 530$; $\mathrm{p}$ value $<0.0001$, Fisher test) and $35 \%$ of differential Jun sites in Fbw $7^{-/-}$(252/715) (Figure 4A). Representative Jun peaks that are increased in $\mathrm{Fbw} 7^{-/-}$and/or Fbw $7^{\mathrm{R} /+}$ are shown in Figure 4B: a) Jun occupancy at $K C N Q 5$ intronic sites was increased only in Fbw $7^{-/-}$cells; b) in ITGA2, Jun occupancy was increased in both $\mathrm{Fbw}^{-/-}$and $\mathrm{Fbw} 7^{\mathrm{R} /+}$, but to an intermediate level in $\mathrm{Fbw} 7^{\mathrm{R} /+}$; and c) in MAML2, Jun occupancy was increased in $\mathrm{Fbw} 7^{\mathrm{R} /+}$ more highly than in $\mathrm{Fbw} 7^{-/-}$. occupancy, as depicted by the heatmap in which the Jun sites from WT, Fbw $7^{\mathrm{R} /+}$, and $\mathrm{Fbw} 7^{-/-}$

292 cells were mapped on all the sites with increased Jun occupancy in Fbw $7^{-/-}$cells (Figure 4C).

293 H3K27ac sites followed this same trend (Figure 4B, 4D). RNA-Seq data also showed that some 294 genes were deregulated in both $\mathrm{Fbw} 7^{-/-}$and $\mathrm{Fbw} 7^{\mathrm{R} /+}$, but to an intermediate level in $\mathrm{Fbw} 7^{\mathrm{R} /+}$

295 (cluster 3 and 4 Figure 1B, 1C). These intermediately affected binding sites and transcripts, in 296 which $\mathrm{Fbw}^{-/-}>\mathrm{Fbw}^{\mathrm{R} /+}>\mathrm{WT}$, consistent with the notion that the Fbw $7^{\mathrm{R} /+}$ mutation is less 297 severe than complete Fbw7 loss. Other Jun differential sites were uniquely impacted by either 298 mutation (Figure 4A), including a subset of sites that were most strongly impacted by Fbw $7^{\mathrm{R} /+}$. 299 RNA-Seq data showed that genes in clusters 5 and 6 were deregulated most strongly in Fbw $7^{\mathrm{R} /+}$

300 (Figure 1B, 1C). In summary, we identified differential Jun sites that are uniquely affected by 301 each Fbw7 mutation type and others that were shared between the two mutant cell lines. Because 302 the $\mathrm{Fbw} 7^{-/-}$and $\mathrm{Fbw} 7^{\mathrm{R} /+}$ cells were derived independently, the shared loci impacted by both 303 mutations with respect to Jun occupancy, H3K27ac, and mRNA expression support the 
304 conclusion that these findings are attributable to Fbw7 status, rather than factors such as clonal 305 variation.

306

307 Fbw7 coordinately regulates Jun and Myc at co-occupied loci.

309 if they were coregulated at shared sites. Approximately $20 \%$ of the Myc and Jun binding sites 310 overlapped in Hct116 WT cells (Figure 4 - figure supplement 1A, p < 0.0001 Fisher Test). Jun

311 and Myc exhibited strikingly coordinate regulation by Fbw7 at these co-occupied differential

312 loci. We identified 78 sites in which both Jun and Myc occupancy were increased in Fbw $7^{-/-}$cells

313 and 53 sites where both Jun and Myc were decreased in Fbw $7^{-/-}$cells (Figure 4E, 4F). In contrast,

314 no sites with discordant changes in Jun and Myc occupancy (e.g., increased Jun but decreased

315 Myc) were found (Figure 4G, 4H). We found similar concordance in co-regulated Jun and Myc

316 sites in $\mathrm{Fbw} 7^{\mathrm{R} /+}$ cells (Figure 4 - figure supplement $1 \mathrm{~B}, 1 \mathrm{C}$ ). We chose one of these coregulated 317 loci, upstream of the CIITA, for further study. 
A

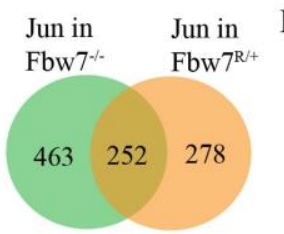

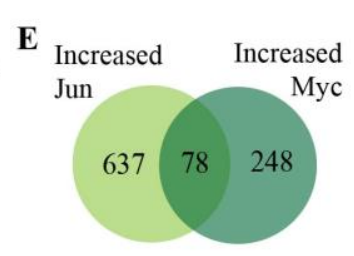

$\mathbf{F}_{\text {Decreased Decreased }}$ Jun Myc

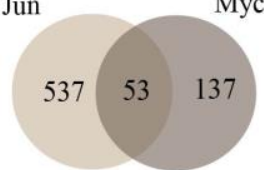

B

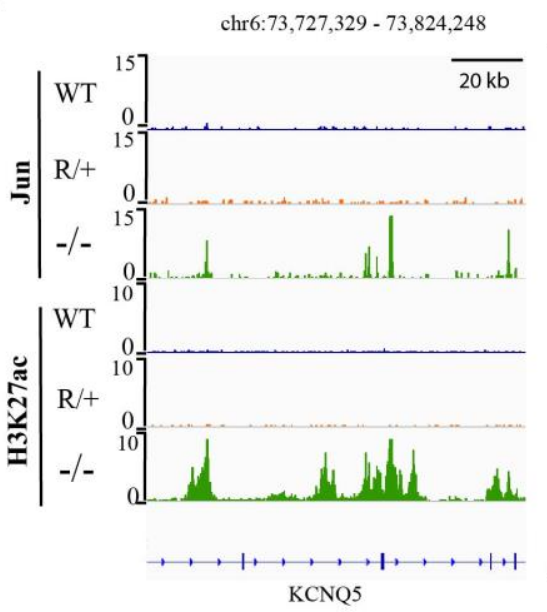

C
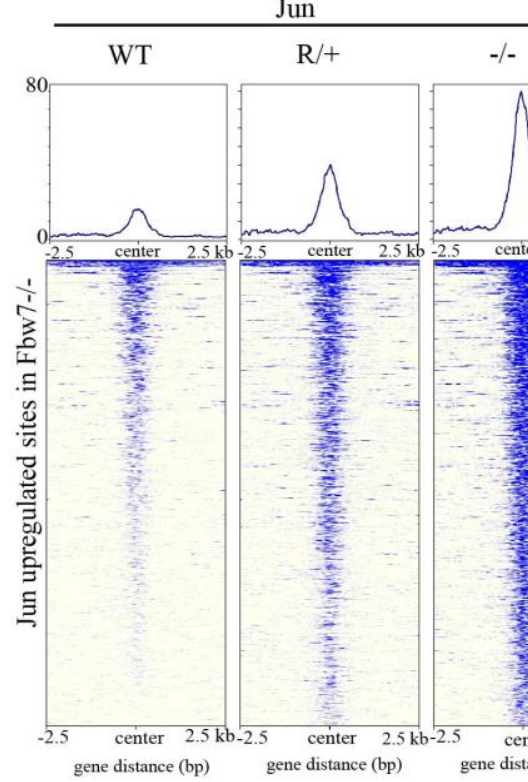

$\operatorname{chr} 5: 52,320,270-52,338,441$

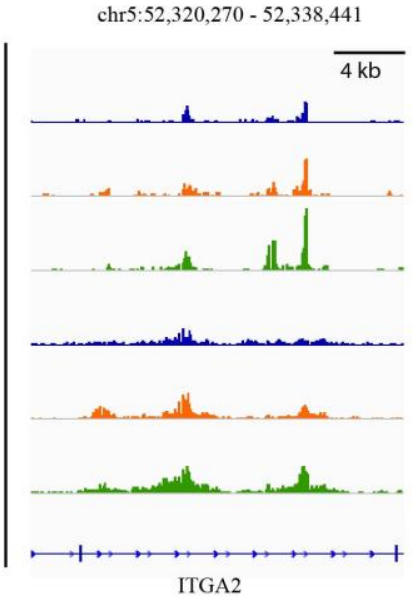

D
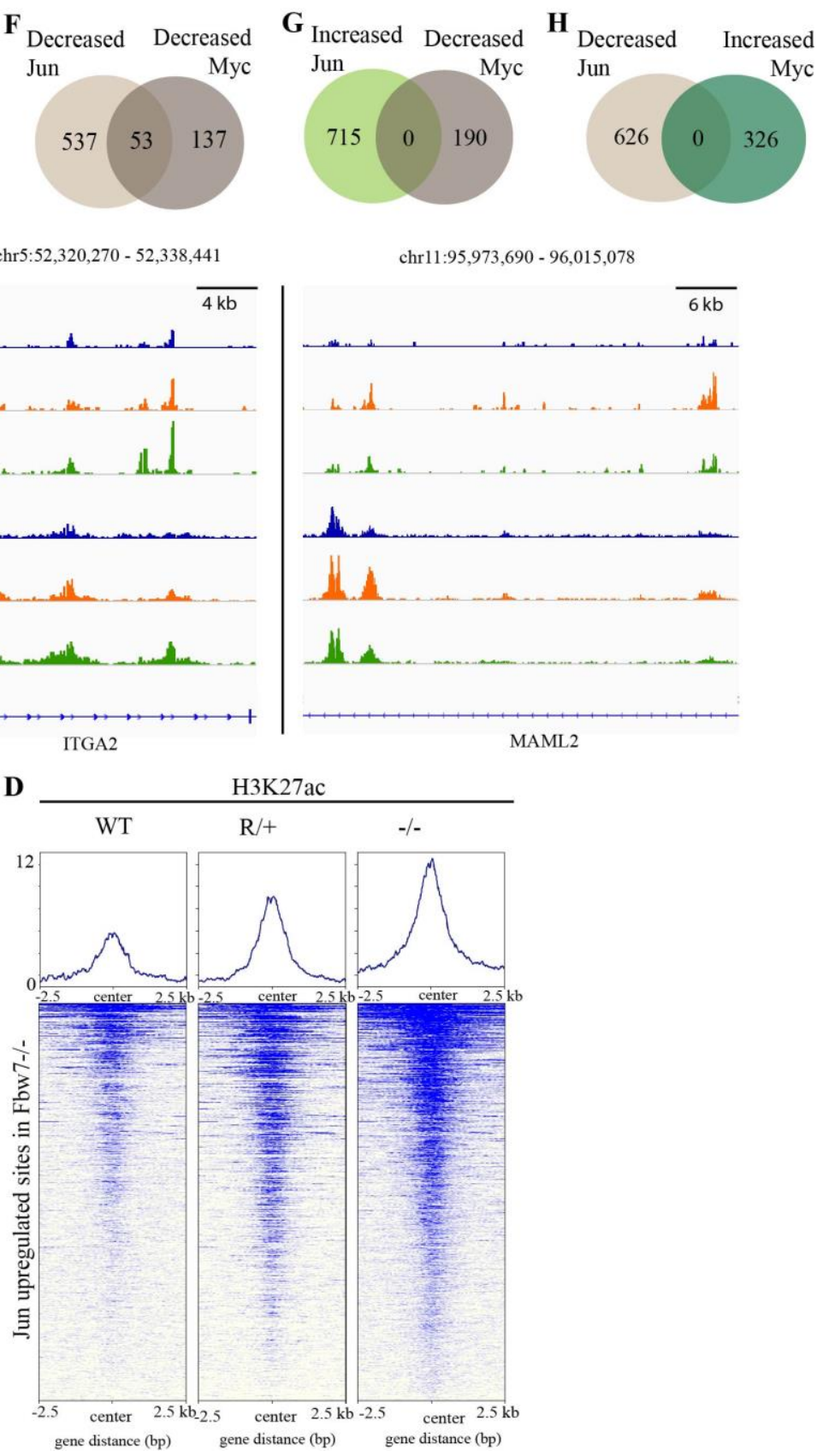

Figure 4. Fbw7 exhibits mutation-type specific regulation and coordinate regulation of multiple TFs. (A) The overlap between peaks with increased Jun in $\mathrm{Fbw} 7^{-/-}$and $\mathrm{Fbw} 7^{\mathrm{R} /+}$ cells. (B) Genome browser view of Jun and $\mathrm{H} 3 \mathrm{~K} 27 \mathrm{ac}$ occupancy in Hct116 WT, $\mathrm{Fbw} 7^{-/-}$, and $\mathrm{Fbw} 7^{\mathrm{R} /+}$ cells at representative loci. Black arrows point to peaks with increased signal uniquely in $\mathrm{Fbw}^{-\digamma_{-}}(\mathrm{KCNQ5})$, in both $\mathrm{Fbw} 7^{-{ }_{-}}$and $\mathrm{Fbw} 7^{\mathrm{R} /+}$ (intermediate level in $\mathrm{Fbw} 7^{\mathrm{R} /+}$ ) (ITGA2) and increased in $\mathrm{Fbw} 7^{\mathrm{R} /+}$ than in $\mathrm{Fbw} 7^{-/-}$(MAML2). (C, D) Heatmap of Jun and H3K27ac signal from each cell type mapped on sites with increased Jun in Fbw $7^{-/-}$cells. (E-H) E-The overlap between peaks with increased Jun and Myc, F- decreased Jun and Myc, G- increased Jun and decreased Myc, H-decreased Jun and increased Myc in Fbw $^{-/-}$cells. See Figure 4 - figure supplement 1. 


\section{Jun and Myc co-regulation by Fbw7 controls MHC Class II gene expression.}

Unlike MHC Class I genes, which are expressed in all cells, MHC Class II genes are

normally expressed only in specific immune cells, where their expression is controlled by the

330 Class II Major Histocompatibility Transactivator protein, or CIITA (Masternak et al., 2000; Ting

$331 \&$ Trowsdale, 2002). CIITA and MHC Class II genes were upregulated in Fbw $7^{-/-}$cells (Figure

332 1C). The CIITA gene contains four promoters (hereafter referred to as PI - PIV) that specify four

333 transcripts with distinct first exons (Muhlethaler-Mottet et al., 1997). While CIITA isoform III is

334 constitutively expressed in antigen presenting cells, isoform IV is inducible by cytokines in non-

335 hematopoietic cells (van der Stoep et al., 2007). The PIII Upstream Regulatory Region (PURR)

336 is located 6kb upstream of PIII and consists of regulatory sites for both constitutive and IFN $\gamma$ -

337 induced CIITA expression (Deffrennes et al., 2001; van der Stoep et al., 2007), as well as an AP-

3381 site (Martins et al., 2007). Both Myc and Jun bound to these upstream regulatory elements

339 (PURR and an element 14kb upstream of CIITA-PIII) and their occupancy were increased in

$340 \mathrm{Fbw}^{-/-}$cells (Figure 5A). Jun and Myc occupancy were also increased at these sites in Fbw $7^{\mathrm{R} /+}$

341 cells, but to a lesser extent. H3K27ac and H3K4me1 were increased at these sites in Fbw7 ${ }^{-/-}$

342 cells, which is indicative of active transcription.

343 RNA-Seq revealed increased CIITA mRNA expression in Fbw7 ${ }^{-/-}$cells (Figure 5B).

344 Isoform-specific primers demonstrated that the $\mathrm{pIII}$ isoform is elevated in $\mathrm{Fbw} 7^{-/-}$cells, but that

345 the pIV isoform is not expressed (Figure 5D). Raji cells are shown as a control cell that expresses

346 both CIITA isoforms. The upregulated CIITA expression in Fbw $7^{-/-}$cells is functionally

347 significant and caused increased expression of MHC Class II genes (HLA-DPA, HLA-DPB,

348 HLA-DRB and HLA-DRA), as shown by both RNA-Seq and by qPCR using primers that detect

349 MHC class II mRNAs (Figure 5B and Figure 5C). In contrast, MHC Class I genes were not 
350 differentially expressed in Fbw7 mutant cells (Figure 5 - figure supplement 1). Flow cytometry

351 revealed increased and heterogeneous MHC Class II protein surface expression in Fbw $7^{-/-}$cells

352 and immunoblotting detected increased protein expression (Figure 5E, Figure 5 - figure

353 supplement 2). The basis for this heterogeneity in protein expression is not presently understood.

354 We also analyzed CIITA expression in primary colorectal cancers (CRCs) in TCGA

355 datasets, which was increased in Fbw7 mutant cancers compared with Fbw7 WT tumors (Figure

$3565 \mathrm{~F})$. Because these primary tumors contain immune infiltrates, the increased CIITA expression

357 could result from CIITA expression in either tumor cells or immune cells. We thus analyzed

358 CRC cell lines in the Cancer Cell Line Encyclopedia, which also revealed elevated CIITA

359 expression in Fbw7 mutant cell lines (Figure 5G) (Ghandi et al., 2019). Because many of the

360 TCGA and CCLE colorectal cancer specimens contain $\mathrm{FBW}^{\mathrm{R} /+}$ mutations, these analyses

361 underrepresent MHC Class II overexpression in Fbw $7^{-/-} \mathrm{CRCs}$. These data support the idea that

362 Fbw7 regulates CIITA expression in colorectal cancer, likely due to co-regulation of Myc and

363 Jun at the PIII upstream regulatory site. 
A
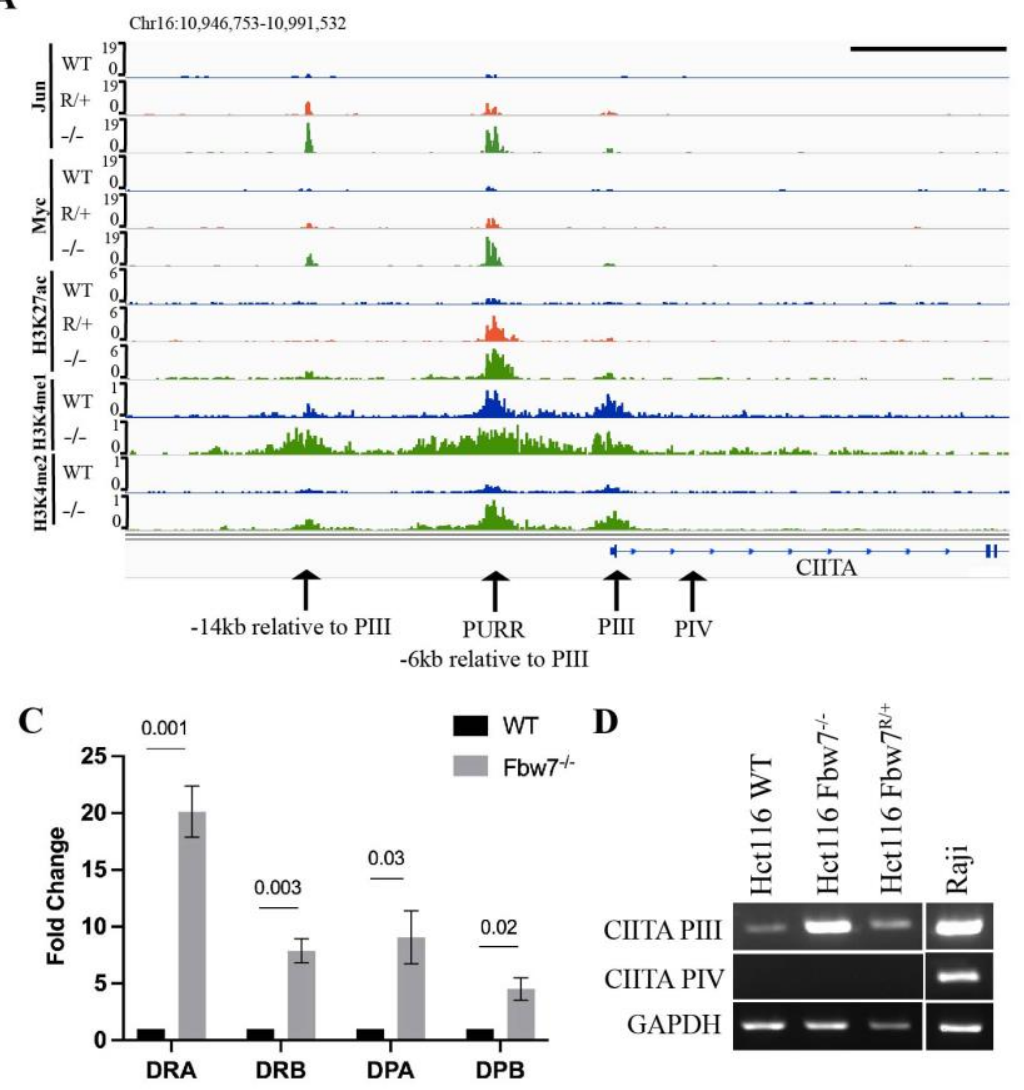

D

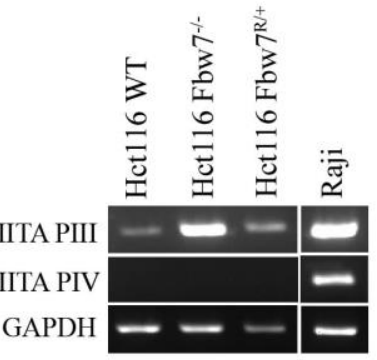

$\mathbf{B}$

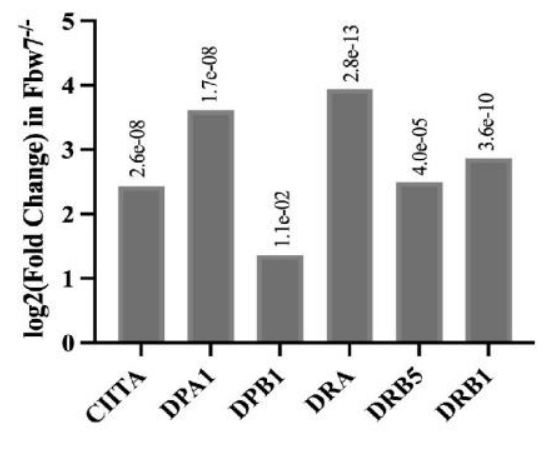

$\mathbf{E}$
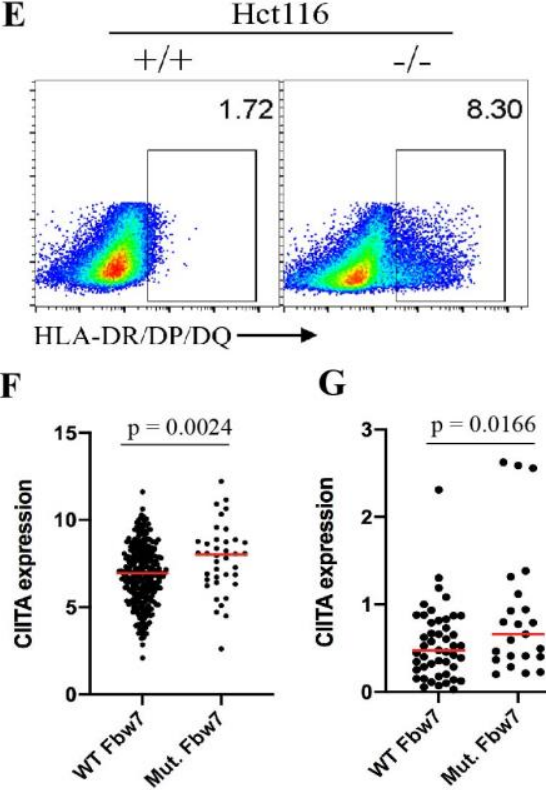

Figure 5. Fbw7 regulates the expression of MHC Class II genes. (A) Genome browser view of TFs and histone modification marks enriched at the promoter and regulatory sites upstream of CIITA gene. Arrows point to (from right to left): PIV (promoter of isoform IV); PIII (promoter of isoform III); PURR (PIII Upstream Regulatory Regions) - a known regulatory site 6 kb upstream of PIII; and a known regulatory site 14 kb upstream to PIII. Black scale bar $=10 \mathrm{~kb}$. (B) Expression fold change of CIITA and MHC Class II genes in Hct116 Fbw $7^{-/-}$with respect to WT cells. FDR values are indicated on top of each bar. $n=3$. (C) Quantitative RT-PCR analysis of MHC Class II (HLA-DRA, HLA-DRB, HLA-DPA, and HLA-DPB) expression in Hct116 Fbw7 $7^{-/}$cells. Mean fold change in $\mathrm{Fbw}^{-/-}$cells with respect to WT cells. Error bars $=\mathrm{SEM}, \mathrm{n}=3$. (D) CIITA isoform III and IV amplified using isoform specific primers in Hct116 and Raji cells. (E) Flow cytometry analysis of HLA-DR/DP/DQ protein expression in Hct116 cells. (F) CIITA expression in primary cancer samples from TCGA COADREAD datasets that have WT Fbw7 (n=297) and mutated Fbw7 (n=43). (G) CIITA expression in colon and rectal cancer cell lines with WT Fbw7 (n=47) and mutated Fbw7 (n=23). Data collected from DepMap portal. See Figure 5 - figure supplement 1, Figure 5 - figure supplement 2 and Figure 5 - source data 1-4. 
that are transformed and clonal, we examined the generalizability of these results by determining how acute Fbw7 deletion in non-transformed cells impact RNA expression and Jun occupancy.

382 We studied U5 NSCs (Bressan et al., 2017), which represent a cell type in which Fbw7 has 383 important developmental and oncogenic activities, and which displays Fbw7-mediated Jun 384 regulation (Hoeck et al., 2010). We used a high efficiency CRISPR/nucleofection protocol to 385 inactivate Fbw7 in two independent experiments without the need for any selection (Figure 6 386 figure supplement 1A) (Hoellerbauer, Kufeld, \& Paddison, 2020; Hoellerbauer, Kufeld, Arora, et 387 al., 2020). Fbw7 was efficiently deleted in U5 NSCs, which modestly impacted S-phase entry 388 and doubling time (Figure 6 - figure supplement 2). Analogous to the Hct116 cell panel, 9\% of 389 protein-coding genes were differentially expressed in Fbw $7^{-/-}$cells compared with WT-U5 NSCs 390 (Figure 6A).

We identified enriched gene sets in the differentially expressed transcripts in Fbw $7^{-/-}$cells

392 (Figure 6B and Figure 6 - source data 3). Surprisingly, many of these pathways were the same as 393 those identified in the Hct116 cells, which included EMT- and ECM-related gene sets, the p53 394 pathway, and MHC class II genes. Gene sets associated with KLF-binding sites were also highly 395 enriched in upregulated transcripts in $\mathrm{Fbw}^{-/-}$NSCs, but not in the downregulated transcripts. 396 While the significance of these broadly defined gene sets common to both NSC and Hct116 cells 397 will require both validation and further study, their conservation between these disparate cell 398 types raises the possibility that they represent core normal and neoplastic Fbw7 functions (see 399 Discussion). The most significant enriched genet set in downregulated differential genes was 400 nervous system development, consistent with Fbw7's role in regulating NSC differentiation. We 
401 also compared the specific Fbw7-dependent differential genes in Fbw $7^{-1-}$ NSCs with those in $402 \mathrm{Fbw}^{-/}$Hct1 16 cells (Figure 6 - figure supplement 6 ). The gene clusters exhibiting the greatest 403 Fbw7-dependence in each heat map were relatively devoid of genes that were expressed in both 404 cell types, suggesting that the most highly Fbw7 dependent genes were those with cell-type 405 specific expression.

406 Jun occupancy in WT and Fbw $7^{-/-}$NSCs closely mirrored that seen in the Hct116 cell 407 panel (Figure 6 - figure supplement 1) in that: (1) only a subset of the Jun binding sites displayed 408 differential occupancy after Fbw7 deletion (8.3\% increased and 4.1\% decreased) sites, and (2) 409 most of the differentially regulated Jun sites occurred in introns and intergenic regions ( $\mathrm{p}$ value $<$ 410 0.0001, Fisher test) (Figure 6C, 6D, Figure 6 - figure supplement 3). Thus, while most of the 411 specific loci impacted by Fbw7 loss in the Hct116 cells NSCs differed, the scope of Fbw7's 412 impact on Jun was quite similar. Upregulation of CIITA and MHC class II expression (Figure 413 6E) after Fbw7 loss was also seen in both Hct116 cells and NSCs. Jun and Myc were bound at 414 regulatory regions upstream of CIITA in NSCs, but only Myc occupancy was increased in Fbw7 $415{ }^{1-}$ NSCs (Figure 6F). Unlike Hct116 cells, NSC cells express a basal level of CIITA, perhaps 416 consistent with constitutive Jun occupancy upstream of CIITA (Figure 6 - figure supplement 4). 417 RNA-Seq and RT-PCR revealed increased MHC Class II gene expression after Fbw7 deletion, 418 which also increased MHC Class II protein expression (Figure 6 - figure supplement 5). 
A

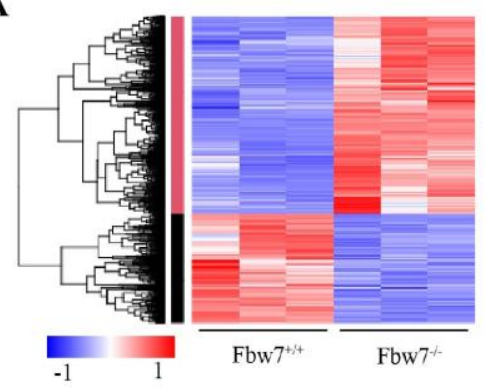

C

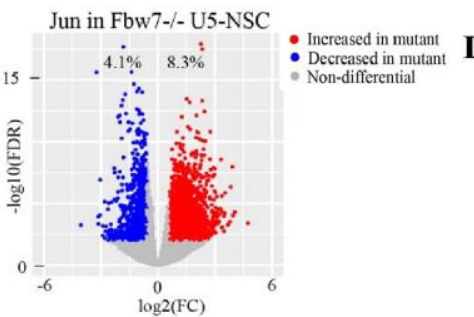

G
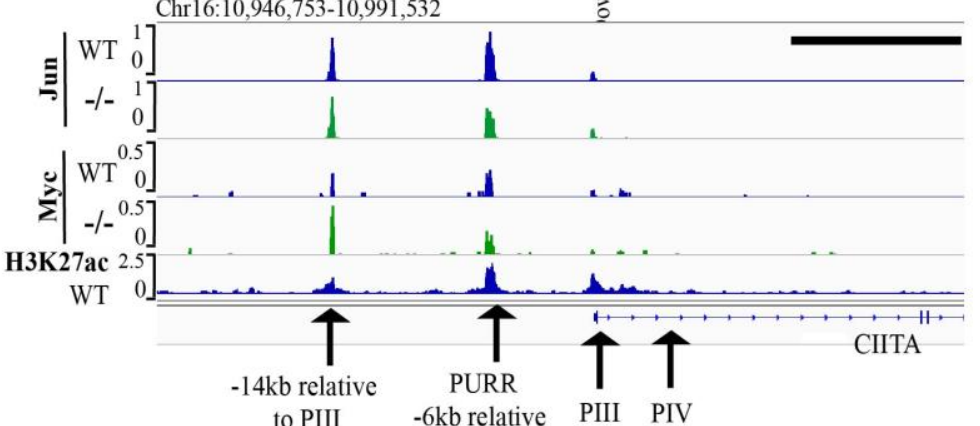
to PIII

B

\begin{tabular}{l|l|l} 
Gene Set & Enriched TF/Pathway/GO Term & Adj-p-value \\
\hline Upregulated in NSC Fbw7-- & KLF11 (TRANSFAC \& JASPAR) & $1.56 \mathrm{E}-08$ \\
& Epithelial Mesenchymal Transition (MSigDB) & $5.61 \mathrm{E}-30$ \\
& p53 Pathway (MSigDB) & $3.03 \mathrm{E}-16$ \\
& TNF-alpha Signaling via NF-kB (MSigDB) & $8.82 \mathrm{E}-15$ \\
& Hypoxia (MSigDB) & $1.18 \mathrm{E}-09$ \\
& Interferon Gamma Response (MSigDB) & $1.14 \mathrm{E}-06$ \\
& Estrogen Response Early (MSigDB) & $5.24 \mathrm{E}-03$ \\
& Myogenesis (MSigDB) & $4.45 \mathrm{E}-05$ \\
& Extracellular matrix organization (GO BP) & $4.03 \mathrm{E}-34$ \\
& Cell migration (GO BP) & $7.31 \mathrm{E}-08$ \\
& Cell population proliferation (GO BP) & $4.68 \mathrm{E}-05$ \\
& Angiogenesis (GO BP) & $5.22 \mathrm{E}-04$ \\
& Collagen-containing extracellular matrix (GO CC) & $2.01 \mathrm{E}-20$ \\
& MHC class II protein complex (G0 CC) & $3.99 \mathrm{E}-09$
\end{tabular}

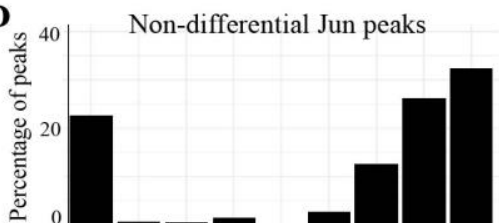

E

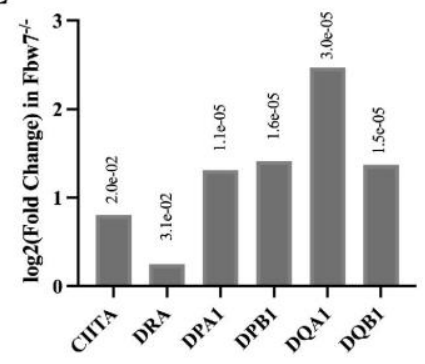

F

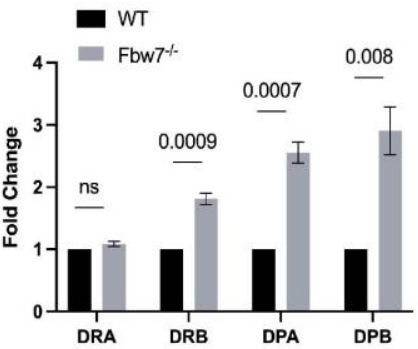

Figure 6. Transcriptional consequences of loss of Fbw7 in neural stem cells. (A) Clustering analysis separates differentially expressed protein-coding genes in NSCs into two groups. Heatmap shows the intensity of expression of each gene (y axis) for three replicates per cell type ( $\mathrm{x}$ axis). Three replicates were from two independently engineered cell samples. (B) TFs, pathways, and GO terms enriched in upregulated genes in Fbw $7^{-/-}$NSCs. (C) Sites with increased (red) and decreased (blue) Jun in Fbw $7^{-/-}$NSCs compared to WT. (D) Non-differential and differential Jun peaks located within each gene feature. (E) Fold change of CIITA and MHC Class II genes in Fbw7 ${ }^{1-}$ NSCs compared to WT. FDR values are given at the top of each bar. $n=3$. (F) Quantitative RT-PCR analysis of MHC Class II (HLA-DRA, HLA-DRB, HLA-DPA, and HLA-DPB) expression in Fbw $7^{-/-}$NSCs. Mean fold change in Fbw $7^{-/-}$cells with respect to WT cells. Error bars $=$SEM, $n=3$. (G) Genome browser view of Myc, Jun, and H3K27ac occupancy on CIITA regulatory regions in WT and Fbw $7^{-/-}$NSCs. Black scale bar $=8 \mathrm{~kb}$. See Figure $6-$ 


\section{Discussion}

432

433

434

435

436

437

438

439

440

441

442

443 sites, as supported by our data implicating Fbw7 recruitment to chromatin by TFs (Figure 3 -

444 figure supplement 1). However, we have not yet successfully mapped endogenous Fbw7 to

445 specific chromatin sites.

446

447

448

449

450 concerted targeting of both Jun and Myc. The expected outcome of Fbw7 loss is substrate

451 accumulation, and most differential sites had increased occupancy in Fbw7 mutant cells.

452 However, we also found differential sites with decreased Jun or Myc occupancy and

453 correspondingly less mRNA expression in Fbw7 mutant cells. The mechanisms through which 
454 Fbw7 loss decreases TF occupancy remain to be elucidated and could involve the many TFs and

455 associated proteins that are targeted by Fbw7. While Myc ubiquitylation impacts transcriptional

456 elongation (Jaenicke et al., 2016), our data do not presently provide insights into how this may

457 contribute to the observed genomic distribution of Fbw7-dependent loci. We examined

458 differential Myc binding sites for specific Myc cellular functions that might be targeted by Fbw7,

459 such as protein synthesis and metabolism. We did not find any evidence for this regulation, but

460 the low number of differential Myc-binding sites that we could link to genes may have limited

461 this analysis.

$462 \quad \mathrm{Fbw} 7^{\mathrm{R} /+}$ mutations may stabilize those substrates that require a fully functional Fbw7

463 dimer and the subset of transcripts impacted by Fbw $7^{\mathrm{R} /+}$ could thus result from dimer-dependent

464 Fbw7 functions (Welcker et al., 2013). If so, the reduced transcriptional consequences seen in

$465 \mathrm{Fbw}^{\mathrm{R} /+}$ cells (compared with $\mathrm{Fbw} 7^{-/-}$) may reflect the regulation of just those substrates

466 impacted by heterozygous Fbw7 missense mutations. Moreover, the many genes and loci with

467 intermediate levels of deregulation in $\mathrm{Fbw} 7^{\mathrm{R} /+}$ cells could be consistent with the "just-enough"

468 model of Fbw $7^{\mathrm{R} /+}$ function. We did not find enriched gene sets that were unique to Fbw $7^{\mathrm{R} /+}$ cells.

469 Instead, most of the enriched gene sets in $\mathrm{Fbw}^{\mathrm{R} /+}$ were also found in $\mathrm{Fbw} 7^{-/-}$cells. While the

470 biologic significance of these enriched gene sets requires experimental validation, they suggest

471 that regulation of cancer-associated processes, like EMT, ECM, and cell migration, may be

472 critical and shared consequences of $\mathrm{Fbw} 7^{-/-}$and $\mathrm{Fbw} 7^{\mathrm{R} /+}$ mutations. The $\mathrm{Fbw} 7^{\mathrm{R} /+}$ and $\mathrm{Fbw} 7^{-/-}$

473 cells not only shared enriched pathways, but also specific genes assigned to these pathways. For

474 example, 10/17 of the $\mathrm{Fbw} 7^{\mathrm{R} /+}$ genes assigned to the MSigDB Epithelial Mesenchymal

475 Transition (EMT) pathway were also found in Fbw $7^{-/-}$cells, as well as $11 / 15 \mathrm{Fbw} 7^{\mathrm{R} /+}$ genes in

476 the MSigDb p53 pathways set. 
478 type, acute versus chronic Fbw7 loss, transformed versus non-transformed cells, clonal versus

479 non-clonal), the remarkably similar consequences of Fbw7 loss in both cases suggests that these

480 features are fundamental properties of Fbw7's normal function and its mechanisms of tumor

481 suppression. For example, the extent of Fbw7-dependent changes in transcription, H3K27ac

482 marks, and Jun binding sites was highly conserved between the two cell types, as was the

483 genomic distribution of the Fbw7-regulated differential sites. There was also extensive overlap

484 between the enriched biological processes found in differential transcripts in $\mathrm{Fbw}^{-/-} \mathrm{NSCs}$ and

485 Fbw $7^{-/-}$Hct116 cells. Pathways related to EMT and ECM were the most highly enriched

486 pathways in NSCs, and they were found in both Fbw7 mutant Hct116 cell lines. Pathways

487 related to EMT (e.g., ECM, cell migration) may thus represent core Fbw7 targets in cancer and

488 development that are conserved across disparate cell types. Future studies will focus on

489 identifying the Fbw7 substrate(s) responsible for these findings, which seem likely to reveal new

490 insights into Fbw7 function. Another enriched pathway associated with Fbw7 loss in both NSCs

491 and Hct116 cells involved genes with binding sites for the KLF proteins, a family of TFs with

492 diverse roles in cell proliferation and differentiation. Several KLF proteins are Fbw7 substrates

493 (KLF2/4/5/10/11); these proteins all share the same binding site consensus and function as either

494 repressors and/or activators (McConnell \& Yang, 2010). These data implicate KLFs as potential

495 mediators of Fbw7-dependent transcription, and the absence of the KLF motif in downregulated

496 genes may further implicate KLF proteins that are transcriptional activators. Finally, another

497 shared consequence of Fbw7 loss in Hct116 cells and NSCs is slower proliferation, which is

498 likely due to both homeostatic responses (e.g., p53) and intrinsic activities of Fbw7 substrates 
499 (e.g., cyclin E). It will thus be important to ascertain how proliferation may relate to the enriched 500 gene sets associated with Fbw7 mutations.

501 Constitutive CIITA expression is normally confined to antigen presenting cells and it was 502 thus striking to find CIITA and MHC Class II genes expressed in Fbw7 mutated colon cancer 503 cells and NSCs. Abnormal CIITA and MHC Class II expression occurs in tumors, including 504 colorectal cancers (Axelrod et al., 2019; Sconocchia et al., 2014). Aberrant CIITA expression in 505 melanomas results from the activation of both IFN $\gamma$-inducible and constitutive CIITA promoters, 506 and deletion of the same AP-1 site that we found differentially occupied by Jun in Fbw7 mutant 507 Hct116 cells compromised CIITA expression in melanoma cells (van der Stoep et al., 2007). The 508 data support a model in which Fbw7 loss augments CIITA expression through increased Jun and 509 Myc occupancy at these regulatory regions.

510 What are the implications of Fbw7-dependent CIITA expression in colorectal cancers?

511 Tumor cell specific MHC Class II expression is generally associated with favorable prognosis, 512 which may be due to increased tumor immunogenicity conferred by MHC Class II expression.

513 Intriguingly, Fbw7 mutations and distant metastasis do not frequently co-occur in colorectal 514 cancers (Muzny et al., 2012). Fbw7 loss may thus confer better prognosis in colorectal cancers, 515 perhaps due to Fbw7-dependent MHC class II upregulation. Accordingly, we found increased 516 CIITA expression in TCGA colorectal tumors and CCLE colorectal cancer cell lines with Fbw7 517 mutations. We previously used machine learning to develop gene expression signatures that 518 predicted Fbw7 mutations in TCGA tumors. While we focused on a metabolic gene signature in 519 that study, we also found that a signature comprised of MHC Class II and other genes associated 520 with immune cells was highly predictive of Fbw7 mutations in colorectal cancers (R. J. Davis et 521 al., 2018 Supplemental Dataset S02). While these analyses were correlative, considering our 
522 current finding that Fbw7 loss induces CIITA expression in Hct116 cells and NSCs, we

523 speculate that Fbw7 mutations in colorectal cancers lead to increased CIITA expression,

524 increased immunogenicity, and better prognosis.

525 Other associations between Fbw7 and immune responses have also been reported. A

526 recent study found that an $\mathrm{Fbw} 7^{\mathrm{R} /+}$ mutation conferred resistance to PD-1 blockade through

527 impaired dsRNA sensing and IFN $\gamma$ signaling in a metastatic melanoma and a murine melanoma

528 model (Gstalder et al., 2020). In this case, $\mathrm{Fbw} 7^{\mathrm{R} /+}$ decreased MHC Class I but not MHC Class II

529 expression and caused a more aggressive phenotype associated with decreased immunogenicity.

530 These discrepancies with our study, which show upregulation of MHC Class II and no impact on

531 MHC Class I, may relate to the different tumor types and/or model systems. In mice, Fbw7 also

532 regulates the tumor microenvironment through a non-tumor-cell-autonomous manner involving

533 expression of the CCL2 chemokine (Yumimoto et al., 2015). Further studies are thus needed to

534 fully appreciate the pathologic and therapeutic implications of Fbw7-related tumor

535 immunogenicity.

536 Finally, it is important to note the potential impact of clonal variation on our studies,

537 which involved Hct116 cell clones. Several factors increase our confidence that our findings we

538 describe are directly attributable to Fbw7 status, rather than clonal evolution. First, we found that

539 a large proportion of differential loci and transcripts were shared between the two Fbw7 mutant

540 Hct116 cell lines (Figure 1C and 4A), and many of these exhibited a gradient of deregulation that

541 tracked with the severity of the mutations $\left(\mathrm{Fbw} 7^{-/-}>\mathrm{Fbw} 7^{\mathrm{R} /+}\right)$. Because these cells were

542 independently derived, it is unlikely that these shared features arose stochastically through clonal

543 evolution in each line. Next, we acutely deleted Fbw7 in the orthogonal and non-clonal NSCs to

544 mitigate against this possibility, and the shared consequences of Fbw7 loss (proportion of 
545 differential sites and transcripts, intergenic location of differential sites, shared biological

546 processes) in these two disparate cell systems support the conclusion that these observations

547 reflect shared and direct consequences of Fbw7 loss. Finally, we studied biological replicates of

548 non-clonal NSCs in which Fbw7 was independently inactivated by high efficiency

549 nucleofection-based CRISPR/Cas9 editing, and the consistent results across these replicates

550 indicates that the differential loci are unlikely to result from "drift" phenomena. In future studies,

551 we plan to adapt the strategy of using high-efficiency gene targeting to acutely delete Fbw7 in

552 primary cells, to study other tissues and stem cells. These studies will also allow us to again

553 assess any contributions of clonality.

554 In summary, these data establish a framework for understanding the global and context-

555 specific effects of Fbw7 mutations across cell types and cancers, and how Fbw7 substrates may 556 act synergistically to control gene expression. 
Materials and Methods

\begin{tabular}{|c|c|c|c|c|}
\hline \multicolumn{5}{|c|}{ Key Resources Table } \\
\hline $\begin{array}{l}\text { Reagent } \\
\text { type } \\
\text { (species) } \\
\text { or } \\
\text { resource }\end{array}$ & Designation & $\begin{array}{l}\text { Source or } \\
\text { reference }\end{array}$ & Identifiers & $\begin{array}{l}\text { Additional } \\
\text { information }\end{array}$ \\
\hline $\begin{array}{l}\text { Gene } \\
\text { (Homo } \\
\text { sapiens) }\end{array}$ & $F B X W 7$ & NCBI & Gene ID: 55294 & $\begin{array}{l}\text { Also known } \\
\text { as Fbw7 } \\
\text { and } \\
\text { FBXW7 }\end{array}$ \\
\hline $\begin{array}{l}\text { Gene } \\
\text { (Homo } \\
\text { sapiens) }\end{array}$ & $J U N$ & NCBI & Gene ID: 3725 & $\begin{array}{l}\text { Also known } \\
\text { as AP1, } \\
\text { AP-1, } \\
\text { cJUN, c- } \\
\text { Jun }\end{array}$ \\
\hline $\begin{array}{l}\text { Gene } \\
\text { (Homo } \\
\text { sapiens) }\end{array}$ & $M Y C$ & NCBI & Gene ID: 4609 & $\begin{array}{l}\text { Also known } \\
\text { as MYC, c- } \\
\text { Myc, cMyc }\end{array}$ \\
\hline $\begin{array}{l}\text { cell line } \\
\text { (Homo } \\
\text { sapiens) }\end{array}$ & Hct116 & $\begin{array}{l}\text { From Dr. } \\
\text { Julian Simon } \\
\text { at Fred Hutch }\end{array}$ & HCT116 CCL-247 & $\begin{array}{l}\text { Adult male } \\
\text { colon } \\
\text { cancer }\end{array}$ \\
\hline $\begin{array}{l}\text { cell line } \\
\text { (Homo } \\
\text { sapiens) }\end{array}$ & $\begin{array}{l}\text { U5 human } \\
\text { neural stem } \\
\text { cells (NSC) }\end{array}$ & Jackson Lab & B6.129P2Gpr37tm1Dgen/J & $\begin{array}{l}\text { Primary } \\
\text { cells }\end{array}$ \\
\hline antibody & $\begin{array}{l}\text { Anti-H3K27ac } \\
\text { Rabbit } \\
\text { Monoclonal }\end{array}$ & Abcam & Cat\# ab45173 & C\&R (1:100) \\
\hline antibody & $\begin{array}{l}\text { Anti- } \\
\text { H3K27me3 } \\
\text { Rabbit } \\
\text { Monoclonal } \\
\text { (C36B11) }\end{array}$ & $\begin{array}{l}\text { Cell Signaling } \\
\text { Technologies }\end{array}$ & Cat\# 9733A & C\&R (1:100) \\
\hline antibody & $\begin{array}{l}\text { Anti-cJun } \\
\text { Rabbit } \\
\text { Polyclonal (H- } \\
79)\end{array}$ & Santa Cruz & Cat\# sc-1694 & C\&R (1:25) \\
\hline
\end{tabular}


Thirimanne 2021

\begin{tabular}{|c|c|c|c|c|}
\hline antibody & $\begin{array}{l}\text { Anti-Myc } \\
\text { Rabbit } \\
\text { Monoclonal } \\
\text { (D3N8F) }\end{array}$ & $\begin{array}{l}\text { Cell Signaling } \\
\text { Technologies }\end{array}$ & Cat\# 13987S & C\&R (1:25) \\
\hline antibody & $\begin{array}{l}\text { Anti- } \\
\text { H3K4me1 } \\
\text { Rabbit } \\
\text { Polyclonal }\end{array}$ & Abcam & Cat\# ab8895 & C\&R (1:100) \\
\hline antibody & $\begin{array}{l}\text { Anti- } \\
\text { H3K4me2 } \\
\text { Rabbit } \\
\text { Monoclonal } \\
\text { (C64G9) }\end{array}$ & $\begin{array}{l}\text { Cell Signaling } \\
\text { Technologies }\end{array}$ & Cat\# 9725 & C\&R (1:100) \\
\hline antibody & $\begin{array}{l}\text { Normal IgG } \\
\text { (Rabbit) }\end{array}$ & Santa Cruz & sc-2027 & C\&R (1:50) \\
\hline antibody & $\begin{array}{l}\text { Anti-Fbw7 } \\
\text { Rabbit } \\
\text { Polyclonal }\end{array}$ & Bethyl & A 301-720A & WB $(1: 1000)$ \\
\hline antibody & $\begin{array}{l}\text { Anti-HLA DR } \\
\text { Mouse } \\
\text { Monoclonal } \\
\text { TAL 1B5 }\end{array}$ & Abcam & ab20181 & WB (1:500) \\
\hline antibody & $\begin{array}{l}\text { Anti-HLA } \\
\text { DR + DP + } \\
\text { DQ Mouse } \\
\text { Monoclonal } \\
\text { CR3/43 }\end{array}$ & Abcam & $a b 7856$ & WB (1:500) \\
\hline antibody & $\begin{array}{l}\text { Anti-Mouse } \\
\text { IgG } \\
\text { peroxidase- } \\
\text { linked } \\
\text { secondary }\end{array}$ & $\begin{array}{l}\text { Cytiva } \\
\text { NA9311ML }\end{array}$ & Cat\# 45-000-679 & $\begin{array}{l}\text { WB } \\
(1: 10,000)\end{array}$ \\
\hline antibody & $\begin{array}{l}\text { Anti-Rabbit } \\
\text { IgG } \\
\text { peroxidase- } \\
\text { linked } \\
\text { secondary }\end{array}$ & $\begin{array}{l}\text { Cytiva } \\
\text { NA9341ML }\end{array}$ & Cat\# 45-000-682 & $\begin{array}{l}\text { WB } \\
(1: 10,000)\end{array}$ \\
\hline
\end{tabular}


Thirimanne 2021

\begin{tabular}{|c|c|c|c|c|}
\hline antibody & $\begin{array}{l}\text { Anti- } \gamma \text { Tubulin } \\
\text { Mouse } \\
\text { Monoclonal }\end{array}$ & Santa Cruz & sc- 17787 & WB $(1: 1000)$ \\
\hline antibody & $\begin{array}{l}\text { Anti-H3 } \\
\text { Mouse } \\
\text { Monoclonal } \\
(96 \mathrm{C} 10)\end{array}$ & $\begin{array}{l}\text { Cell Signaling } \\
\text { Technologies }\end{array}$ & Cat\# 3638S & WB $(1: 1000)$ \\
\hline antibody & $\begin{array}{l}\text { PE Anti-HLA } \\
\text { DR + DP + } \\
\text { DQ Mouse } \\
\text { Monoclonal } \\
\text { WR18 }\end{array}$ & Abcam & $\mathrm{ab} 23901$ & $\mathrm{FC}(1: 50)$ \\
\hline antibody & $\begin{array}{l}\text { PE Anti-HLA } \\
\text { DR Mouse } \\
\text { Monoclonal }\end{array}$ & BioLegend & Cat\# 307605 & $\mathrm{FC}(1: 50)$ \\
\hline $\begin{array}{l}\text { commercial } \\
\text { assay or kit }\end{array}$ & $\begin{array}{l}\text { Qiagen } \\
\text { RNeasy Mini } \\
\text { Kit }\end{array}$ & Qiagen & Cat\# 74104 & \\
\hline $\begin{array}{l}\text { commercial } \\
\text { assay or kit }\end{array}$ & $\begin{array}{l}\text { iScript } \\
\text { Reverse } \\
\text { Transcription } \\
\text { Supermix }\end{array}$ & BioRad & Cat\# 1708841 & \\
\hline $\begin{array}{l}\text { commercial } \\
\text { assay or kit }\end{array}$ & $\begin{array}{l}\text { Platinum } \\
\text { SYBR Green } \\
\text { qPCR } \\
\text { SuperMix- } \\
\text { UDG with } \\
\text { Rox }\end{array}$ & Invitrogen & Cat\# 11744100 & \\
\hline $\begin{array}{l}\text { software, } \\
\text { algorithm }\end{array}$ & $\begin{array}{l}\text { Beckman } \\
\text { Biomek FX } \\
\text { liquid } \\
\text { handling robot }\end{array}$ & $\begin{array}{l}\text { Genomics and } \\
\text { Bioinformatics } \\
\text { Center at Fred } \\
\text { Hutch }\end{array}$ & & $\begin{array}{l}\text { Automated } \\
\text { CUT\&RUN }\end{array}$ \\
\hline $\begin{array}{l}\text { software, } \\
\text { algorithm }\end{array}$ & $\begin{array}{l}\text { ChemiDoc } \\
\text { Touch } \\
\text { Imaging } \\
\text { System OS } \\
2.3 .0 .07\end{array}$ & BioRad & & \\
\hline
\end{tabular}


559 RNA-Seq: RNA isolation, library preparation, sequencing, and data analysis

560 RNA was isolated using the Qiagen RNeasy Mini Kit (Cat\# 74104) following the manufacturer's

561 instructions. Three replicates per cell type were included for each replicate. Three replicates per

562 cell condition were included in experiments. Hct116 triplicates were obtained from the same

563 genetically engineered clone, however they were harvested from separately cultured plates. NSC

564 replicates were generated with two independent CRISPR/Cas9 nucleofections and cultured

565 separately for the three independent samples. RNA quality and integrity were determined

566 (A260/280 1.8 - 2.1, A260/230 > 1.7, RIN $\geq 9$ ). Libraries were prepared by the Fred Hutch

567 Genomics Center using the TruSeq RNA Samples Prep Kit v2 (Illumina Inc., San Diego CA,

568 USA). Sequencing was performed on an Illumina HiSeq 2500 with 50 bp paired-end reads

569 (PE50). RNA-Seq for U5-NSCs was an exception. Knockouts were generated separately on two

570 different days and cells from separate nucleofection reactions were used as the three replicates,

571 hence biological replicates. Libraries were prepared using TruSeq Stranded mRNA and

572 sequencing was performed using an Illumina NovaSeq 6000 employing a paired-end 50 base

573 read length (PE50).

574

575 Fastq files were filtered to exclude reads that didn't pass Illumina's base call quality threshold.

576 STAR v2.7.1 (Dobin et al., 2013) with 2-pass mapping was used to align paired-end reads to

577 human genome build hg19 and GENCODE gene annotation v31lift37

578 (https://www.gencodegenes.org/human/). FastQC 0.11 .8

579 (https://www.bioinformatics.babraham.ac.uk/projects/fastqc/) and RSeQC 3.0.0 (Wang et al., 580 2012) were used for QC including insert fragment size, read quality, read duplication rates, gene 581 body coverage and read distribution in different genomic regions. FeatureCounts (Liao et al., 
582 2014) in Subread 1.6.5 was used to quantify gene-level expression. For stranded libraries, only

583 coding strand derived reads were counted. Bioconductor package edgeR 3.26.8 (Robinson et al.,

584 2009) was used to detect differential gene expression between conditions. Genes with low

585 expression were excluded by requiring at least one count per million in at least $\mathrm{N}$ samples $(\mathrm{N}$ is

586 equal to one less than the number of samples in the smallest group). The filtered expression

587 matrix was normalized by TMM method (Robinson \& Oshlack, 2010) and subject to significance

588 testing using generalized linear model and quasi-likelihood method. Genes were deemed

589 differentially expressed if absolute fold changes were above 1.5 and FDRs were less than 0.05 .

590

591 Cleavage Under Target and Release Using Nuclease (CUT\&RUN)

592 Three replicates per cell condition were included in experiments. Hct116 triplicates were

593 obtained from the same genetically engineered clone, however they were harvested from

594 separately cultured plates. NSC replicates were generated with two independent CRISPR/Cas9

595 nucleofections and cultured separately for the three independent samples. Manual or automated

596 CUT\&RUN were performed as previously described (Janssens et al., 2018; Skene et al., 2018;

597 Skene \& Henikoff, 2017). Briefly, cells were harvested using Accutase, counted and washed

598 twice with Wash Buffer (20mM HEPES pH 7.5, $150 \mathrm{mM} \mathrm{NaCl}, 0.5 \mathrm{mM}$ spermidine and one

599 Roche Complete EDTA free protein inhibitor tablet per $50 \mathrm{~mL}$ ). Cells were bound to

600 Concanavalin A-coated magnetic beads (20uL per one million cells). Then cells were

601 permeabilized with Dig Wash buffer (Wash Buffer with 0.05\% digitonin) while being incubated

602 with primary antibody overnight at $4{ }^{\circ} \mathrm{C}$. Cell-bead mixture was washed twice with Dig-Wash

603 buffer and incubated with Protein A-MNase (pA-MN) for 1 hour at $4^{\circ} \mathrm{C}$. After washing the mix

604 with Dig Wash buffer twice, cells were placed on an ice-cold block and incubated with $2 \mathrm{mM}$ 
$605 \mathrm{CaCl}_{2}$ in Dig Wash buffer to activate $\mathrm{pA}-\mathrm{MN}$ digestion. After the specific digestion period the 606 reaction was inhibited with 2X Stop Buffer (340 mM NaCl, 20mM EDTA, 4mM EGTA, 0.05\%

607 digitonin, $0.05 \% \mathrm{mg} / \mathrm{ml}$ glycogen, $5 \mathrm{ug} / \mathrm{mL}$ RNase, $2 \mathrm{pg} / \mathrm{mL}$ heterologous spike-in DNA). The 608 samples were incubated at $37^{\circ} \mathrm{C}$ for $30 \mathrm{~min}$ to release the digested DNA fragments into the 609 supernatant. The supernatant was collected and libraries were prepared as previously explained 610 (Janssens et al., 2018). Paired-end 25 base read length (PE25) sequencing was performed using 611 an Illumina HiSeq 2500 platform at Fred Hutch Genomics Shared Resources.

612 Deviations from the above described protocol:

613 1. Automated CUT\&RUN: Manual preparation included harvesting cells, counting, washing, permeabilizing and antibody addition. After cells were incubated with the antibody at $4{ }^{\circ} \mathrm{C}$ overnight, next day the samples were submitted for automated CUT\&RUN which was performed by the Genomics and Bioinformatics Center at Fred Hutch on a BioMek platform.

2. Used nuclei instead of cells: H3K4me1 and H3K4me2 were mapped using the CUT\&RUN protocol as previously described using isolated nuclei (Skene \& Henikoff, 2017).

621 A summary of all CUT\&RUN samples with conditions and method used can be found at 622 Additional source data 1.

\section{CUT\&RUN data analysis}

625 Basic analysis: Sequencing reads were aligned to hg19 using Bowtie2: bowtie2 --end-to-end -626 very-sensitive --no-overlap --no-dovetail --no-unal --no-mixed --no-discordant -q -I 10 -X 700 -X 627 path/to/Bowtie2/indices -1 read1.fastq.gz -2 read2.fastq.gz 
628 CPM normalized bigwig files were generated using bedtools genomecov.

629 Peaks were called using MACS2. Peak calling was performed for each target with and without 630 the IgG control.

631 Narrow peaks with IgG control: macs2 callpeak --name TARGET --treatment

$632 \mathrm{path} / \mathrm{to} / \mathrm{TARGET/hg19.bam} \mathrm{--control} \mathrm{path/to/IgG/hg19.bam} \mathrm{--format} \mathrm{BAMPE} \mathrm{--gsize} \mathrm{hs} \mathrm{--keep-}$ 633 dup all -q 0.05

634 Narrow peaks without IgG control: macs2 callpeak --name TARGET --treatment

635 path/to/TARGET/hg19.bam --format BAMPE --gsize hs --keep-dup all -q 0.05

636 IgG-controlled peaks that overlap with no-control peaks were retained for further analyses. For

637 each TF/histone mark mapped in each genotype, peaks from three replicates were considered to 638 make a final peak-set to use for downstream analysis.

640 Differential binding analysis: Merged peak set for each target was used for the analysis.

641 FeatureCounts (Liao et al., 2014) in Subread 1.6.5 was used to count reads mapped to merged

642 peaks in each sample. Bioconductor package edgeR 3.26.8 (Robinson et al., 2009) was used to

643 detect differential peaks between conditions. Peaks with low read numbers were excluded using

644 edgeR function filterByExpr with min.count $=10$ and min.total .count $=15$. The filtered count

645 matrix was normalized by TMM method (Robinson \& Oshlack, 2010) and subjected to

646 significance testing using generalized linear model and quasi-likelihood method. Peaks were

647 deemed differentially bound if absolute fold changes were above 1.5 and FDRs were less than

6480.01 for H3K27ac and Jun data, and FDR 0.05 for Myc data. Differential sites for H3K27ac, Jun

649 and Myc are provided as source data.

650 


\section{Other data processing, analysis, and visualization}

652

662 (method=spearman).

2. Correlation matrices were_generated using deepTools (Ramírez et al., 2016).

1. Correlation between RNA-Seq and the distribution of histone marks around Transcriptional Start Sites (TSSs).

A reference list of hg19 genes was downloaded from the UCSC Table Browser. Genes were oriented according to the directionality of gene transcription and specified a $2 \mathrm{~kb}$ window around TSSs. Genes that have an overlapping TSS within the $2 \mathrm{~kb}$ window and mitochondrial genes were removed, creating a list of 22,222 TSSs. The gene list was sorted in descending order of their RNA-Seq FPKM values. CUT\&RUN H3K27ac and H3K27me3 signal (merged from three replicates) were mapped on to the ordered genomic sites. The coverage of histone marks was quantified using bedtools coverage and converted to FPKM values. Correlation between RNASeq and histone mark FPKM values was calculated using $\mathrm{R}$ cor.test function

3. Gene set enrichment analysis (Gene Ontology terms) was done using the Enrichr webbased tool (Kuleshov et al., 2016). Up- and downregulated genes (FDR $\leq 0.05)$ in Fbw7 mutant cells were separately run through Enrichr. Enriched gene sets with Adjusted p value $<0.05$ were extracted and then manually curated to remove redundant gene sets with $>40 \%$ overlap. Complete output and summarized gene sets are in Figure 1 - source data 3 (Hct116) and Figure 6 - source data 3 (NSCs.)

4. Motif identification. For all motif analysis we used the The MEME Suite (Bailey et al., 2009). We used bedtools getfasta to generate FASTA files for genomic sites of interest (Quinlan \& Hall, 2010). For motif discovery analysis we submitted the center 100 bp sequence of peaks to MEME-ChIP. MEME-ChIP was used with default parameters in 
Classic mode. HOCOMOCO Human (v11 FULL) motif database was used. We used the

675

676

677

678

679

680

681

682

683

684

685

686

687

688

689

690

691

692

693

694

695

696

position-weight matrix (PWM) of the motif discovered by MEME-ChIP as the input for

FIMO, to quantify the abundance of the motif. We used FIMO with a threshold value of

p.value $\leq 0.01$ to capture all motif configurations and then filtered the output to select

only the motifs with the highest FIMO motif scores (the higher the score, the more

similar to the input motif). For differential motif analysis, we used MEME-ChIP in

Differential Enrichment mode with default parameters.

5. Annotations. To assign gene regions where peaks are located, we used ChIPseeker, an R/Bioconductor package (G. Yu et al., 2015). We used the nearest gene method to assign a peak to a gene using the bedtools closest tool (Quinlan \& Hall, 2010). Gencode Human Release 31 (GRCh37) Comprehensive gene annotation list was used to generate a list of genes with full gene coordinates which was used to annotate peaks to the nearest gene.

6. Data Visualization. Plots were generated using R (https://www.r-project.org) (R Core Team, 2020). Heatmaps were generated using Deeptools (Ramírez et al., 2016).

7. Venn diagrams. Intersection between genomic sites were generated using Intervene Venn module (Khan \& Mathelier, 2017).

8. Primary cancer and cell line data analysis. CIITA expression data from Fbw7 WT and mutated colon and rectal cancers were collected from the TCGA COADREAD database via UCSC Xena browser (Goldman et al., 2020) (Figure 5 - source data 2). CIITA expression in Fbw7 WT and mutated colorectal cancer cell lines were collected from the DepMap Portal (https://depmap.org/portal/) (Barretina et al., 2012). Statistical analysis was performed on GraphPad Prism. Unpaired t-test (two tailed) was used to determine statistical significance of CIITA differential expression of TCGA and CCLE data sets. 

show examples of CUT\&RUN binding data as peaks. Schematic figures were created with BioRender.com.

700

701 Antibodies

702 All antibodies are listed in the Key Resource Table.

703

704 Cell culture

705 Hct116 cells were grown in DMEM with 10\% FBS and PenStrep. For CUT\&RUN and RNAseq

706 experiments $2 \times 10^{6}$ cells were plated per $10 \mathrm{~cm}$ dish two days prior to harvesting. Cells were 707 harvested using Accutase. Human fetal tissue derived U5 NCSs were cultured in NeuroCult NS-

708 A basal medium (Stem Cell Technologies) supplemented with N2 (made in-house 2x stock in 709 Advanced DMEM/F-12 (Thermo Fisher Scientific)), B27 (Thermo Fisher Scientific), antibiotic710 antimycotic (Thermo Fisher Scientific), Glutamax (Thermo Fisher Scientific), EGF and bFGF

711 (Peprotech). NSCs were cultured in Laminin coated plates. Accutase was used to harvest cells

712 for experiments. Genetically engineered NSCs $\left(\mathrm{Fbw}^{-{ }^{-}}\right)$did not undergo any post-nucleofection

713 selection and were cultured for less than two weeks prior to harvesting for experiments. The

714 identity of Hct116 cells was authenticated by STR profiling and cells tested negative for 715 Mycoplasma contamination by PCR assay.

\section{Chromatin fractionation.}

718 Untreated and Bortezomib treated ( $0.5 \mathrm{uM}$ for $10 \mathrm{hrs}$.) cells were harvested and counted. Cells 719 were resuspended in $50 \mu \mathrm{LCSK}$ buffer (10 mM HEPES pH 6.8, 100mM NaCl, 1mM EGTA, 
$7201 \mathrm{mM}$ EDTA, 2mM MgCl $2,300 \mathrm{mM}$ Sucrose, $0.1 \%$ Triton X-100 and Protease inhibitor) - $50 \mathrm{ul}$

721 per million cells) (Kim et al., 2008). Cells were allowed to lyse for $5 \mathrm{~min}$ on ice and centrifuged

722 for $5 \mathrm{~min}$ at $4^{0} \mathrm{C}$ at $1500 \mathrm{~g}$. The supernatant, which is the soluble fraction (S), was removed to a

723 new tube. The pellet was resuspended in $1 \mathrm{ml}$ of CSK buffer, then centrifuged for $5 \mathrm{~min}$ at $4^{0} \mathrm{C}$ at

$7241500 \mathrm{~g}$. The supernatant was thoroughly removed. Next, NP40 buffer with protease inhibitor and

$725250 \mathrm{U} / \mathrm{ml}$ benzonase was added to the cell pellet (same volume as CSK buffer was used to lyse

726 cells). Cells were incubated for $30 \mathrm{~min}$ on ice. This was the chromatin fraction (C). Both soluble

727 and chromatin fractions were sonicated and centrifuged to remove debris $\left(5 \mathrm{~min}\right.$ at $4^{0} \mathrm{C}$ at

728 maximum speed). Total protein in all chromatin fractions was quantified using the Bradford

729 assay and samples were normalized to total protein content. Equal volumes of chromatin and

730 soluble fractions from each sample were used to immunoprecipitate Fbw7. Chromatin

731 fractionation of Fbw7 was determined by >3 independent experiments.

732

733 Immunoprecipitations and western blot analysis

734 Whole cell extracts (WCE) were made by lysing cells in $0.5 \%$ NP-40 buffer with protease

735 inhibitor cocktail (made in-house). Then WCE were sonicated and spun to remove debris. To

736 immunoprecipitate Fbw7 from whole or fractionated cell lysates anti-Fbw7 Bethyl A301-720A

737 antibody and Protein A beads were added and incubated for at least $2 \mathrm{hrs}$ at $4^{0} \mathrm{C}$. Beads were then

738 washed $3 \mathrm{X}$ with $1 \mathrm{ml} \mathrm{NP40} \mathrm{lysis} \mathrm{buffer.} \mathrm{Eluted} \mathrm{protein} \mathrm{was} \mathrm{electrophoresed} \mathrm{on} \mathrm{8 \%}$

739 polyacrylamide gels and transferred to PVDF which was blotted against Fbw7 using anti-Fbw7

740 Bethyl A301-720A (1:1000) and HRP conjugated anti-Rabbit secondary antibody (1:10,000).

741 Membranes treated with ECL (made in-house) were visualized on a BioRad ChemiDoc imaging

742 system. 


\section{PCR amplification of CIITA}

744 RNA was isolated from Hct116 and Raji cells using the Qiagen RNeasy Mini Kit (Cat \# 74104).

745 cDNA was prepared using iScript Reverse Transcription Supermix (Cat \# 1708841). CIITA PIII

746 and PIV were amplified using specific primers (PIII : F -

747 5'GCTGGGATTCCTACACAATGC3', R - 5'GGGTTCTGAGTAGAGCTCAATC3' and PIV :

748 F - 5'GGGAGCCCGGGGAACA3', R - 5'GATGGTGTCTGTGTCGGGTT3') at 60C

749 annealing temperature for 38 cycles (H. Chen et al., 2015). GAPDH was amplified as the control

750 (25 cycles) using primers F - 5'GGTCGGAGTCAACGGATTTG3' and R -

751 5'ATGAGCCCCAGCCTTCTCCAT3'. Platinum Taq DNA polymerase was used following the

752 manufacturer's instructions.

753

754 Reverse transcription and quantitative real-time PCR (RT-PCR and qPCR)

755 RNA was isolated using the Qiagen RNeasy Mini Kit (Cat\# 74104) following the manufacturer's

756 protocol and quantified using a NanoDrop Spectrophotometer. One ug of total RNA was reverse

757 transcribed into cDNA using the iScript Reverse Transcription Supermix for RT-qPCR (Bio-

758 Rad) according to the manufacturer's protocol. cDNA was quantified using Platinum SYBR

759 Green qPCR SuperMix-UDG with Rox (Invitrogen) in the ABI QuantiStudio5 Real Time PCR

760 System (Thermo Scientific). Three separately extracted RNA samples per genotype were used

761 and three replicates of each sample were included in the 384 well plate. mRNA expression levels

762 were normalized to the housekeeping gene Actin. The $2^{-\Delta \Delta \mathrm{CT}}$ method was used to calculate

763 differential mRNA expression in mutants compared to control samples. Primers used for qPCR

764 (5'-3'): Actin F- CACCATTGGCAATGAGCGGTTC, R-AGGTCTTTGCGGATGTCCACGT;

765 CIITA F- GCTGGGATTCCTACACAATGC, R- GGGTTCTGAGTAGAGCTCAATC; HLA- 

DRB F- GAGCAAGATGCTGAGTGGAGTC, R- CTGTTGGCTGAAGTCCAGAGTG; HLADPA F- ATCCAGCGTTCCAACCACACTC, R- CGTTGAGCACTGGTGGGAAGAA; HLADPB F- GTGCAGACACAACTACGAGCTG, R- CCTGGGTAGAAATCCGTCACGT.

\section{Flow cytometry.}

772 For live cell FACS analysis, cells were harvested, washed once in PBS, and incubated with

773 antibodies in $1 \mathrm{X}$ PBS for 1 hour on ice. Ghost Dye $\mathrm{TM}^{\mathrm{TM}}$ Violet 510 was used to discriminate live

774 cells. For FACS analysis of fixed cells, cells were processed as described previously (Diab et al.,

775 2020), with the following modifications. For DNA replication analysis, cells were pulsed with 10

$776 \mu \mathrm{M}$ 5-ethynyl-20-deoxyuridine (EdU) for 20-60 minutes. Following EdU labeling, cells were

777 harvested using TrypLE Express (ThermoFisher Scientific) and fixed in 2\% paraformaldehyde

778 (PFA) for 20 minutes at room temperature, washed once with PBS, resuspended in ice-cold

779 methanol, and allowed to sit overnight at $-20^{\circ} \mathrm{C}$ prior to further processing. Cells were then

780 washed twice with $1 \mathrm{~mL}$ BD Perm/Wash Buffer (BD Biosciences), Following a Click-iT step for

781 EdU labeling according to manufacturer's protocol (Thermo Fisher Scientific), cells were

782 incubated with the appropriate primary antibodies in 3\% BSA in PBS for 1 hour at room

783 temperature. Cells were washed, incubated in secondary antibody for at least one hour and in

784 DAPI (1:1000, BD Biosciences, 564907) for at least 15 minutes, washed again, and resuspended

785 in Stain Buffer (FBS - BD Biosciences). Samples were run on a BD FACSCelesta or

786 FACSymphony, visualized with FACS Express software (DeNovo), and analyzed using FlowJo

787 software v10.6.1. 
Cell proliferation assays.

$79011 \times 10^{5} \mathrm{Hct} 116$ cells and $0.7 \times 10^{5}$ U5 NCSs per well were seeded in 6- and 12-well plates

791 respectively. After 24 hours, cellular confluency was monitored up to 85 hours using an

792 IncuCyte S3 Live-Cell Imager (Sartorius). Proliferation was measured as percent confluence at

793 each time point normalized to percent confluence at time 0 . Population doubling time was

794 calculated using GraphPad Prism 9.3.1 (Parameters: nonlinear regression fit: exponential

795 (Malthusian) growth).

796

\section{Generation of U5-NSC homozygous Fbw7 knockouts}

798 A previously described protocol to generate homozygous null mutations using CRISPR-Cas9

799 and nucleofection was followed (Hoellerbauer, Kufeld, \& Paddison, 2020; Hoellerbauer, Kufeld, 800 Arora, et al., 2020). Briefly the protocol is as follows:

801 CRISPR sgRNA were designed using Broad Institute's GPP Web Portal. The output list of 802 sgRNAs was manually curated to choose three sgRNAs targeting FBXW7. Exon 3, 4 and 9 in 803 FBXW7 were targeted by 5'AAGAGCGGACCTCAGAACCA3',

804 5'CTGAGGTCCCCAAAAGTTGT3', 5'ACATTAGTGGGACATACAGG3' guides

805 respectively. A control sgRNA was included 5'GTAGCGAACGTGTCCGGCGT3'. sgRNAs

806 were purchased from Synthego.

807 Cas9:sgRNA RNP nucleofection: sgRNAs were reconstituted by adding 10uL of 1X TE Buffer $8081.5 \mathrm{nmol}$ of dried sgRNA. A working stock of 30uM sgRNA was used henceforth. A working 809 stock of Cas9 (10.17 pmol/ul) was made. To prepare RNP complexes, $1.87 \mathrm{uL}$ sgRNA, $1.84 \mathrm{uL}$ 810 sNLS-SpCas9-sNLS (Aldevron) and 18.29 uL SG Cell Line Nucleofector Solution (Lonza) were 811 mixed to make a $22 \mathrm{uL}$ final volume. The mixture was incubated at room temperature for 15 
812 minutes to allow RNP complexes to form. To nucleofect, $1.3 \times 10^{5}$ cells were harvested. The

813 cells were washed with PBS and resuspended with RNPs. (We were able to successfully

814 nucleofect up to $8.5 \times 10^{5}$ cells with the same volume of RNPs.) Cells were electroporated using

815 the Amaxa 4D Nucleofector X unit and program EN-138. Nucleofected cells were plated in pre-

816 warmed media.

817 CRISPR editing efficiency analysis: Extraction of genomic DNA, PCR amplification of target

818 site and efficiency analysis was done as previously described (Hoellerbauer, Kufeld, \& Paddison,

819 2020; Hoellerbauer, Kufeld, Arora, et al., 2020). The primer pairs used to amplify CRISPR target

820 sites in Exon 3: 5'TCATCACACACTGTTCTTCTGGA3' and

821 5'TGTCTACCCTAGAACAGCTGT3'; Exon 4: 5'TGTGTACCTGTGATCTCTGGG3' and

822 5'CACCTTGCTGTGCAACCATC3'; Exon 9: 5'ACTGCTTTCATGTCGTGTTTCC3' and

823 5'AGGAAGCTGACAACACTAGCA3'. We found that the pool of three sgRNA was the most

824 successful at deleting $F B X W 7$. This was confirmed by blotting for immunoprecipitated Fbw7 in

825 each nucleofected sample (Figure 6 - figure supplement 1).

826

827 Data Availability: All data generated and used in this manuscript are deposited in GEO:

828 GSE184041

829

830

831

832

833

834

Scripts available at https://github.com/hnthirima

\section{Supplemental Figures:}

836 Figure 1 - figure supplement 1

837 Figure 1 - figure supplement 2

838 Figure 2 - figure supplement 1

839 Figure 2 - figure supplement 2 
Figure 2 - figure supplement 3

841 Figure 3 - figure supplement 1

842 Figure 3 - figure supplement 2

843 Figure 3 - figure supplement 3

844 Figure 3 - figure supplement 4

845 Figure 4 - figure supplement 1

846 Figure 5 - figure supplement 1

847 Figure 5 - figure supplement 2

848 Figure 6 - figure supplement 1

849 Figure 6 - figure supplement 2

850 Figure 6 - figure supplement 3

851 Figure 6 - figure supplement 4

852 Figure 6 - figure supplement 5

Supplemental Figure Legends:

Figure 1 - figure supplement 1: Principal Component Analysis (PCA) of RNA-Seq from

Figure 1 - figure supplement 2: Proliferation of Fbw7 mutant Hct116 cells. S.E.M. Proliferation was measured at each time point normalized to percent confluence at time 0 . Doubling time, WT $20.9 \mathrm{hrs}$, Fbw $7^{\mathrm{R} /+} 24.9 \mathrm{hrs}$, Fbw $7^{-/-} 25.9 \mathrm{hrs}$ (B) Flow cytometry analysis of DNA replication in Fbw7 mutant cells. Density plots of EdU versus DNA content (DAPI) in Hct116 cells. Single cells were identified by gating events on DAPI-H/DAPI-A. Cells were labeled with EdU prior to harvest and were later fixed and immuno-stained for flow cytometry. CUT\&RUN profiles in Het116 cells. Correlation matrix of three replicates from Hct116 WT, $\mathrm{Fbw}^{-1 /}$ (Del) and $\mathrm{Fbw} 7^{\mathrm{R} /+}(\mathrm{R})$ cells. IgG negative control for each cell type included. Peaks from the three cell types were merged to create a final peak-set to perform the correlation analysis. 
Figure 2 - figure supplement 3: Complete output of the MEME-ChIP analysis on H3K27ac differential sites. (A) MEME-ChIP analysis on the sequences of H3K27ac increased sites in Fbw $7^{-/-}$cells. (B) MEME- ChIP analysis on the sequences of non-differential H3K27ac sites in Fbw $7^{-1-}$ cells (negative control, 1409 sites). *FIMO analysis revealed that AP-1 motif was enriched in approximately 30-35\% of H3K27ac sites that were decreased in Fbw $7^{-/}$(p value $\leq$ $1.8 \mathrm{e}-5)$, increased in Fbw $7^{\mathrm{R} /+}(30.2 \%$ p value $=1.8 \mathrm{e}-5)$, decreased in $\mathrm{Fbw} 7^{\mathrm{R} /+}(35 \% \mathrm{p}$ value $\leq$ $1.5 \mathrm{e}-5)$, however only $17 \%$ in non-differential sites (1409 sites) ( $\mathrm{p}$ value $\leq 1.8 \mathrm{e}-5)$.

Figure 3 - figure supplement 1: Fbw7 abundance in chromatin $(C)$ and soluble (S) fractions from Hct116 WT, Fbw $7^{\mathrm{R} /+}$ and $\mathrm{Fbw} 7^{\mathrm{R} / \mathrm{R}}$ cells treated with and without Bortezomib.

Figure 3 - figure supplement 2: Validation of Jun and Myc CUT\&RUN profiles. (A) Hierarchically clustered correlation matrix of Jun and Myc signal mapped in Hct116 WT, Fbw7 ${ }^{-}$ ${ }_{1-}(\mathrm{Del})$ and $\mathrm{Fbw}^{\mathrm{R} /+}(\mathrm{R})$ cells. IgG negative control for each cell type included. Peaks from the three cell types were merged to create a final peak-set. (B) Sequence logo of the AP-1 motif enriched in the center 100bp sequence of Jun peaks in Hct116 WT (E value 1.3e-53) and sequence logo of E-box motif enriched in the center 100bp sequence of Myc peaks in Hct116 WT (1.7e-4). AP-1 motif was input to FIMO to scan for the motif in full sequence of 25,527 Jun peaks in Hct116 WT. FIMO output showed that motifs with score between15.73 to 12.11 occurred 26,547 times ( $\mathrm{p}$ value $\leq 6.46 \mathrm{E}-05$ ). E-box motif was input to FIMO to scan for the motif in full sequence of 24,111 Myc peaks in Hct116 WT. FIMO output showed that motifs with score between $15.32-9.24$ occurred 9343 times ( $\mathrm{p}$ value $\leq 0.00024$ ). Motif score range was determined by the exact similarity to TGAG/CTCA (AP-1 motif) or CACGTG (E box).

905

Figure 3 - figure supplement 3: Percentage of Myc and Jun peaks located at different gene features.

Figure 3 - figure supplement 4: Transcription of genes with differential promoter proximal Myc and Jun occupancy in Fbw7 mutant cells. Hierarchically clustered genes showing the transcription of genes that have increased or decreased Myc and Jun occupancy at gene proximal sites in $\mathrm{Fbw} 7^{-/-}$and $\mathrm{Fbw} 7^{\mathrm{R} /+}$ cells.

Figure 4 - figure supplement 1: Comparison between Jun and Myc peaks in Hct116 cells (A) The overlap between Jun and Myc peaks in Hct116 WT cells. (p value $<0.0001$, Fisher Test) (B) The overlap between peaks with increased Jun occupancy in Fbw $7^{-/-}$and $\mathrm{Fbw} 7^{\mathrm{R} /+}$ cells, and decreased Myc occupancy in $\mathrm{Fbw}^{-/ /}$and $\mathrm{Fbw} 7^{\mathrm{R} /+}$ cells. (C) The overlap between decreased Jun occupancy in $\mathrm{Fbw} 7^{-/-}$and $\mathrm{Fbw} 7^{\mathrm{R} /+}$ cells, and increased Myc occupancy in $\mathrm{Fbw} 7^{-/-}$and $\mathrm{Fbw} 7^{\mathrm{R} /+}$ cells.

Figure 5 - figure supplement 1: Expression fold change of MHC Class I genes in Het116 Fbw $7^{-/-}$with respect to WT cells. FDR values are indicated at top of each bar $(\mathrm{n}=3)$. 
Figure 5 - figure supplement 2: MHC class II protein expression in Hct116 cells. Western blot detecting HLA-DR in Hct116 cells. Protein intensity of HLA-DR band was measured using Image $\mathrm{J}$ in comparison to the loading control. HLA-DR protein is $\sim 2$ fold higher in $\mathrm{Fbw}^{-/-}$cells in comparison to WT $(n=2)$.

Figure 6 - figure supplement 1: Validation of U5-NSC Fbw7 $7^{-/-}$generation and CUT\&RUN Jun signal (A) Western blot showing Fbw7; samples 1-4: U5 NSCs with sgRNA targeting Fbw7 exon 3, 4, 9 and all three exons in one pool; samples 5-6: U5 NSCs with control sgRNA 1x and 3x; and sample 7: Hct116 WT. (B) Sequence logo of AP-1 motif enriched in Jun peaks in U5 NSCs $(\mathrm{E}$ value $=1.2 \mathrm{e}-146)$.

Figure 6 - figure supplement 2: Proliferation of Fbw7 mutant U5 NSCs.

(A) Cell proliferation was monitored with an IncuCyte for 81 hours. Data are shown as mean \pm S.E.M. Proliferation was measured at each time point normalized to percent confluence at time 0 . Doubling Time, WT $61.3 \mathrm{hrs}$ and Fbw $7^{-/-} 88.82$ hrs (B) Flow cytometry analysis of DNA replication in Fbw7 mutant cells. Density plots of EdU versus DNA content (DAPI) in NSCs. Single cells were identified by gating events on DAPI-H/DAPI-A. Cells were labeled with EdU prior to harvest and were later fixed and immuno-stained for flow cytometry.

Figure 6 - figure supplement 3: Percentage of peaks with decreased Jun in U5 NSC Fbw7 ${ }^{-/-}$

Figure 6 - figure supplement 4: CIITA isoform III amplified using isoform specific primers

Figure 6 - figure supplement 5: MHC class II protein expression in Hct116 cells. (A) Flow cytometry analysis of HLA-DR in Fbw7 mutant NSCs. Density plots of side scatter (SSC) versus PE HLA-DR. (B) Western blot detecting HLA-DR/DP/DQ in NSCs. Protein intensity of HLA band was measured using ImageJ in comparison to the loading control. HLA protein is $\sim 3$ fold higher in $\mathrm{Fbw}^{-/-}$cells in comparison to WT. and NSCs. (A) Hierarchical clustering of differentially expressed (DE) protein-coding genes in Hct116. Expression level of the same genes in NSCs is also mapped. Genes that are not captured in NSC are in grey. $\log _{2} \mathrm{FC}$ of DE genes specific to Hct116 cells was higher than the DE genes shared by both Hct116 and NSCs (Wilcoxon test: p-value $=5.33 \mathrm{e}-16$ ). (B) Hierarchical clustering of differentially expressed (DE) protein-coding genes in NSC. Expression level of the same genes in Hct116 cells is also mapped. $\log _{2} \mathrm{FC}$ of DE genes specific to NSCs was higher than the DE genes shared by both Hct116 and NSCs (Wilcoxon test: p-value $=3.727 \mathrm{e}-10$ ). 
Source data files (with title and legend):

Figure 1 - source data 1: Differential expression analysis of Hct116 RNA-Seq. This Excel file contains the differential analysis output of Hct116 RNA-Seq data from WT, Fbw $7^{-/-}$(Del) and $\mathrm{Fbw} 7^{\mathrm{R} /+}(\mathrm{R}) . \mathrm{DE}=0$, not differentially expressed in the mutant compared to WT; $\mathrm{DE}=1$, differentially expressed in the mutant compared to WT.

Figure 1 - source data 2: Hierarchical cluster output file. This Excel file includes genes that belong to each cluster in the hierarchical cluster analysis.

Figure 1- source data 3: Enrichr output for Hct116 differentially expressed genes. This Excel file includes the TRANSFAC \& JASPAR, MSigDB and GO Term outputs enriched in differential (up- or downregulated) genes in $\mathrm{Fbw}^{-/-}$and $\mathrm{Fbw} 7^{\mathrm{R} /+} \mathrm{Hct} 116$ cells.

Figure 2 - source data 1: H3K27ac differential sites. This Excel file includes lists of peaks with increased and decreased H3K27ac signal in $\mathrm{Hct} 116 \mathrm{Fbw}^{-/-}$and $\mathrm{Fbw} 7^{\mathrm{R} /+}$ relative to WT. Fold change and FDR listed for each peak.

Figure 2 - source data 2: Summary of CUT\&RUN differential sites. This Excel file includes a summary (total number of differential sites, percentage, number of annotated genes) of H3K27ac, Jun and Myc differential sites in Hct116 cells and Jun differential sites in U5-NSCs.

Figure 3 - source data 1: Original western blots for Figure 3A and Figure 3 - figure supplement 1.

Figure 3 - source data 2: Jun and Myc differential sites in Hct116 cells. This Excel file includes lists of peaks with increased and decreased Jun and Myc signal in Hct116 $\mathrm{Fbw}^{-/-}$and Fbw $7^{\mathrm{R} /+}$ relative to WT. Fold change and FDR listed for each peak.

Figure 5 - source data 1: Original gels for Figure 5C.

Figure 5 - source data 2: TCGA COADREAD data used for Figure 5D. This Excel file includes the CIITA expression counts for WT and Fbw7-mutant Colorectal tumors.

Figure 5 - source data 3: Colorectal cancer cell line data from DepMap used for Figure 5E.

Figure 5 - source data 4: Quantitative RT-PCR analysis of MHC Class II genes in Hct116 cells.

Figure 5 - source data 5: Original western blots for Figure 5 - figure supplement 5.

Figure 6 - source data 1: Confirming loss of Fbw7 in U5-NSC Fbw $7^{-/-}$cells. This folder contains the original western blots for Figure 6 - figure supplement 1A. Western blots that confirm the loss of Fbw7 in two others separately performed nucleofection reactions are also included. 
Figure 6 - source data 2: Differential expression analysis of U5-NSC RNA-Seq. This Excel file contains the differential analysis output of U5-NSC RNA-Seq data from control (Ctrl23, Ctrl4.1, Ctrl4.2) and Fbw7 ${ }^{-/-}(\mathrm{Fb} 23, \mathrm{Fb} 4.1, \mathrm{Fb} 4.2)$ cells. $\mathrm{DE}=0$, not differentially expressed in the mutant compared to WT; DE $=1$, differentially expressed in the mutant compared to WT.

Figure 6 - source data 3: Enrichr output for U5-NSC differentially expressed genes. This Excel file includes the TRANSFAC \& JASPAR, MSigDB and GO Term outputs enriched in differential (up- or downregulated) genes in $\mathrm{Fbw} 7^{-/-}$NSCs.

Figure 6 - source data 4: Jun differential sites in U5-NSCs. (U5F= Fbw7 $7^{-/-}$and U5W $=\mathrm{WT}$ )

Figure 6 - source data 5: Original gels for Figure 6 - figure supplement 3.

Figure 6 - source data 6: Quantitative RT-PCR analysis of MHC Class II genes in NSCs.

Figure 6 - source data 7: Original western blots for Figure 6 - figure supplement 5.

Additional source data 1: Summary of all CUT\&RUN experiments. Experimental conditions of all CUT\&RUN experiments included in the study.

\section{Competing Interest Statement}

B.E.C is a consultant and equity holder for Coho Therapeutics, a start-up biotechnology company. Coho Therapeutics did not support nor was involved in the research described in this manuscript.

All other authors have no competing interests.

\section{Acknowledgments}

This research was supported by the following grants: NCI/NIH T32 CA080416 (H.N.T.), NCI/NIH R01 CA215647 (B.E.C.), R01 HG010492 (S.H.), R01NS119650 and R01 CA190957 (P.J.P) and the Genomics \& Bioinformatics Shared Resource of the Fred Hutch/University of Washington Cancer Consortium (P30 CA015704). 
1040 We thank Jeff Delrow, Matthew Fitzgibbon, Alyssa Dawson, and Philip Corrin in the Genomics 1041 Shared Resources at Fred Hutchinson Cancer Research Center for support with experimental 1042 design, helpful discussions, library preparation and sequencing. We thank Markus Welcker for 1043 helpful discussions and critical reading of the manuscript. We thank past and present Henikoff 1044 lab members including Jorja Henikoff, Christine Codomo, Michael Meers, Jay Sarthy, Terri 1045 Bryson, and Peter Skene for helpful discussions regarding data analysis, reagents, library 1046 preparation and sequencing. We also thank Pia Hoellerbauer in the Paddison lab for assistance 1047 with neural stem cell culturing and knockout generation.

1048

1049 
1050

1051

1052

1053

1054

1055

1056

1057

1058

1059

1060

1061

1062

1063

1064

1065

1066

1067

1068

1069

1070

1071

1072

\section{References}

Axelrod, M. L., Cook, R. S., Johnson, D. B., \& Balko, J. M. (2019). Biological consequences of MHC-II expression by tumor cells in cancer. Clinical Cancer Research, 25(8), 2392-2402. https://doi.org/10.1158/1078-0432.CCR-18-3200

Bailey, T. L., Boden, M., Buske, F. A., Frith, M., Grant, C. E., Clementi, L., Ren, J., Li, W. W., \& Noble, W. S. (2009). MEME Suite: Tools for motif discovery and searching. Nucleic Acids Research, 37(SUPPL. 2), 202-208. https://doi.org/10.1093/nar/gkp335

Barretina, J., Caponigro, G., Stransky, N., Venkatesan, K., Margolin, A. A., Kim, S., Wilson, C. J., Lehár, J., Kryukov, G. V., Sonkin, D., Reddy, A., Liu, M., Murray, L., Berger, M. F., Monahan, J. E., Morais, P., Meltzer, J., Korejwa, A., Jané-Valbuena, J., ... Garraway, L. A. (2012). The Cancer Cell Line Encyclopedia enables predictive modelling of anticancer drug sensitivity. Nature, 483(7391), 603-607. https://doi.org/10.1038/nature11003

Bressan, R. B., Dewari, P. S., Kalantzaki, M., Gangoso, E., Matjusaitis, M., Garcia-Diaz, C., Blin, C., Grant, V., Bulstrode, H., Gogolok, S., Skarnes, W. C., \& Pollard, S. M. (2017). Efficient CRISPR/cas9-assisted gene targeting enables rapid and precise genetic manipulation of mammalian neural stem cells. Development (Cambridge), 144(4), 635-648. https://doi.org/10.1242/dev.140855

Carrieri, F. A., \& Dale, J. K. (2017). Turn it down a Notch. Frontiers in Cell and Developmental Biology, 4(JAN), 1-9. https://doi.org/10.3389/fcell.2016.00151

Chen, E. Y., Tan, C. M., Kou, Y., Duan, Q., Wang, Z., Meirelles, G. V., Clark, N. R., \& Ma'ayan, A. (2013). Enrichr: Interactive and collaborative HTML5 gene list enrichment analysis tool. BMC Bioinformatics, 14. https://doi.org/10.1186/1471-2105-14-128

Chen, H., Li, Y., Lin, X., Cui, D., Cui, C., Li, H., \& Xiao, L. (2015). Functional disruption of 
human leukocyte antigen II in human embryonic stem cell. Biological Research, 48, 1-9. https://doi.org/10.1186/s40659-015-0051-6

Cremona, C. A., Sancho, R., Diefenbacher, M. E., \& Behrens, A. (2016). Fbw7 and its counteracting forces in stem cells and cancer: Oncoproteins in the balance. Seminars in Cancer Biology, 36, 52-61. https://doi.org/10.1016/j.semcancer.2015.09.006

Csizmok, V., Montecchio, M., Lin, H., Tyers, M., Sunnerhagen, M., \& Forman-Kay, J. D. (2018). Multivalent Interactions with Fbw7 and Pin1 Facilitate Recognition of c-Jun by the SCFFbw7 Ubiquitin Ligase. Structure, 26(1), 28-39.e2. https://doi.org/10.1016/j.str.2017.11.003

Davis, H., \& Tomlinson, I. (2012). CDC4/FBXW7 and the "just enough" model of tumourigenesis. Journal of Pathology, 227(2), 131-135. https://doi.org/10.1002/path.4004

Davis, M. A., Larimore, E. A., Fissel, B. M., Swanger, J., Taatjes, D. J., \& Clurman, B. E. (2013). The SCF-Fbw7 ubiquitin ligase degrades MED13 and MED13L and regulates CDK8 module association with Mediator. Genes and Development, 27(2), 151-156. https://doi.org/10.1101/gad.207720.112

Davis, R. J., Gönen, M., Margineantu, D. H., Handeli, S., Swanger, J., Hoellerbauer, P., Paddison, P. J., Gu, H., Raftery, D., Grim, J. E., Hockenbery, D. M., Margolin, A. A., \& Clurman, B. E. (2018). Pan-cancer transcriptional signatures predictive of oncogenic mutations reveal that Fbw7 regulates cancer cell oxidative metabolism. Proceedings of the National Academy of Sciences of the United States of America, 115(21), 5462-5467. https://doi.org/10.1073/pnas.1718338115

Davis, R. J., Welcker, M., \& Clurman, B. E. (2014). Tumor suppression by the Fbw7 ubiquitin ligase: mechanisms and opportunities. Cancer Cell, 26(4), 455-464. 
1096

1097

1098

1099

1100

1101

1102

1103

1104

1105

1106

1107

1108

1109

1110

1111

1112

1113

1114

1115

1116

1117

1118

https://doi.org/10.1016/j.ccell.2014.09.013

Deffrennes, V., Vedrenne, J., Stolzenberg, M.-C., Piskurich, J., Barbieri, G., Ting, J. P., Charron, D., \& Alcaïde-Loridan, C. (2001). Constitutive Expression of MHC Class II Genes in Melanoma Cell Lines Results from the Transcription of Class II Transactivator Abnormally Initiated from Its B Cell-Specific Promoter. The Journal of Immunology, 167(1), 98-106. https://doi.org/10.4049/jimmunol.167.1.98

Deshaies, R. J., \& Joazeiro, C. A. P. (2009). RING domain E3 ubiquitin ligases. Annual Review of Biochemistry, 78, 399-434. https://doi.org/10.1146/annurev.biochem.78.101807.093809

Diab, A., Gem, H., Swanger, J., Kim, H. Y., Smith, K., Zou, G., Raju, S., Kao, M., Fitzgibbon, M., Loeb, K. R., Rodriguez, C. P., Méndez, E., Galloway, D. A., Sidorova, J. M., \& Clurman, B. E. (2020). FOXM1 drives HPV+ HNSCC sensitivity to WEE1 inhibition. Proceedings of the National Academy of Sciences of the United States of America, 117(45), 28287-28296. https://doi.org/10.1073/pnas.2013921117

Díaz, V. M., \& de Herreros, A. G. (2016). F-box proteins: Keeping the epithelial-tomesenchymal transition (EMT) in check. Seminars in Cancer Biology, 36, 71-79. https://doi.org/10.1016/j.semcancer.2015.10.003

Diefenbacher, M. E., Popov, N., Blake, S. M., Schülein-Völk, C., Nye, E., Spencer-Dene, B., Jaenicke, L. A., Eilers, M., \& Behrens, A. (2014). The deubiquitinase USP28 controls intestinal homeostasis and promotes Colorectal cancer. Journal of Clinical Investigation, 124(8), 3407-3418. https://doi.org/10.1172/JCI73733

Dobin, A., Davis, C. A., Schlesinger, F., Drenkow, J., Zaleski, C., Jha, S., Batut, P., Chaisson, M., \& Gingeras, T. R. (2013). STAR: Ultrafast universal RNA-seq aligner. Bioinformatics, 29(1), 15-21. https://doi.org/10.1093/bioinformatics/bts635 
1119 Endres, T., Solvie, D., Heidelberger, J. B., Andrioletti, V., Baluapuri, A., Ade, C. P., Muhar, M., 1120 Eilers, U., Vos, S. M., Cramer, P., Zuber, J., Beli, P., Popov, N., Wolf, E., Gallant, P., \&

1121

1122

1123

1124

1125

1126

1127

1128

1129

1130

1131

1132

1133

1134

1135

1136

1137

1138

1139

1140

1141

Eilers, M. (2021). Ubiquitylation of MYC couples transcription elongation with doublestrand break repair at active promoters. Molecular Cell, 81(4), 830-844.e13. https://doi.org/10.1016/j.molcel.2020.12.035

Fryer, C. J., White, J. B., \& Jones, K. A. (2004). Mastermind recruits CycC:CDK8 to phosphorylate the Notch ICD and coordinate activation with turnover. Molecular Cell, 16(4), 509-520. https://doi.org/10.1016/j.molcel.2004.10.014

Ghandi, M., Huang, F. W., Jané-Valbuena, J., Kryukov, G. V., Lo, C. C., McDonald, E. R., Barretina, J., Gelfand, E. T., Bielski, C. M., Li, H., Hu, K., Andreev-Drakhlin, A. Y., Kim, J., Hess, J. M., Haas, B. J., Aguet, F., Weir, B. A., Rothberg, M. V., Paolella, B. R., ... Sellers, W. R. (2019). Next-generation characterization of the Cancer Cell Line Encyclopedia. Nature, 569(7757), 503-508. https://doi.org/10.1038/s41586-019-1186-3

Goldman, M. J., Craft, B., Hastie, M., Mcdade, F., Banerjee, A., Luo, Y., Rogers, D., Brooks, A. N., Haussler, D., Cruz, S., Cruz, S., \& Cruz, S. (2020). Visualizing and interpreting cancer genomics data via the Xena platform. 38(6), 675-678. https://doi.org/10.1038/s41587-0200546-8.Visualizing

Grim, J. E., Gustafson, M. P., Hirata, R. K., Hagar, A. C., Swanger, J., Welcker, M., Hwang, H. C., Ericsson, J., Russell, D. W., \& Clurman, B. E. (2008). Isoform- and cell cycledependent substrate degradation by the Fbw7 ubiquitin ligase. Journal of Cell Biology, 181(6), 913-920. https://doi.org/10.1083/jcb.200802076

Gstalder, C., Liu, D., Miao, D., Lutterbach, B., Devine, A. L., Lin, C., Shettigar, M., Pancholi, P., Buchbinder, E. I., Carter, S. L., Manos, M. P., Rojas-Rudilla, V., Brennick, R., Gjini, E., 
Chen, P. H., Lako, A., Rodig, S., Yoon, C. H., Freeman, G. J., ... Haq, R. (2020). Inactivation of fbxw7 impairs dsrna sensing and confers resistance to pd-1 blockade. Cancer Discovery, 10(9), 1296-1311. https://doi.org/10.1158/2159-8290.CD-19-1416

1145 Gupta, S., Seth, A., \& Davis, R. J. (1993). Transactivation of gene expression by Myc is inhibited by mutation at the phosphorylation sites Thr-58 and Ser-62. Proceedings of the National Academy of Sciences of the United States of America, 90(8), 3216-3220.

Hagedorn, M., Delugin, M., Abraldes, I., Allain, N., Belaud-Rotureau, M. A., Turmo, M., Prigent, C., Loiseau, H., Bikfalvi, A., \& Javerzat, S. (2007). FBXW7/hCDC4 controls glioma cell proliferation in vitro and is a prognostic marker for survival in glioblastoma patients. Cell Division, 2, 1-12. https://doi.org/10.1186/1747-1028-2-9

Hao, B., Oehlmann, S., Sowa, M. E., Harper, J. W., \& Pavletich, N. P. (2007). Structure of a Fbw7-Skp1-Cyclin E Complex: Multisite-Phosphorylated Substrate Recognition by SCF

Hemann, M. T., Bric, A., Teruya-Feldstein, J., Herbst, A., Nilsson, J. A., Cordon-Cardo, C., Ubiquitin Ligases. Molecular Cell, 26(1), 131-143.

Hoeck, J. D., Jandke, A., Blake, S. M., Nye, E., Spencer-Dene, B., Brandner, S., \& Behrens, A. (2010). Fbw7 controls neural stem cell differentiation and progenitor apoptosis via Notch and c-Jun. Nature Neuroscience, 13(11), 1365-1372. https://doi.org/10.1038/nn.2644

1164 Hoellerbauer, P., Kufeld, M., Arora, S., Wu, H. J., Feldman, H. M., \& Paddison, P. J. (2020). A 
simple and highly efficient method for multi-allelic CRISPR-Cas9 editing in primary cell cultures. Cancer Reports, 3(5), 1-14. https://doi.org/10.1002/cnr2.1269

1167

1168

1169

1170

1171

1172

1173

1174

1175

1176

1177

1178

1179

1180

1181

1182

1183

1184

1185

1186

1187

Hoellerbauer, P., Kufeld, M., \& Paddison, P. J. (2020). Efficient Multi-Allelic Genome Editing of Primary Cell Cultures via CRISPR-Cas9 Ribonucleoprotein Nucleofection. Current Protocols in Stem Cell Biology, 54(1), e126. https://doi.org/10.1002/cpsc.126

Jaenicke, L. A., von Eyss, B., Carstensen, A., Wolf, E., Xu, W., Greifenberg, A. K., Geyer, M., Eilers, M., \& Popov, N. (2016). Ubiquitin-Dependent Turnover of MYC Antagonizes MYC/PAF1C Complex Accumulation to Drive Transcriptional Elongation. Molecular Cell, 61(1), 54-67. https://doi.org/10.1016/j.molcel.2015.11.007

Janssens, D. H., Wu, S. J., Sarthy, J. F., Meers, M. P., Myers, C. H., Olson, J. M., Ahmad, K., \& Henikoff, S. (2018). Automated in situ chromatin profiling efficiently resolves cell types and gene regulatory programs. Epigenetics and Chromatin, 11(1), 1-14. https://doi.org/10.1186/s13072-018-0243-8

Karlić, R., Chung, H. R., Lasserre, J., Vlahoviček, K., \& Vingron, M. (2010). Histone modification levels are predictive for gene expression. Proceedings of the National Academy of Sciences of the United States of America, 107(7), 2926-2931. https://doi.org/10.1073/pnas.0909344107

Khan, A., \& Mathelier, A. (2017). Intervene: A tool for intersection and visualization of multiple gene or genomic region sets. BMC Bioinformatics, 18(1), 1-8. https://doi.org/10.1186/s12859-017-1708-7

Kim, J. M., Kee, Y., Gurtan, A., \& D’Andrea, A. D. (2008). Cell cycle-dependent chromatin loading of the Fanconi anemia core complex by FANCM/FAAP24. Blood, 111(10), 52155222. https://doi.org/10.1182/blood-2007-09-113092 
1188 Kominami, K. I., Ochotorena, I., \& Toda, T. (1998). Two F-box/WD-repeat proteins Pop1 and 1189 Pop2 form hetero- and homo- complexes together with cullin-1 in the fission yeast SCF 1190 (Skp1-Cullin-1-F- box) ubiquitin ligase. Genes to Cells, 3(11), 721-735. https://doi.org/10.1046/j.1365-2443.1998.00225.x

1192 Kuleshov, M. V., Jones, M. R., Rouillard, A. D., Fernandez, N. F., Duan, Q., Wang, Z., Koplev, 1193 S., Jenkins, S. L., Jagodnik, K. M., Lachmann, A., McDermott, M. G., Monteiro, C. D., 1194 Gundersen, G. W., \& Ma'ayan, A. (2016). Enrichr: a comprehensive gene set enrichment https://doi.org/10.1093/nar/gkw377

1197 Lan, H., Tan, M., Zhang, Q., Yang, F., Wang, S., Li, H., Xiong, X., \& Sun, Y. (2019). LSD1 1198 destabilizes FBXW7 and abrogates FBXW7 functions independent of its demethylase activity. Proceedings of the National Academy of Sciences of the United States of America, 116(25), 12311-12320. https://doi.org/10.1073/pnas.1902012116

Lee, E. K., \& Diehl, J. A. (2014). SCFs in the new millennium. Oncogene, 33(16), 2011-2018. https://doi.org/10.1038/onc.2013.144

1203

1204

1205

1206

1207

1208

1209

1210

Li, N., Babaei-Jadidi, R., Lorenzi, F., Spencer-Dene, B., Clarke, P., Domingo, E., Tulchinsky, E., Vries, R. G. J., Kerr, D., Pan, Y., He, Y., Bates, D. O., Tomlinson, I., Clevers, H., \& Nateri, A. S. (2019). An FBXW7-ZEB2 axis links EMT and tumour microenvironment to promote colorectal cancer stem cells and chemoresistance. Oncogenesis, 8(3). https://doi.org/10.1038/s41389-019-0125-3

Li, N., Lorenzi, F., Kalakouti, E., Normatova, M., Babaei-Jadidi, R., Tomlinson, I., \& Nateri, A. S. (2015). FBXW7-mutated colorectal cancer cells exhibit aberrant expression of phosphorylated-p53 at Serine-15. Oncotarget, 6(11), 9240-9256. 
https://doi.org/10.18632/oncotarget.3284

1212 Liao, Y., Smyth, G. K., \& Shi, W. (2014). FeatureCounts: An efficient general purpose program

1213 for assigning sequence reads to genomic features. Bioinformatics, 30(7), 923-930.

1214 https://doi.org/10.1093/bioinformatics/btt656

1215 Liu, N., Li, H., Li, S., Shen, M., Xiao, N., Chen, Y., Wang, Y., Wang, W., Wang, R., Wang, Q.,

1216 Sun, J., \& Wang, P. (2010). The Fbw7/human CDC4 tumor suppressor targets

1217 proproliferative factor KLF5 for ubiquitination and degradation through multiple phosphodegron motifs. Journal of Biological Chemistry, 285(24), 18858-18867. https://doi.org/10.1074/jbc.M109.099440 network in cancer. Nature Reviews Cancer, 10(1), 65-76. https://doi.org/10.1038/nrc2681

1226 Masternak, K., Muhlethaler-Mottet, A., Villard, J., Zufferey, M., Steimle, V., \& Reith, W. (2000). CIITA is a transcriptional coactivator that is recruited to MHC class II promoters by multiple synergistic interactions with an enhanceosome complex. Genes and Development, 14(9), 1156-1166. https://doi.org/10.1101/gad.14.9.1156

McConnell, B. B., \& Yang, V. W. (2010). Mammalian Krüppel-Like factors in health and diseases. In Physiological Reviews (Vol. 90, Issue 4). https://doi.org/10.1152/physrev.00058.2009

Minella, A. C., Grim, J. E., Welcker, M., \& Clurman, B. E. (2007). p53 and SCFFbw7 
cooperatively restrain cyclin E-associated genome instability. Oncogene, 26(48), 69486953. https://doi.org/10.1038/sj.onc.1210518

Minella, Alex C., Swanger, J., Bryant, E., Welcker, M., Hwang, H., \& Clurman, B. E. (2002). p53 and p21 form an inducible barrier that protects cells against cyclin E-cdk2 deregulation. Current Biology, 12(21), 1817-1827. https://doi.org/10.1016/S0960-9822(02)01225-3

Muhlethaler-Mottet, A., Otten, L. A., Steimle, V., \& Mach, B. (1997). Expression of MHC class II molecules in different cellular and functional compartments is controlled by differential usage of multiple promoters of the transactivator CIITA. EMBO Journal, 16(10), 28512860. https://doi.org/10.1093/emboj/16.10.2851

Muzny, D. M., Bainbridge, M. N., Chang, K., Dinh, H. H., Drummond, J. A., Fowler, G., Kovar, C. L., Lewis, L. R., Morgan, M. B., Newsham, I. F., Reid, J. G., Santibanez, J., Shinbrot, E., Trevino, L. R., Wu, Y. Q., Wang, M., Gunaratne, P., Donehower, L. A., Creighton, C. J., ... Thomson., E. (2012). Comprehensive molecular characterization of human colon and rectal cancer. Nature, 487(7407), 330-337. https://doi.org/10.1038/nature11252

Nash, P., Tang, X., Orlicky, S., Chen, Q., Gertler, F. B., Mendenhall, M. D., Sicheri, F., Pawson, T., \& Tyers, M. (2001). Multisite phosphorylation of a CDK inhibitor sets a threshold for the onset of DNA replication. Nature, 414(6863), 514-521. https://doi.org/10.1038/35107009

Nateri, A. S., Riera-Sans, L., Da, C. C., \& Behrens, A. (2004). The ubiquitin ligase SCFFbw7 antagonizes apoptotic JNK signaling. Science, 303(5662), 1374-1378. https://doi.org/10.1126/science. 1092880

Orlicky, S., Tang, X., Willems, A., Tyers, M., \& Sicheri, F. (2003). Structural basis for phosphodependent substrate selection and orientation by the SCFCdc4 ubiquitin ligase. 
1258

1259

1260

1261

1262

1263

1264

1265

1266

1267

1268

1269

1270

1271

1272

1273

1274

1275

1276

1277

1278

1279

Priyadarshini, R., Hussain, M., Attri, P., Kaur, E., Tripathi, V., Priya, S., Dhapola, P., Saha, D., Madhavan, V., Chowdhury, S., \& Sengupta, S. (2018). BLM Potentiates c-Jun Degradation and Alters Its Function as an Oncogenic Transcription Factor. Cell Reports, 24(4), 947961.e7. https://doi.org/10.1016/j.celrep.2018.06.101

Punga, T., Bengoechea-Alonso, M. T., \& Ericsson, J. (2006). Phosphorylation and ubiquitination of the transcription factor sterol regulatory element-binding protein-1 in response to DNA binding. Journal of Biological Chemistry, 281(35), 25278-25286. https://doi.org/10.1074/jbc.M604983200

Quinlan, A. R., \& Hall, I. M. (2010). BEDTools: A flexible suite of utilities for comparing genomic features. Bioinformatics, 26(6), 841-842. https://doi.org/10.1093/bioinformatics/btq033

R Core Team. (2020). R: A language and environment for statistical computing. $R$ Foundation for Statistical Computing, Vienna, Austria.

Ramírez, F., Ryan, D. P., Grüning, B., Bhardwaj, V., Kilpert, F., Richter, A. S., Heyne, S., Dündar, F., \& Manke, T. (2016). deepTools2: a next generation web server for deepsequencing data analysis. Nucleic Acids Research, 44(W1), W160-W165. https://doi.org/10.1093/nar/gkw257

Reith, W., LeibundGut-Landmann, S., \& Waldburger, J. M. (2005). Regulation of MHC class II gene expression by the class II transactivator. Nature Reviews Immunology, 5(10), 793-806. https://doi.org/10.1038/nri1708

Robinson, M. D., McCarthy, D. J., \& Smyth, G. K. (2009). edgeR: A Bioconductor package for differential expression analysis of digital gene expression data. Bioinformatics, 26(1), 139- 
140. https://doi.org/10.1093/bioinformatics/btp616

1281

1282

1283

1284

1285

1286

1287

1288

1289

1290

1291

1292

1293

1294

1295

1296

1297

1298

1299

1300

1301

1302

Robinson, M. D., \& Oshlack, A. (2010). A scaling normalization method for differentialexpression analysis of RNA-seq data. Genome Biology, 11(3), 1-9. http://genomebiology.com/2010/11/3/R25

Sconocchia, G., Eppenberger-Castori, S., Zlobec, I., Karamitopoulou, E., Arriga, R., Coppola, A., Caratelli, S., Spagnoli, G. C., Lauro, D., Lugli, A., Han, J., Iezzi, G., Ferrone, C., Ferlosio, A., Tornillo, L., Droeser, R., Rossi, P., Attanasio, A., Ferrone, S., \& Terracciano, L. (2014). HLA class II antigen expression in colorectal carcinoma tumors as a favorable prognostic marker. Neoplasia (United States), 16(1), 31-42.

https://doi.org/10.1593/neo.131568

Shimizu, K., Nihira, N. T., Inuzuka, H., \& Wei, W. (2018). Physiological functions of FBW7 in cancer and metabolism. Cellular Signalling, 46(February), 15-22. https://doi.org/10.1016/j.cellsig.2018.02.009

Skaar, J. R., Pagan, J. K., \& Pagano, M. (2013). Mechanisms and function of substrate recruitment by F-box proteins. Nature Reviews. Molecular Cell Biology, 14(6), 369-381. https://doi.org/10.1038/nrm3582

Skene, P. J., Henikoff, J. G., \& Henikoff, S. (2018). Targeted in situ genome-wide profiling with high efficiency for low cell numbers. Nature Protocols, 13(5), 1006-1019.

https://doi.org/10.1038/nprot.2018.015

Skene, P. J., \& Henikoff, S. (2017). An efficient targeted nuclease strategy for high-resolution mapping of DNA binding sites. ELife, 6, 1-35. https://doi.org/10.7554/eLife.21856

Tan, Y. M., Sangfelt, O., \& Spruck, C. (2008). The Fbxw7/hCdc4 tumor suppressor in human cancer. Cancer Letters, 271(1), 1-12. https://doi.org/10.1016/j.canlet.2008.04.036 
1303 Tang, X., Orlicky, S., Lin, Z., Willems, A., Neculai, D., Ceccarelli, D., Mercurio, F., Shilton, B.

1304 H., Sicheri, F., \& Tyers, M. (2007). Suprafacial Orientation of the SCFCdc4 Dimer

1305 Accommodates Multiple Geometries for Substrate Ubiquitination. Cell, 129(6), 1165-1176.

1306 https://doi.org/10.1016/j.cell.2007.04.042

1307 Thomas, L. R., \& Tansey, W. P. (2011). Proteolytic Control of the Oncoprotein Transcription

1308 Factor Myc. In Advances in Cancer Research (Vol. 110). Elsevier Inc. https://doi.org/10.1016/B978-0-12-386469-7.00004-9

Ting, J. P. Y., \& Trowsdale, J. (2002). Genetic control of MHC class II expression. Cell, 109(2 SUPPL. 1), 21-33. https://doi.org/10.1016/S0092-8674(02)00696-7

van der Stoep, N., Quinten, E., Alblas, G., Plancke, A., van Eggermond, M. C. J. A., Holling, T. M., \& van den Elsen, P. J. (2007). Constitutive and IFN $\gamma$-induced activation of MHC2TA promoter type III in human melanoma cell lines is governed by separate regulatory elements within the PIII upstream regulatory region. Molecular Immunology, 44(8), 2036-2046. https://doi.org/10.1016/j.molimm.2006.09.013

Wang, L., Wang, S., \& Li, W. (2012). RSeQC: Quality control of RNA-seq experiments. Bioinformatics, 28(16), 2184-2185. https://doi.org/10.1093/bioinformatics/bts356

1319 Wei, W., Jin, J., Schlisio, S., Harper, J. W., \& Kaelin, W. G. (2005). The v-Jun point mutation 1320 allows c-Jun to escape GSK3-dependent recognition and destruction by the Fbw7 ubiquitin ligase. Cancer Cell, 8(1), 25-33. https://doi.org/10.1016/j.ccr.2005.06.005

1322 Welcker, M., \& Clurman, B. E. (2007). Fbw7/hCDC4 dimerization regulates its substrate 1323 interactions. Cell Division, 2, 7. https://doi.org/10.1186/1747-1028-2-7

1324 Welcker, M., \& Clurman, B. E. (2008). FBW7 ubiquitin ligase: A tumour suppressor at the 1325 crossroads of cell division, growth and differentiation. Nature Reviews Cancer, 8(2), 83-93. 
https://doi.org/10.1038/nrc2290

Welcker, M., Larimore, E. A., Swanger, J., Bengoechea-Alonso, M. T., Grim, J. E., Ericsson, J., Zheng, N., \& Clurman, B. E. (2013). Fbw7 dimerization determines the specificity and robustness of substrate degradation. Genes and Development, 27(23), 2531-2536. https://doi.org/10.1101/gad.229195.113

Welcker, M., Orian, A., Jin, J., Grim, J. E., Grim, J. A., Harper, J. W., Eisenman, R. N., \& Clurman, B. E. (2004). The Fbw7 tumor suppressor regulates glycogen synthase kinase 3 phosphorylation-dependent c-Myc protein degradation. Proceedings of the National Academy of Sciences of the United States of America, 101(24), 9085-9090. https://doi.org/10.1073/pnas.0402770101

Welcker, M., Wang, B., Rusnac, D., Hussaini, Y., Swanger, J., Zheng, N., \& Clurman, B. E. (2022). Two diphosphorylated degrons control c-Myc degradation by the Fbw7 tumor suppressor. 7872(January), 1-13.

Yada, M., Hatakeyama, S., Kamura, T., Nishiyama, M., Tsunematsu, R., Imaki, H., Ishida, N., Okumura, F., Nakayama, K., \& Nakayama, K. I. (2004). Phosphorylation-dependent degradation of c-Myc is mediated by the F-box protein Fbw7. EMBO Journal, 23(10), 2116-2125. https://doi.org/10.1038/sj.emboj.7600217

Yeh, C. H., Bellon, M., \& Nicot, C. (2018). FBXW7: A critical tumor suppressor of human cancers. Molecular Cancer, 17(1), 1-19. https://doi.org/10.1186/s12943-018-0857-2

Yu, G., Wang, L. G., \& He, Q. Y. (2015). ChIP seeker: An R/Bioconductor package for ChIP peak annotation, comparison and visualization. Bioinformatics, 31(14), 2382-2383. https://doi.org/10.1093/bioinformatics/btv145

Yu, S., Wang, F., Tan, X., Gao, G. li, Pan, W. J., Luan, Y., \& Ge, X. (2018). FBW7 targets 
KLF10 for ubiquitin-dependent degradation. Biochemical and Biophysical Research Communications, 495(2), 2092-2097. https://doi.org/10.1016/j.bbrc.2017.11.187

Yumimoto, K., Akiyoshi, S., Ueo, H., Sagara, Y., Onoyama, I., Ueo, H., Ohno, S., Mori, M., Mimori, K., \& Nakayama, K. I. (2015). F-box protein FBXW7 inhibits cancer metastasis in a non-cell-autonomous manner. Journal of Clinical Investigation, 125(2), 621-635. https://doi.org/10.1172/JCI78782

Yumimoto, K., \& Nakayama, K. I. (2020). Recent insight into the role of FBXW7 as a tumor suppressor. Seminars in Cancer Biology, 67(November 2019), 1-15.

Zhang, J., Zhu, F., Li, X., Dong, Z., Xu, Y., Peng, C., Li, S., Cho, Y. Y., Yao, K., Zykova, T. A., Bode, A. M., \& Dong, Z. (2012). Rack1 protects N-terminal phosphorylated c-Jun from Fbw7-mediated degradation. Oncogene, 31(14), 1835-1844.

Zhang, W., \& Koepp, D. M. (2006). Fbw7 isoform interaction contributes to cyclin E proteolysis. Molecular Cancer Research, 4(12), 935-943. https://doi.org/10.1158/1541-

Zhang, Y., Zhang, X., Ye, M., Jing, P., Xiong, J., Han, Z., Kong, J., Li, M., Lai, X., Chang, N., Zhang, J., \& Zhang, J. (2018). FBW7 loss promotes epithelial-to-mesenchymal transition in non-small cell lung cancer through the stabilization of Snail protein. Cancer Letters, 419, for ubiquitin-mediated degradation and suppresses breast cell proliferation. Cancer Research, 70(11), 4728-4738. https://doi.org/10.1158/0008-5472.CAN-10-0040 
Thirimanne 2021

1372 Zhao, Y., \& Sun, Y. (2013). The FBW7-KLF2 axis regulates endothelial functions. Cell

$1373 \quad$ Research, 23(6), 741-743. https://doi.org/10.1038/cr.2013.50

1374 


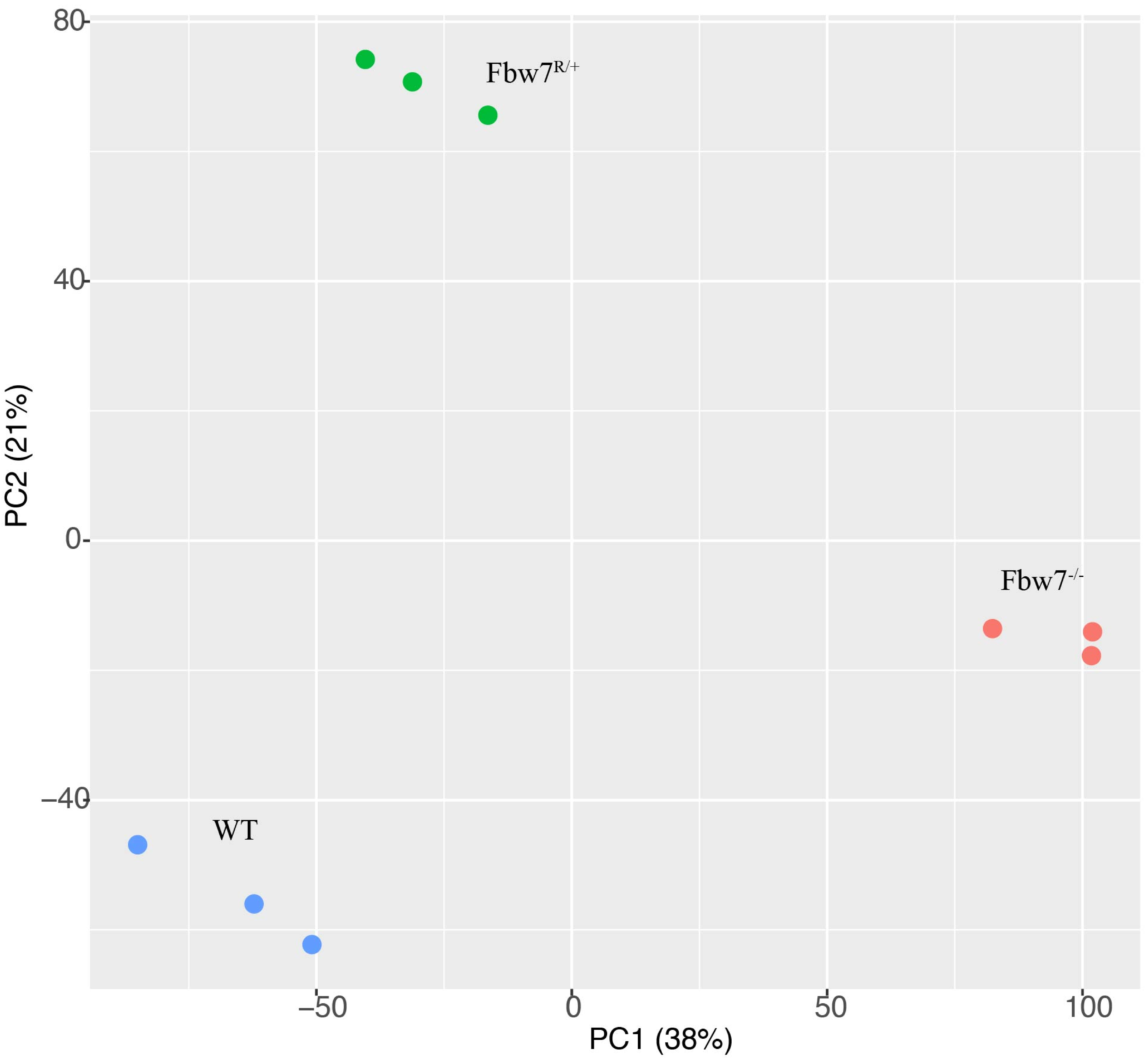




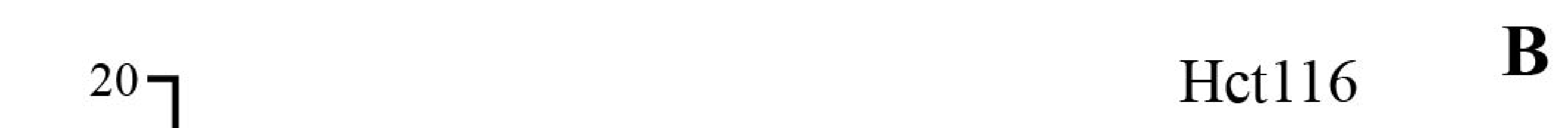

B

Hct116

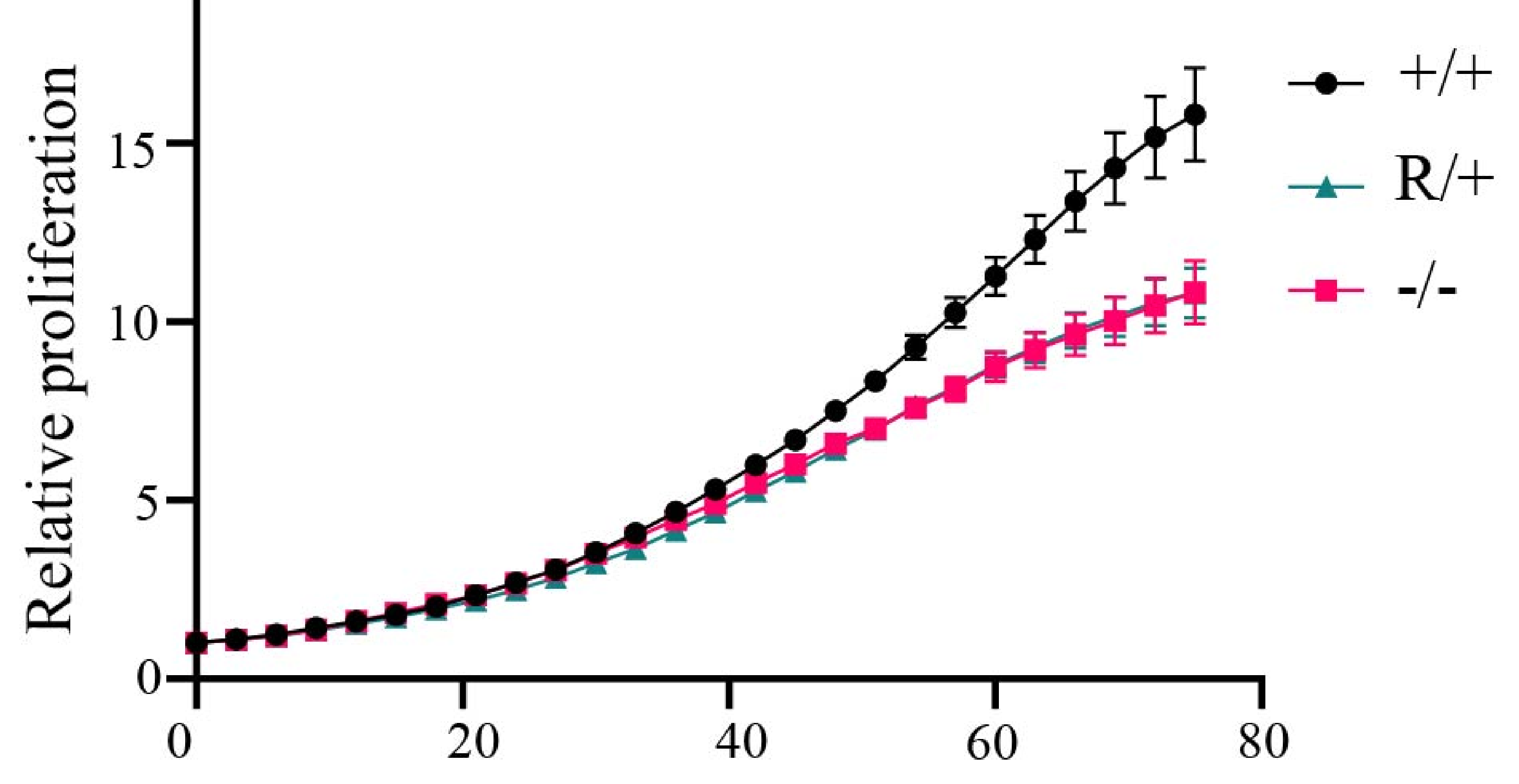

$1: \frac{7}{4+1}$

$\mathrm{R} /+$

$-/-$

DNA content

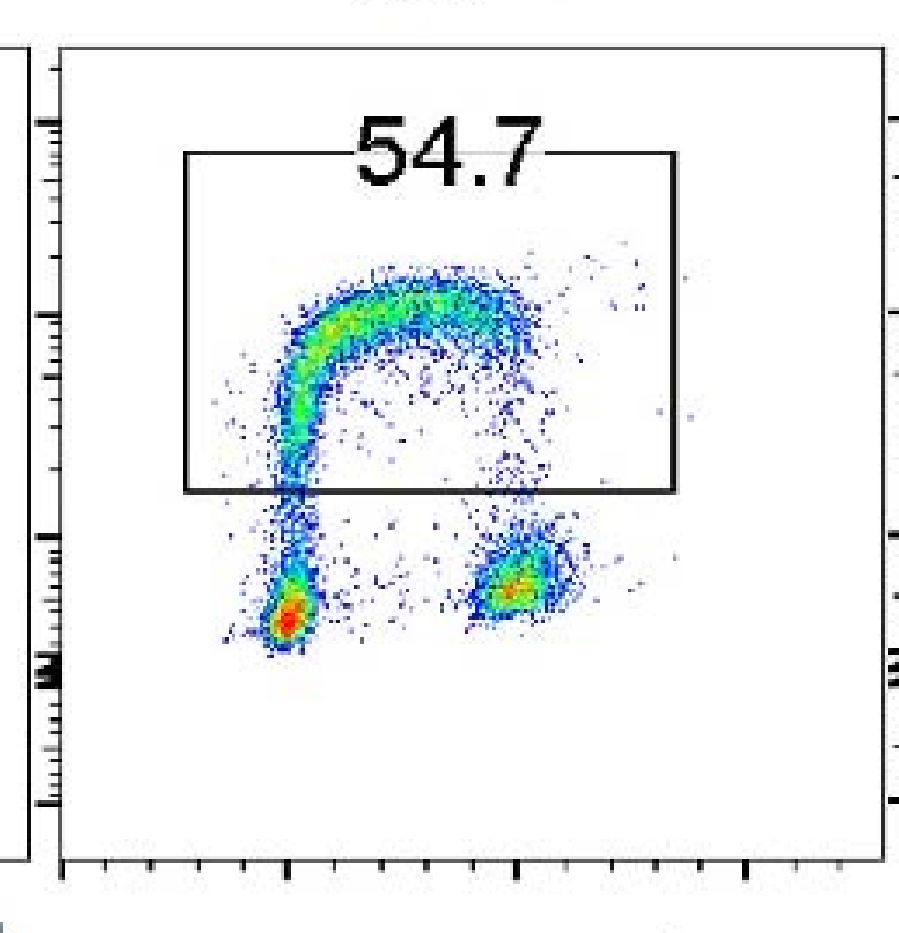

กี้

Hours 


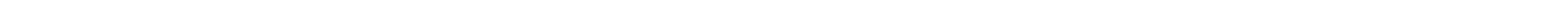


A

B

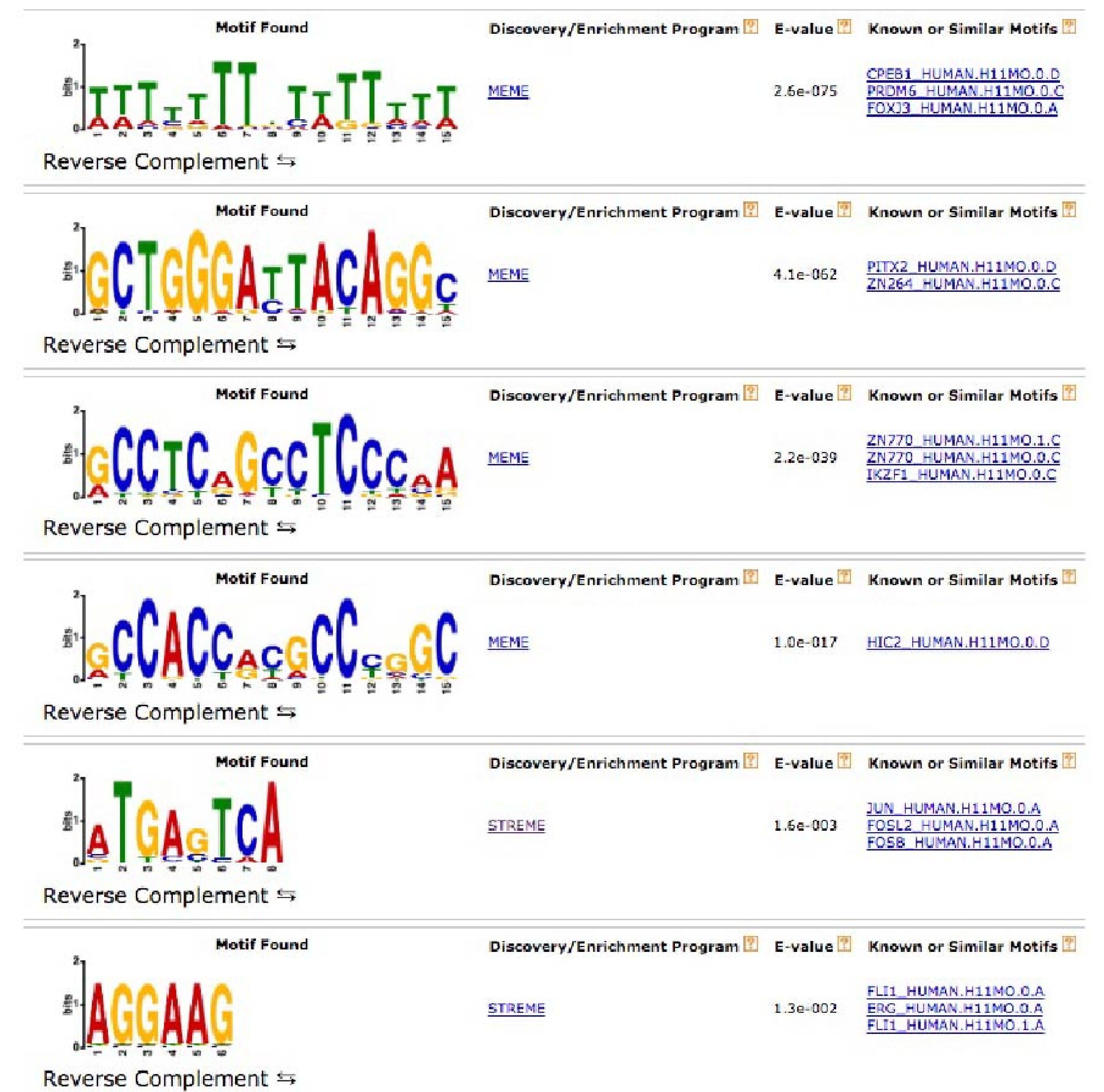

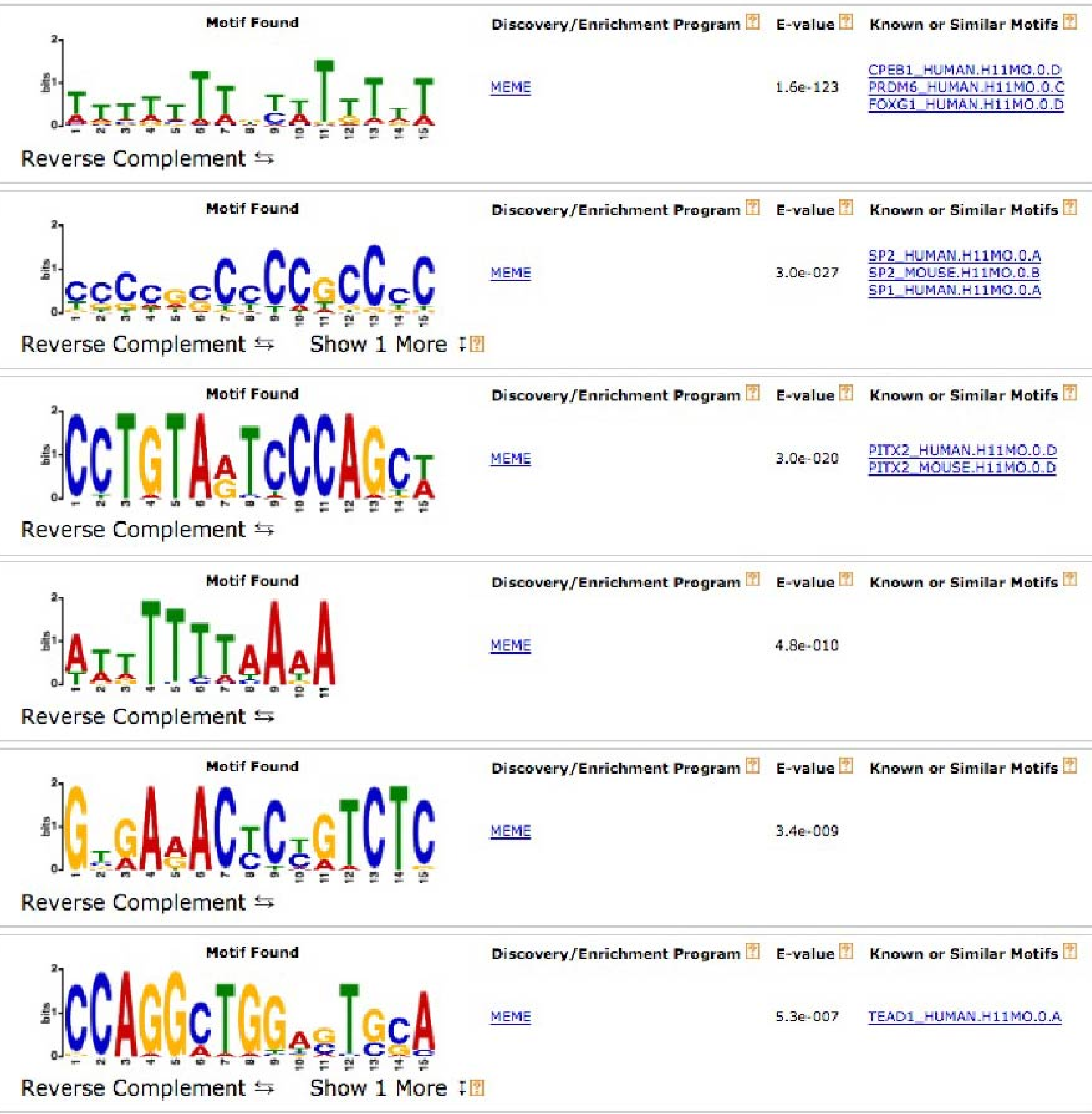


Bortezomib

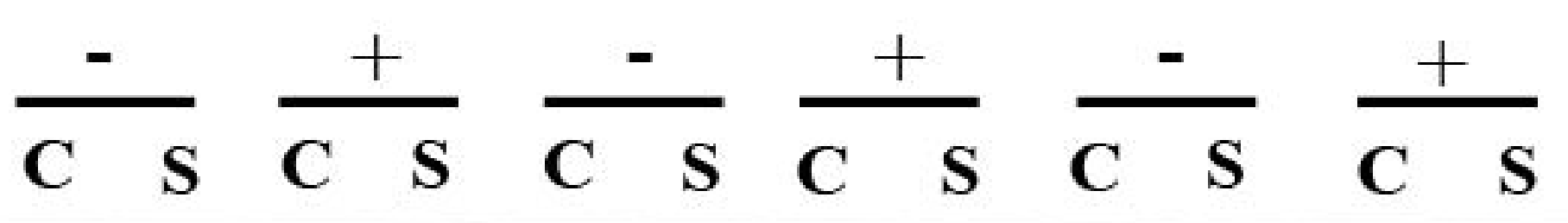

IP: Fbw7

IB:p21 


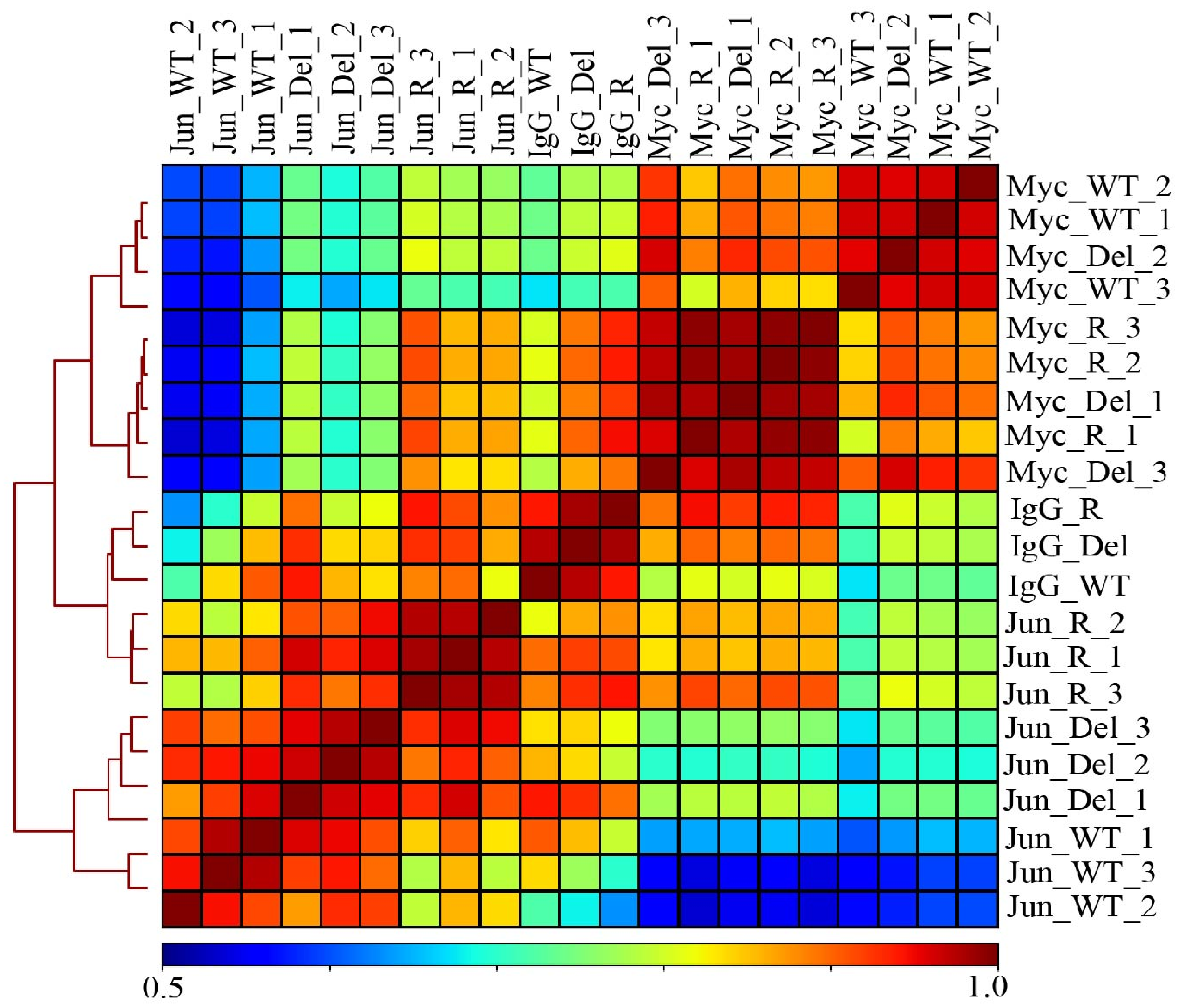

Hct116 WT Jun peaks

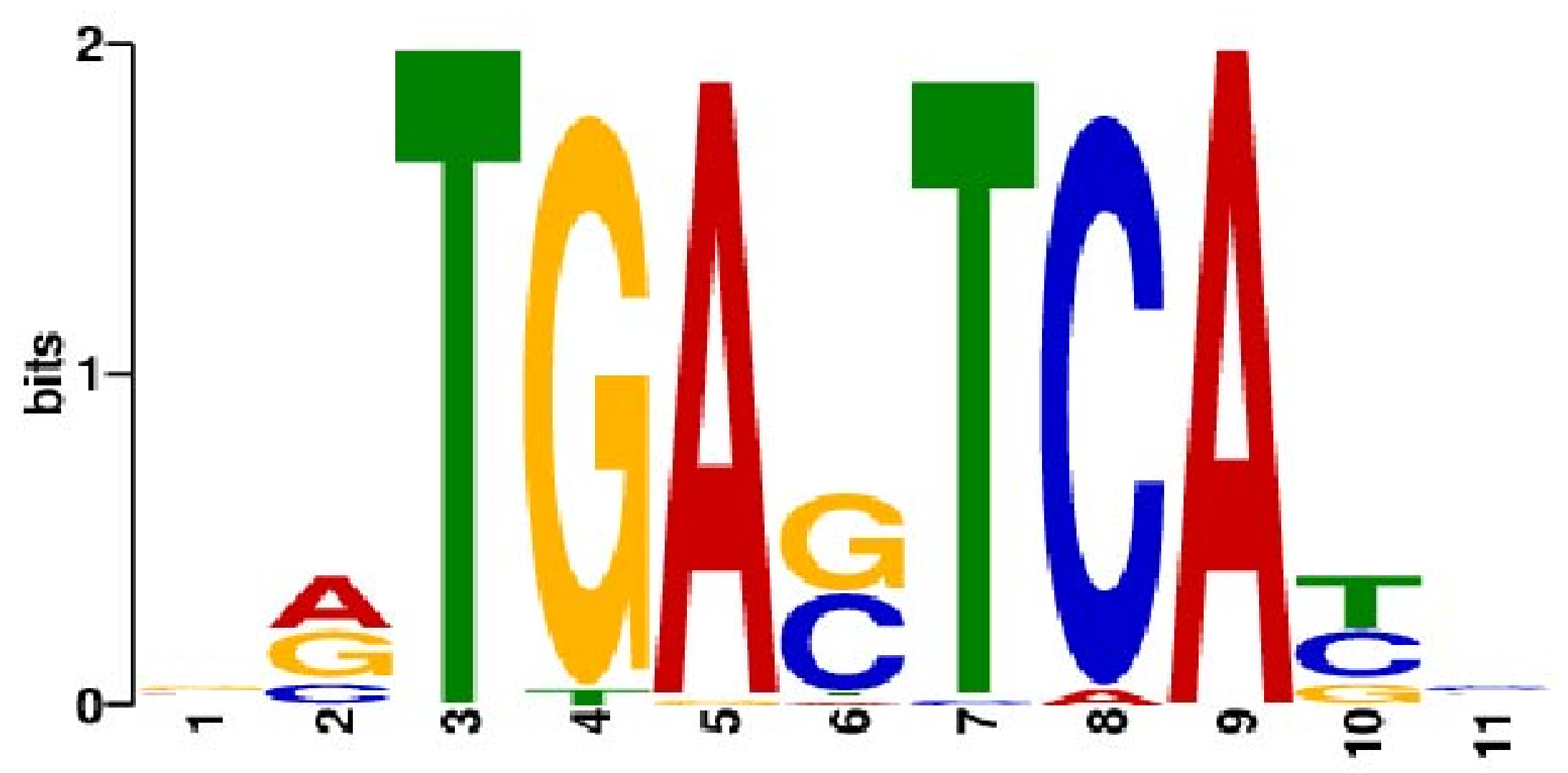

Hct116 WT Myc peaks

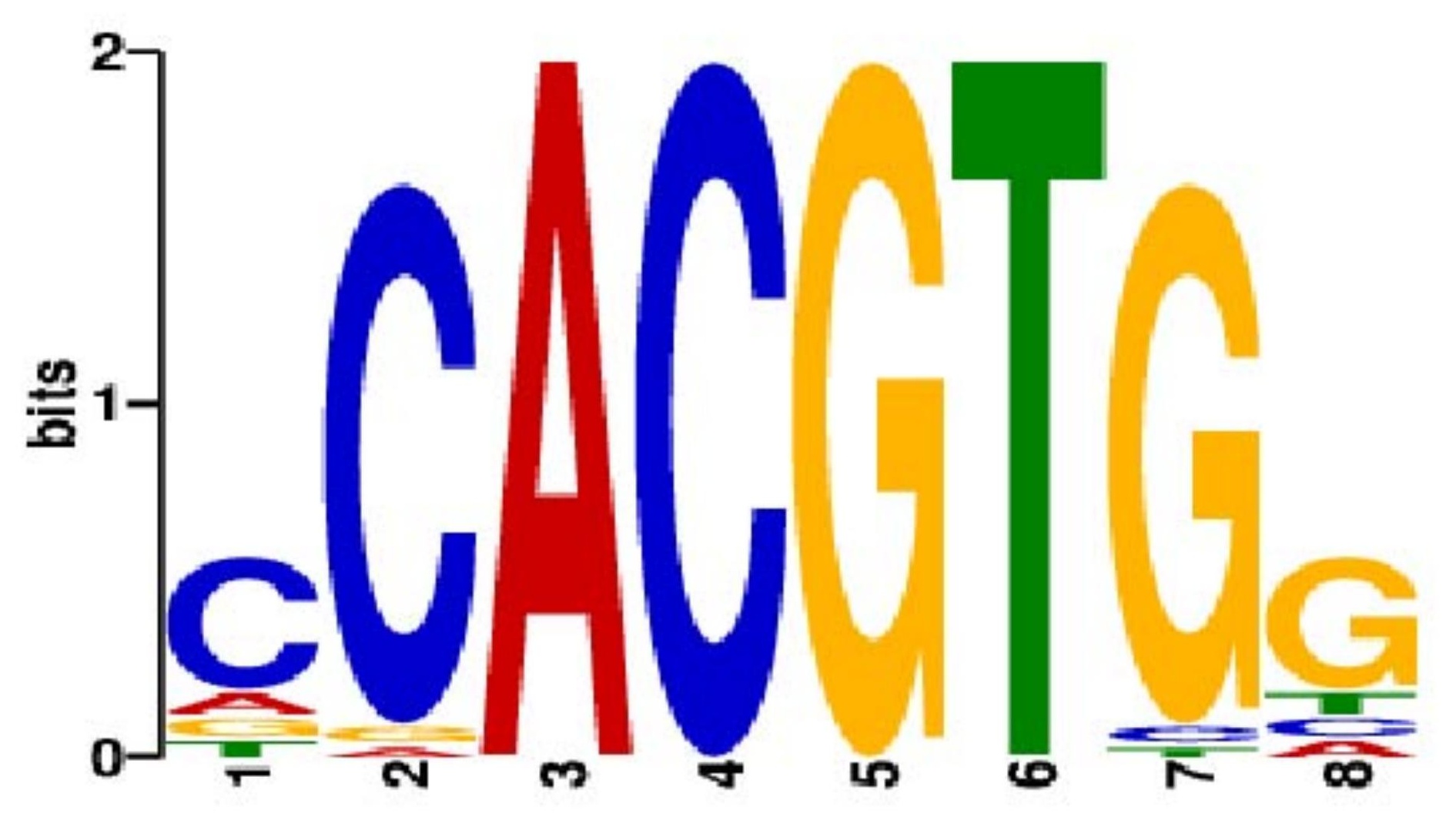


$\mathbf{A}$

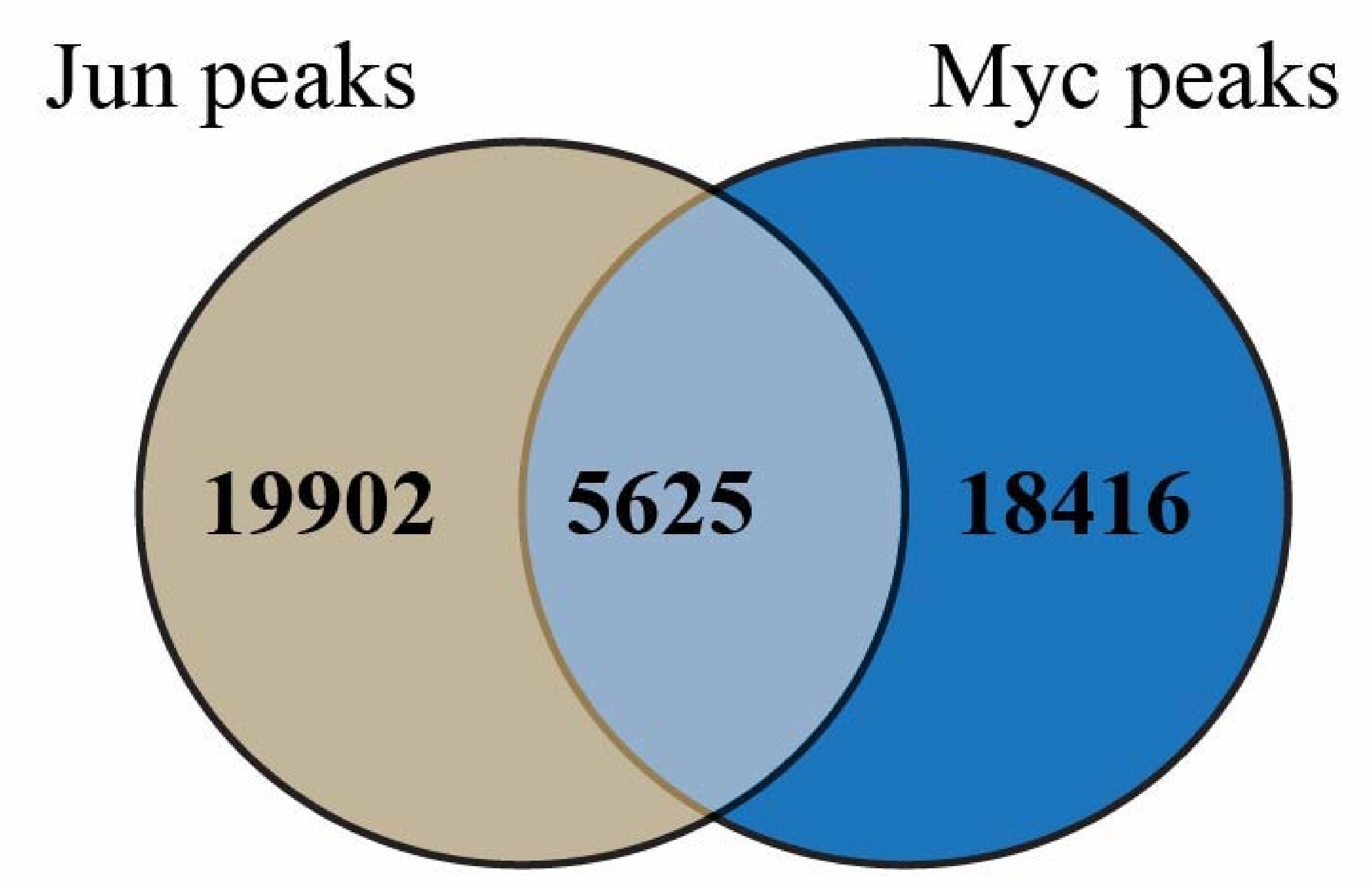

B Jun Up in R

Myc Down in $\mathrm{R}$

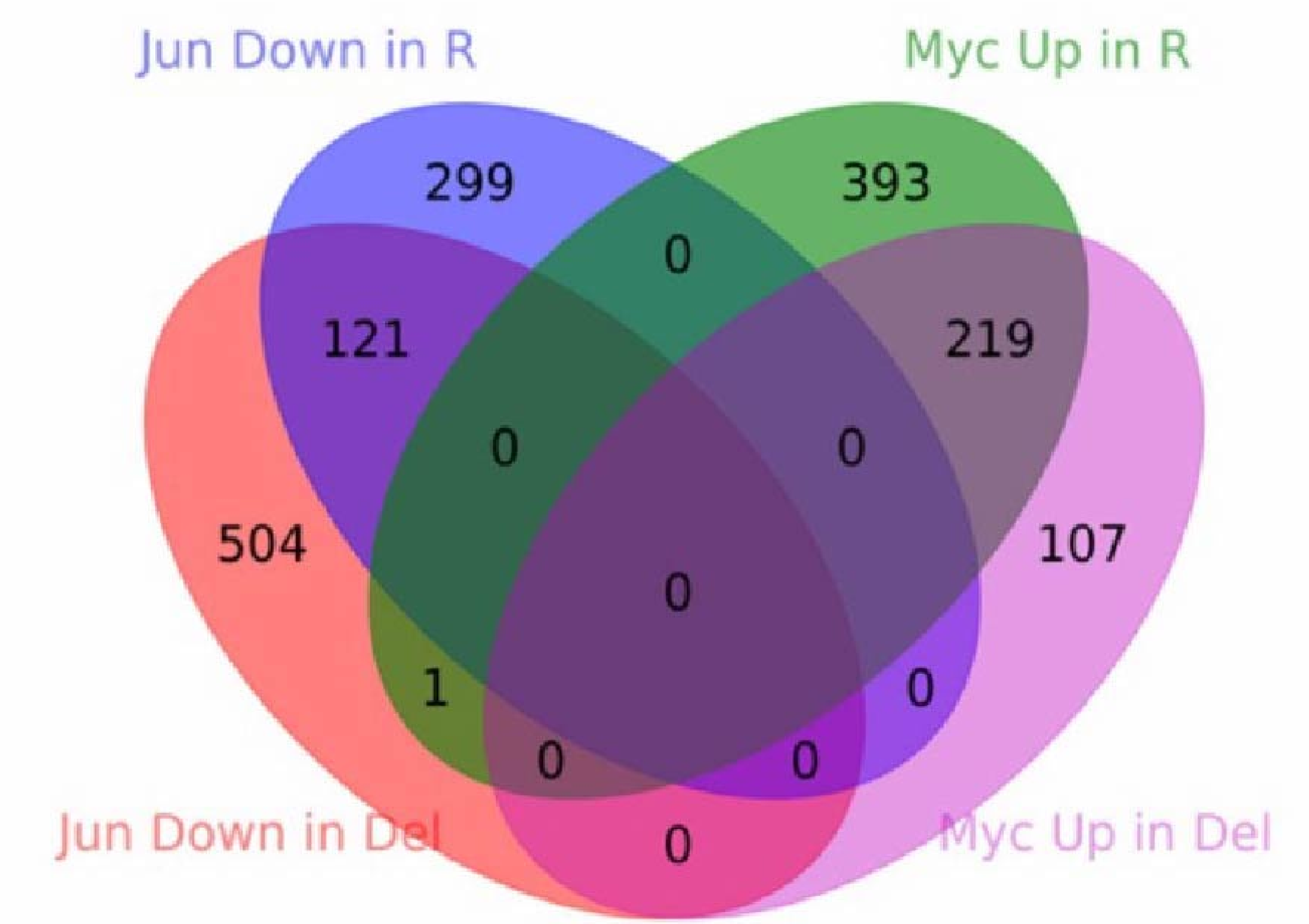




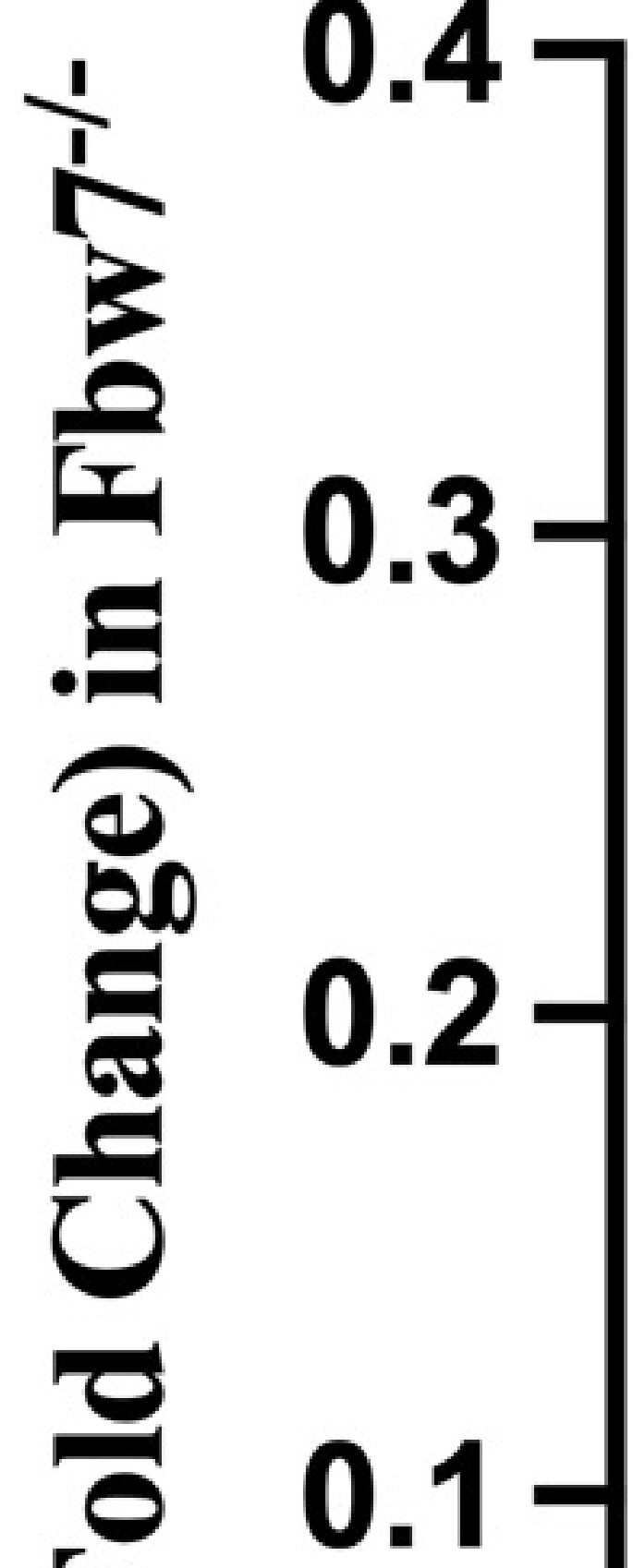

0.001

0.002

0.013

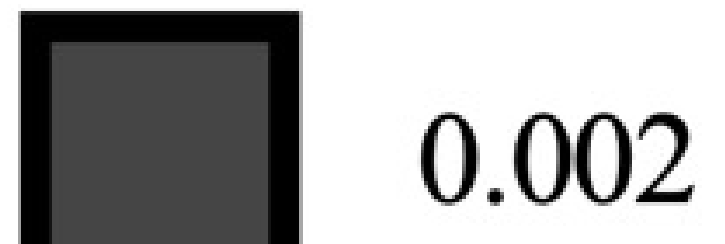

头

ํㅣㅇ

0.0
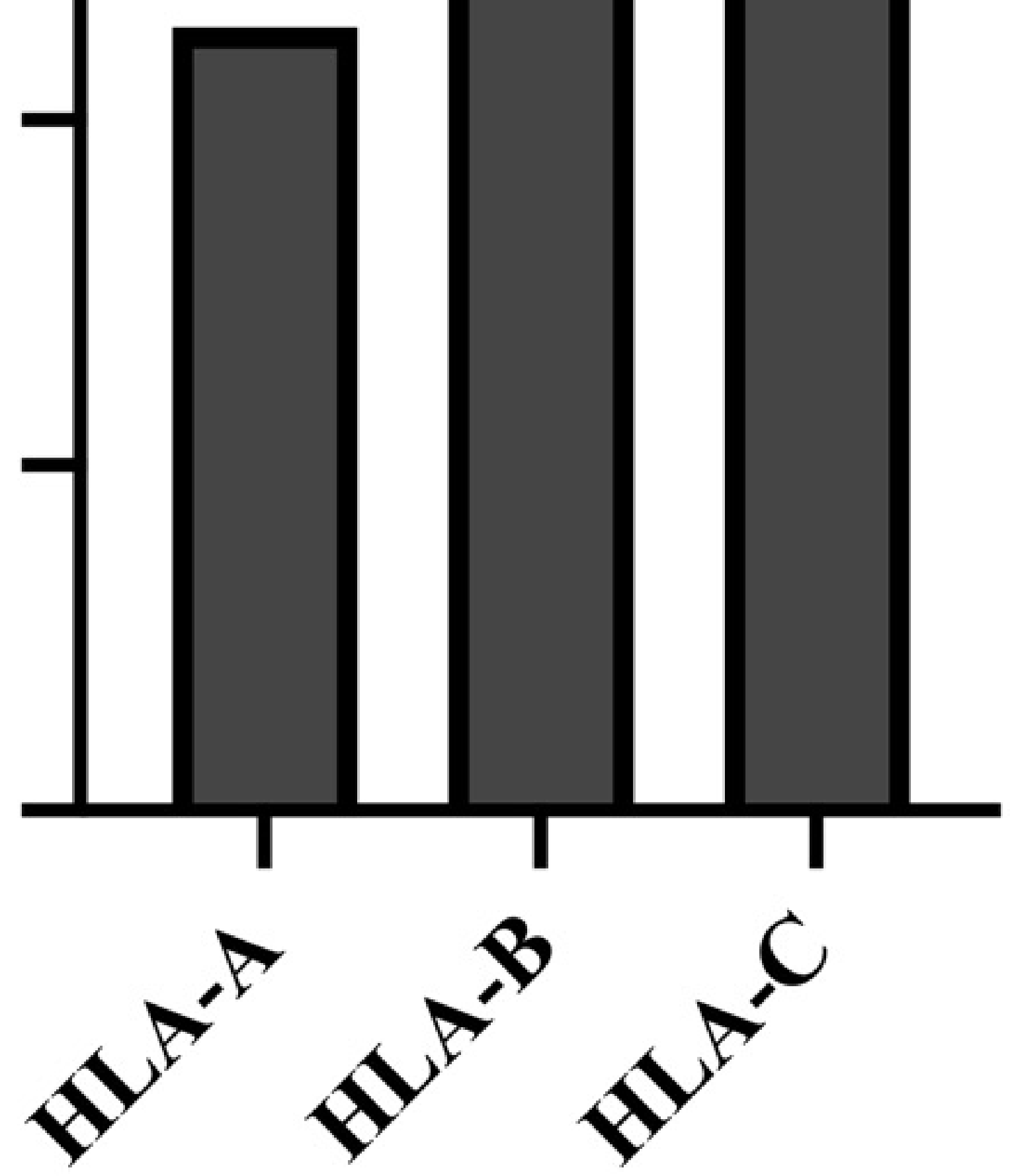


\section{WT $\quad \mathrm{Fbw}^{-1-}$}

\section{HLA-DR}

\section{Tubulin}

\begin{tabular}{c|c|c|c} 
& \multicolumn{2}{|c|}{ Ratio (Net protein / Net Loading Control) } & \multirow{2}{*}{ Fold } \\
\cline { 2 - 3 } & WT & Fbw $^{-/-}$ & Increase \\
\hline Trial 01 & 1.63 & 2.82 & 1.73 \\
\hline Trial 02 & 0.81 & 1.80 & 2.21
\end{tabular}


A

IP: Fbw7

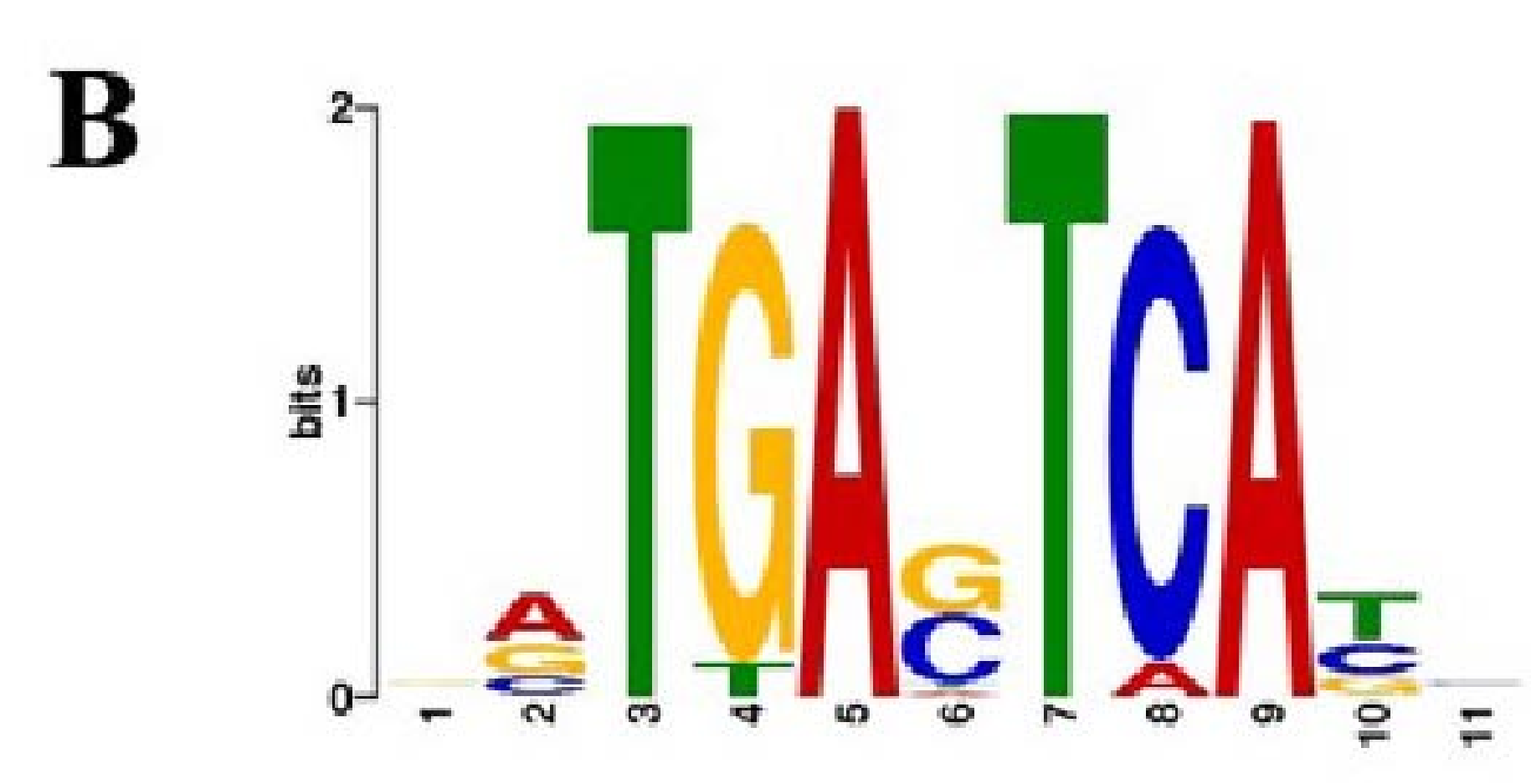


A

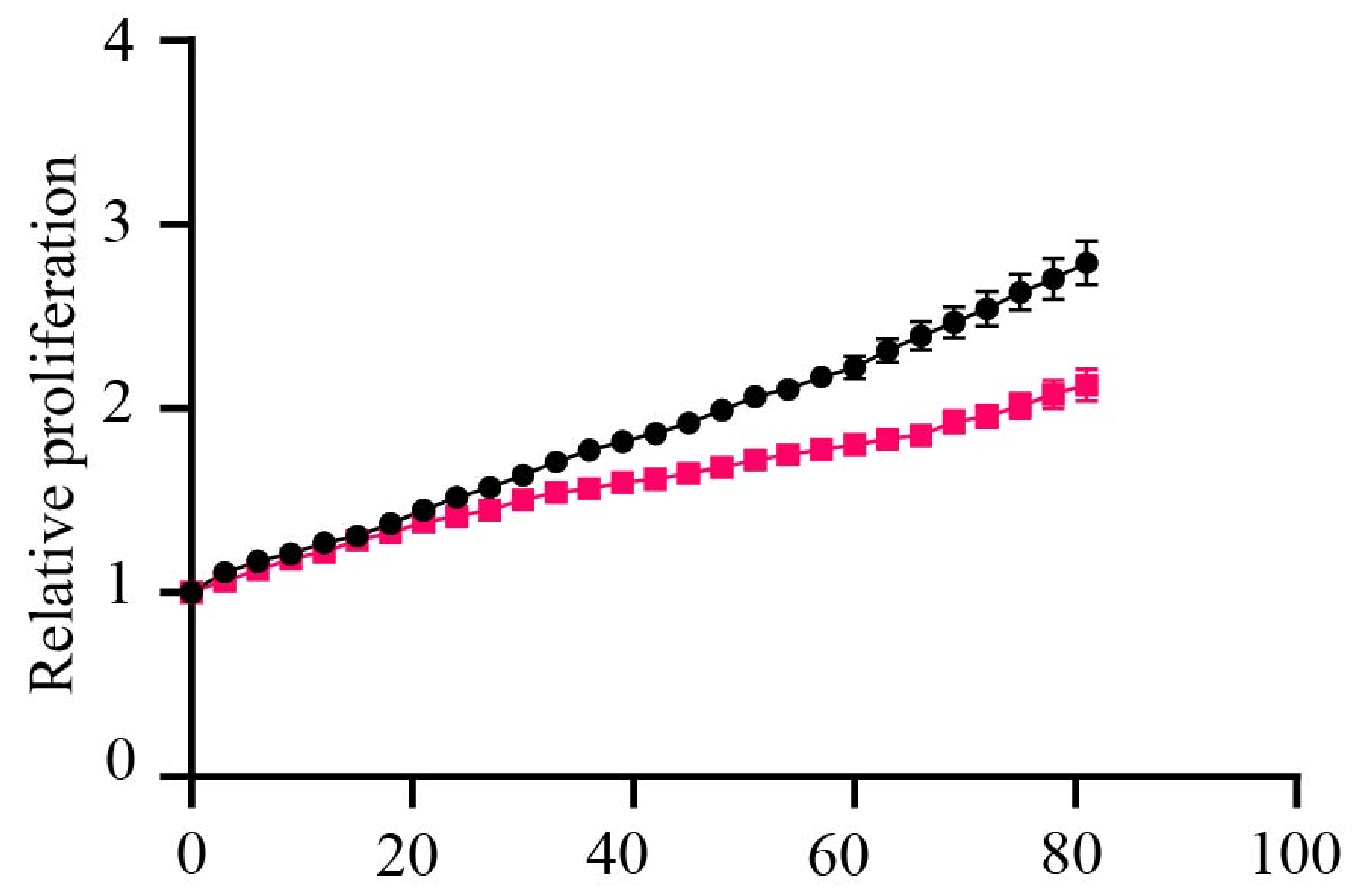

B

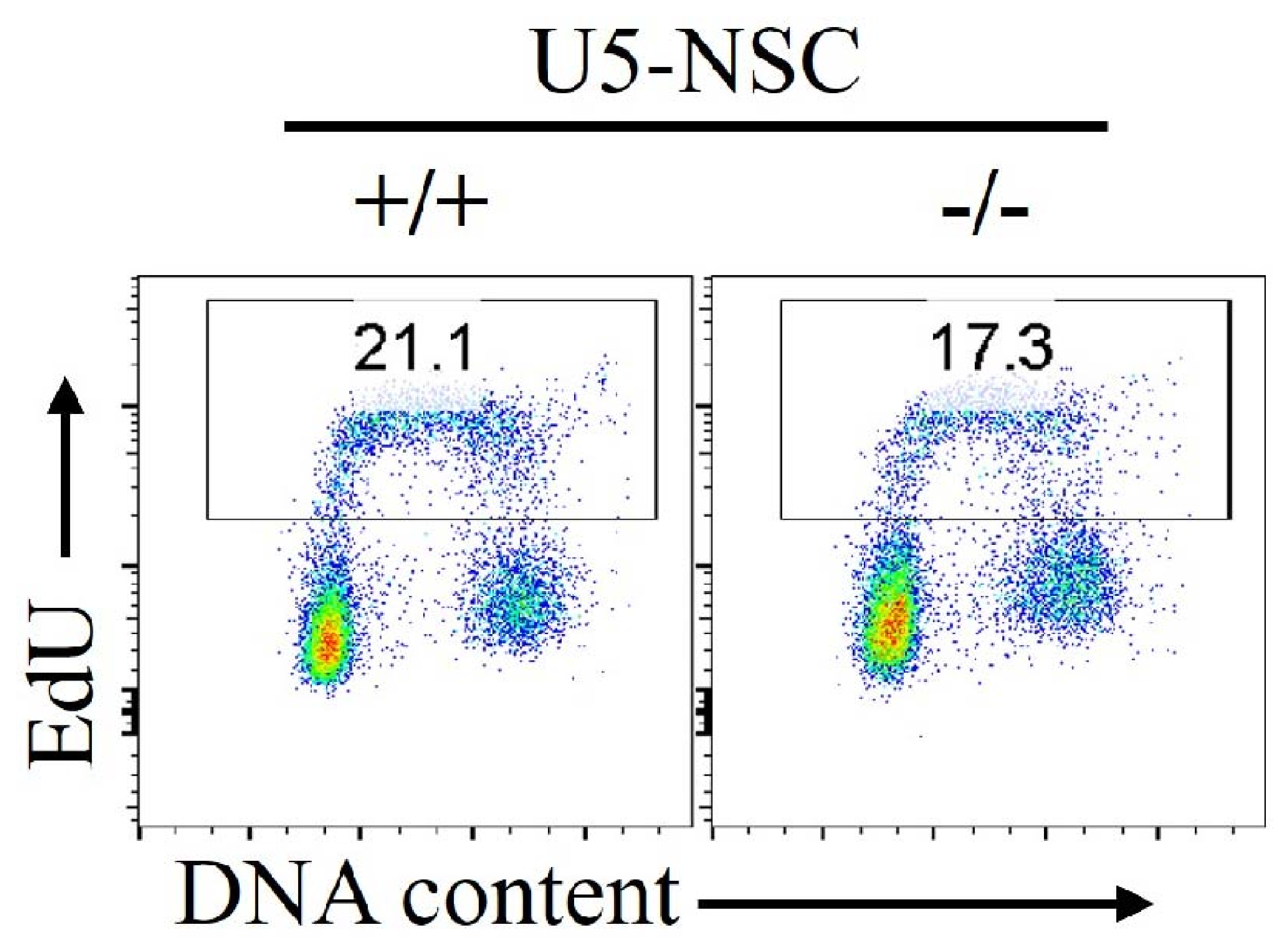




\section{Decreased Jun in NSC Fbw7 $7^{-/-}$}
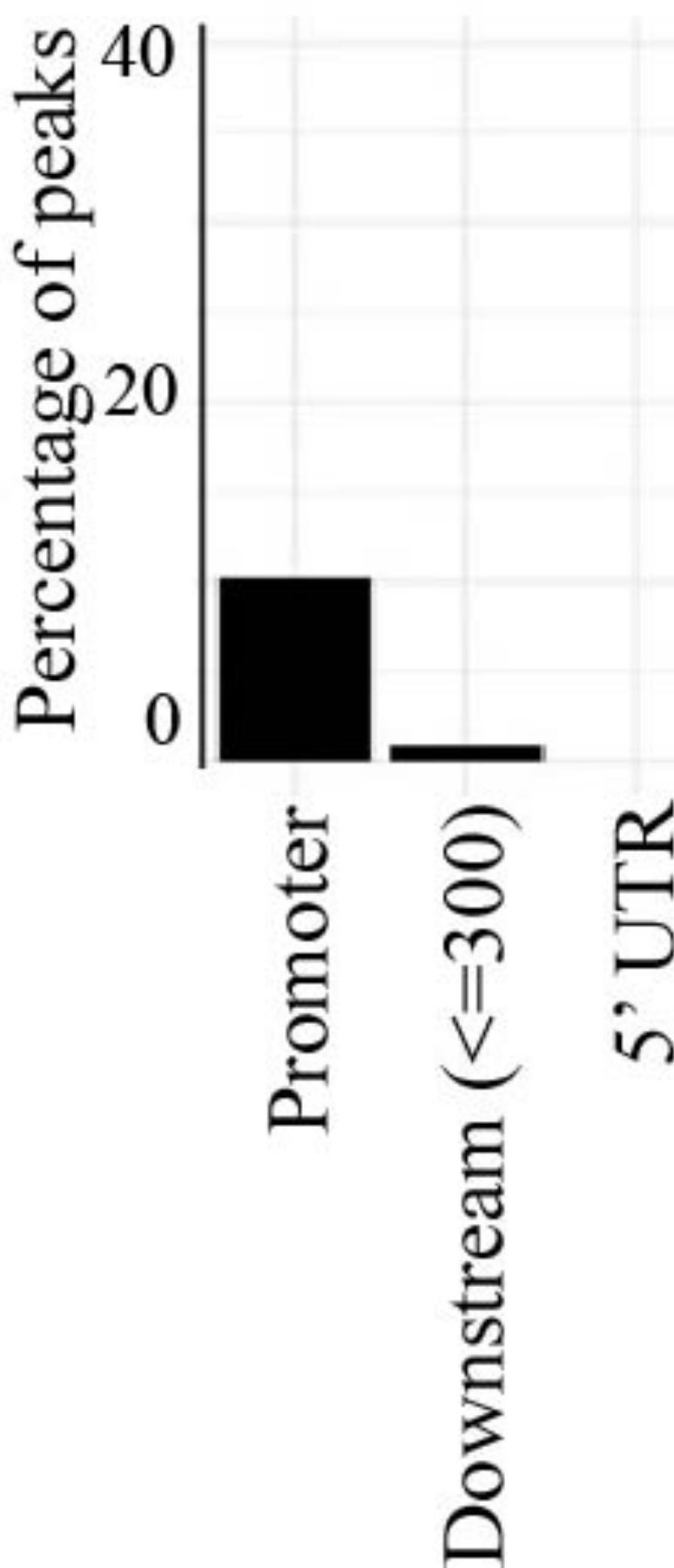

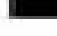

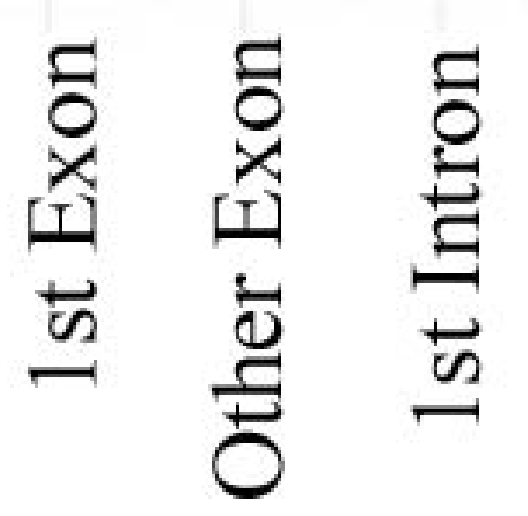

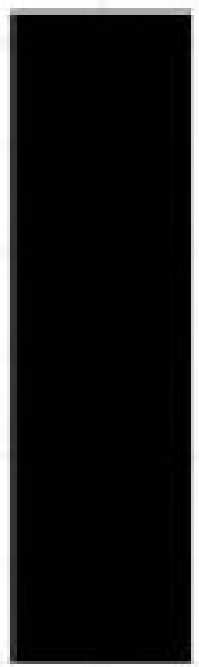
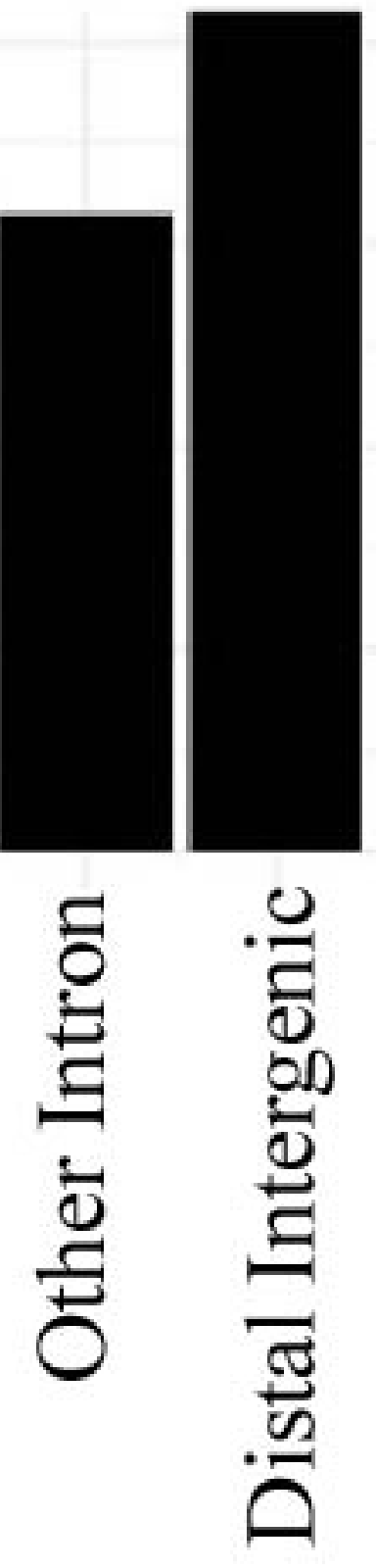


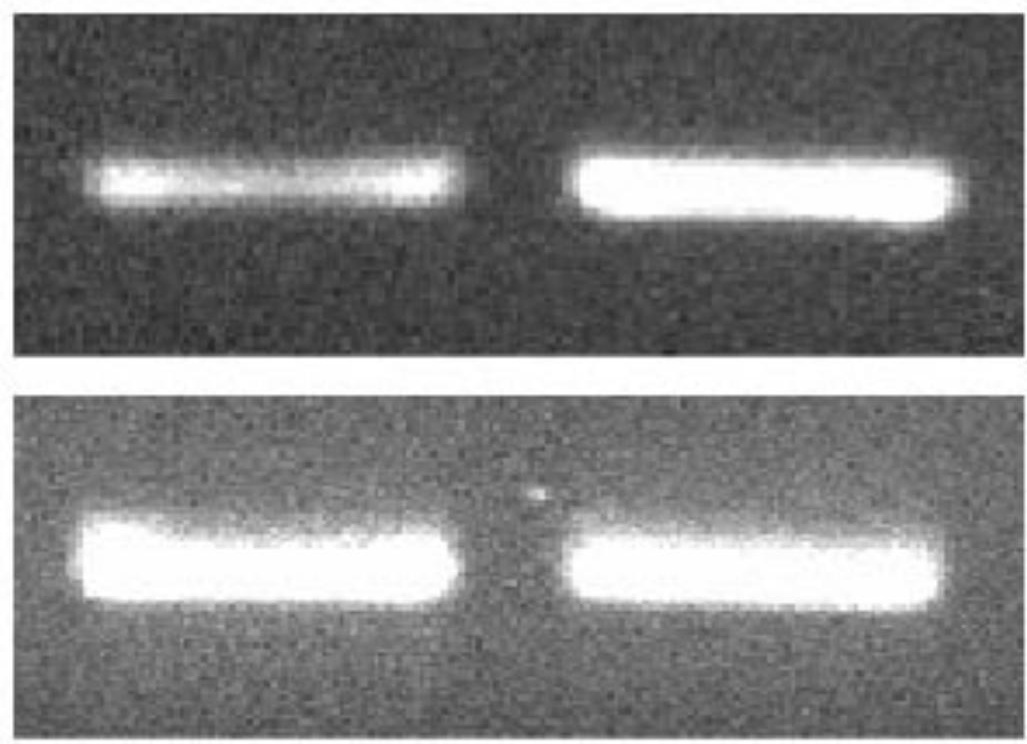



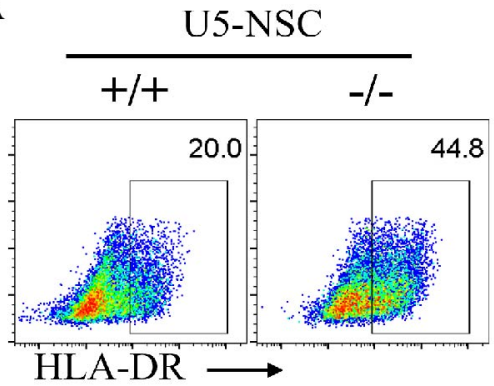

B

\begin{tabular}{l|l} 
& WT $\quad$ Fbw $7^{-/-}$ \\
HLA-DR & \\
/DP/DQ & \\
Tubulin &
\end{tabular}

\begin{tabular}{c|c|c|c} 
& \multicolumn{2}{|c|}{ Ratio (Net protein / Net Loading Control) } & \multirow{2}{*}{$\begin{array}{c}\text { Fold } \\
\text { Increase }\end{array}$} \\
\cline { 2 - 3 } & WT & Fbw7 $^{-/-}$ & 2.92 \\
\hline Trial 01 & 2.88 & 8.40 &
\end{tabular}


